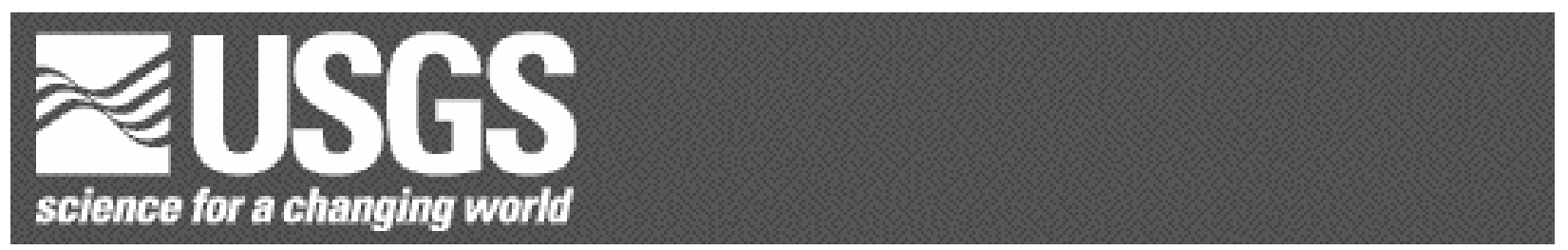

\title{
Abstracts of the Annual Meeting of Planetary Geologic Mappers, Washington, D.C. 2005
}

Edited By Tracy K.P. Gregg, ${ }^{1}$ Kenneth L. Tanaka, ${ }^{2}$ and R. Stephen Saunders 3 Open-File Report 2005-1271

2005

Any use of trade, firm, or product names is for descriptive purposes only and does not imply endorsement by the U.S. Government.

\section{U.S. DEPARTMENT OF THE INTERIOR}

U.S. GEOLOGICAL SURVEY

${ }^{1}$ The State University of New York at Buffalo, Department of Geology, 710 Natural Sciences Complex, Buffalo, NY 14260-3050.

${ }^{2}$ U.S. Geological Survey, 2255 N. Gemini Drive, Flagstaff, AZ 86001.

${ }^{3}$ NASA Headquarters, Office of Space Science, 300 E. Street SW, Washington, DC 20546. 
Introduction/Summary of 2005 Planetary Mappers Meeting

Center for Earth and Planetary Studies, National Air and Space Museum

Smithsonian Institution

Washington, D.C.

June $23-24,2005$

Approximately 30 people attended the annual Planetary Mappers Meeting, locally hosted by Dr. Kevin Williams at the Center for Earth and Planetary Studies. The meeting room was in the National Air and Space Museum, providing an apt setting for our discussions of extraterrestrial geologic studies.

The progress of current Mars maps was presented on June 23. Mappers increasingly use data collected by the Thermal Emission Imaging System (THEMIS); daytime infrared (IR) and visible images are particularly useful for constraining and mapping geologic relations. J. Grant, K. Williams, and C. Fortezzo presented a series of 1:500K-scale maps in the Margaritifer Terra region, focusing on the spatial and temporal distribution of channeled and standing water in the region. Maps in this region range from those just proposed in 2005, to those recently submitted for review. Combined THEMIS (visible and daytime IR) and Mars Orbiter Laser Altimeter (MOLA) data have proved to be a powerful combination in this area. K. Shockey and J. Zimbelman presented their progress in understanding the Medusae Fossae Formation; this led to a discussion about what limits the size of a mappable unit. In a first for the USGS Planetary Mapping program, P. Mouginis-Mark will be generating a geologic map based entirely on THEMIS visible images ( 19 m/pixel) and Mars Orbiter Camera (MOC) narrow-angle images ( $<6 \mathrm{~m} /$ pixel). The Olympus Mons caldera map will be generated at a scale of 1:200,000. K. Tanaka and K. Herkenhoff discussed their mapping of the polar regions of Mars. D. Crown, M. Farley and T. Gregg focused on their work around the Hellas region; D. Crown also discussed his investigations near the dichotomy boundary to understand the formation of debris aprons.

On June 24, we discussed the status of mapping on Io, Europa, Ganymede, the Moon, and Venus. D. Williams is leading a team to generate a global geologic map of Io; the changing nature of this planet requires that a single paper map will be published, with electronic layers in GIS format for individual, variable features. K. Tanaka described progress of the global geologic map of Europa, which is an effort led by R. Greeley. Ganymede is also the subject of a global geologic map; W. Patterson stated that the map was being generated in $60^{\circ}$ x $60^{\circ}$ quadrangles by separate co-investigators. L. Gaddis is PI on a pilot project for remapping the Moon. J. Skinner reported that they have begun mapping a 1:2,500,000-scale quadrangle centered on Copernicus and are using Clementine and Lunar Orbiter IV data as the base map. Results of recent Venus mapping were presented by J. Head, M. Ivanov, and V. Hansen.

During scheduled discussion, the mappers deliberated and reached consensus on the following diverse topics. First, the annual meeting in 2006 will be held on June 24 and 25. We tentatively chose that it will be held in Pocatello or Boise, Idaho in 2006 and at the Planetary Science Institute in Tucson, Arizona in 2007. Second, the GEologic 
Mapping Subcommittee (GEMS) panel will create and distribute a "New Mappers Handbook" to inform new and present mappers about where to find pertinent information online (and elsewhere) about the current mapping program. Third, the size of the "smallest mappable unit" in a map should be governed by the map resolution. The resolution of the map was initially chosen to maximize the scientific story within the map area; therefore, if a unit is too small to be clearly mapped at this scale, it should not be officially included. However, it is important to note that the use of figures in the map text is encouraged. In the event where a possible or likely unit is identified in the map area, but is too small to be clearly identified on the final printed map, the mapper is encouraged to include as many figures as necessary within the text to reveal the complexity in the region. We agreed that maps should continue to be science-driven. However, some concern was expressed regarding the funding of characterization products (e.g., a global Thermal Emission Spectrometer (TES) map of Mars). What program officially funds these, if any, and where should proposals to produce these be submitted? GEMS agreed to talk with program managers at NASA to determine the appropriate venue for these products. Finally, we noted that USGS should provide new Mars mapping projects with processed THEMIS images that mappers can mosaic themselves; Geographic Information Systems software provides excellent tools for generating dynamic image mosaics.

The meeting concluded with a behind-the-scenes tour of the Smithsonian Natural History Museum's meteorite collection, led by curator Tim McCoy. Mappers were treated to a wealth of meteorite samples, including some from Mars. We all thoroughly enjoyed seeing — and carefully holding with our latex-gloved hands - these beautiful pieces of geologic significance. 


\section{CONTENTS}

\section{Venus}

Venus: Geologic Mapping and History of the Beta Regio Structure

A.T. Basilevsky

Spatially Isolated Time-Transgressive Venus Evolution: An Alternate Hypothesis

V.L. Hansen

Geologic Map of the Meskhent Tessera Quadrangle (V-3), Venus

M.A. Ivanov and J.W. Head

Geological Mapping in the Meskhent Tessera (V-3) Quadrangle, Venus: Evidence for Early Formation and Preservation of Regional Topography

M.A. Ivanov and J.W. Head

Geological Mapping of the Lakshmi Planum Quadrangle (V-7), Venus: Preliminary Results

M.A. Ivanov and J.W. Head

Geological Mapping of the Fredegonde Quadrangle (V-57), Venus: Preliminary Results M.A. Ivanov and J.W. Head

Geologic Map of the Greenaway Quadrangle (V-24), Venus: A Progress Report N.P. Lang and V.L. Hansen

Mapping of V-28 and V-53

E.R. Stofan, J.E. Guest, and A.W. Brian

\section{Galilean Satellites}

Mapping Ganymede at 1:15M: A Progress Report

G.W. Patterson, J.W. Head, G.C. Collins, R.T. Pappalardo, L.M. Prockter, and B.K. Lucchitta

Progress in Geologic Mapping of Europa

K.L. Tanaka, P.H. Figueredo, R. Greeley, T.M. Hare, K.F. Mullins, D.A. Senske, and E.J. Kolbe

Global Geologic Mapping of Io Using Galileo and Voyager Data

D.A. Williams, L. Keszthelyi, and D. Crown

\section{Moon}


Copernicus 1:25M Scale Mapping: Datasets, Methods, and Results of the Lunar Geologic Mapping Pilot Program

L. Gaddis, J.A. Skinner, T.M. Hare, and B.R. Hawke

The Origin of Lunar Crater Rays: Implications for the Copernican-Eratosthenian Boundary

B.R. Hawke, L.R. Gaddis, D.T. Blewett, J.M. Boyce, B.A. Campbell, T.A. Giguere, J.J. Gillis, P.G. Lucey, C.A. Peterson, M.S. Robinson, and G.A. Smith

\section{Mars}

Martian Highland/Lowland Boundary Zones: Geologic Mapping in Deuteronilus Mensae and Hellas Planitia

D.A. Crown, L. Bleamaster, and F.C. Chuang

MTM Quadrangles -15257 and -20257: Western Hesperia Planum, Mars

M.A. Farley, T.K.P. Gregg, and D.A. Crown

Loire Valles to Newcomb Crater: "Tracing” the Valleys Back to Their Sources

C.M. Fortezzo, K.K. Williams, and J.A. Grant

Mapping in Margaritifer Terra: Completed, Underway, and Proposed

J.A. Grant, K.K. Williams, and C.M. Fortezzo

Geologic Mapping of Hesperia Planum, Mars

T.K.P. Gregg, and D.A. Crown

Geologic Map of the MTM 85200 Quadrangle, Planum Boreum Region of Mars

K.E. Herkenhoff and J.A. Skinner

Geologic Mapping of Olympus Mons Caldera, Mars

P.J. Mouginis-Mark

Mapping of the Medusae Fossae Formation using THEMIS Images

K.M. Shockey and J.R. Zimbelman

Geologic Mapping of the Polar Regions of Mars: Preliminary Results and Climate Implications

K.L. Tanaka and E.J. Kolbe

Valleys, Volcanoes, Channels, and Chaos near Margaritifer Basin

K.K. Williams, C.M. Fortezzo, and J.A. Grant 
VENUS: GEOLOGIC MAPPING AND HISTORY OF THE BETA REGIO STRUCTURE. A. T. Basilevsky, Vernadsky Institute of Geochemistry and Analytical Chemistry, RAS, Moscow, 119991, Russia atbas@geokhi.ru.

Introduction: This paper combines the results of our previous [1] and recent [2] Magellan-image-based mapping of the V17 quadrangle $\left(25-50^{\circ} \mathrm{N}, 270-300^{\circ} \mathrm{E}\right)$ (Figs. 1 and 2) with the results of our research on the stratigraphy and geological history of other regions of Venus [e.g., 3-14].

Material and tectonic units of the area. We have mapped 8 material units (some with subunits) and 3 tectonic units:

1) Tessera terrain material (tt) forms islands embayed by practically all younger units. As in other areas of Venus, its surface has two or more intersecting systems of ridges and grooves of obvious tectonic origin [e.g., $3,15,16]$. On the images, unit $t$ appears radar bright with almost no areas free of tectonic structures (Fig. 3).

2) Material of densely fractured plains (pdf) is observed as islands mostly embayed by the $p w r / p s h$ regional plains. Its surface morphology is dominated by densely packed grooves.

3) Material of fractured and ridged plains (pfr) is observed either as elongated areas with clusters of broad gently-sloping ridges forming what is usually called ridge-belts [17] or as rather broad plains only locally deformed into a few ridges (Fig. 4). Unit pfr embays units $t t$ and $p d f$ and is embayed by units $p s h, p w r, p l, p s$.
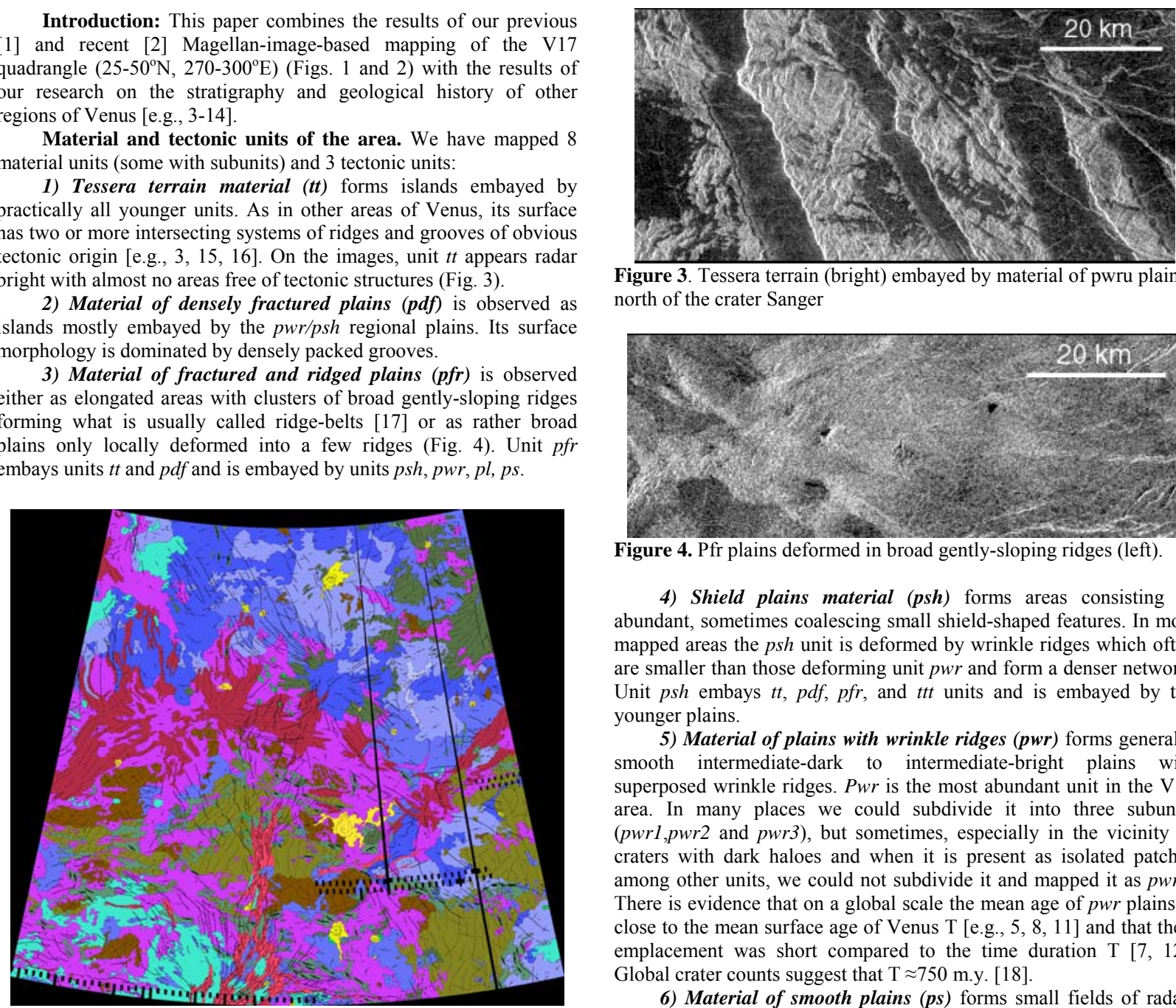

Figure 3. Tessera terrain (bright) embayed by material of pwru plains north of the crater Sanger

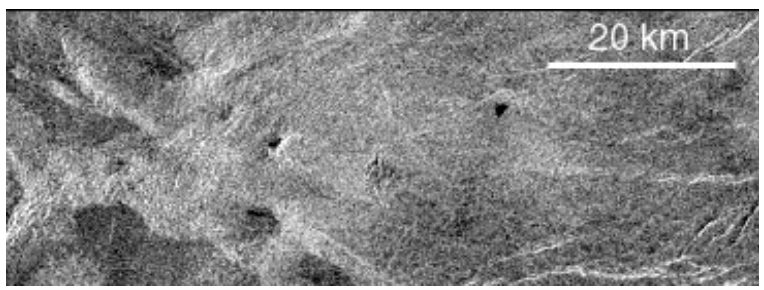

Figure 4. Pfr plains deformed in broad gently-sloping ridges (left).

4) Shield plains material (psh) forms areas consisting of abundant, sometimes coalescing small shield-shaped features. In most mapped areas the psh unit is deformed by wrinkle ridges which often are smaller than those deforming unit $p w r$ and form a denser network. Unit psh embays $t t, p d f, p f r$, and ttt units and is embayed by the younger plains.

5) Material of plains with wrinkle ridges (pwr) forms generally smooth intermediate-dark to intermediate-bright plains with superposed wrinkle ridges. Pwr is the most abundant unit in the V17 area. In many places we could subdivide it into three subunits (pwr1,pwr2 and pwr3), but sometimes, especially in the vicinity of craters with dark haloes and when it is present as isolated patches among other units, we could not subdivide it and mapped it as pwru. There is evidence that on a global scale the mean age of pwr plains is close to the mean surface age of Venus $\mathrm{T}$ [e.g., 5, 8, 11] and that their emplacement was short compared to the time duration $\mathrm{T}[7,12]$. Global crater counts suggest that $T \approx 750$ m.y. [18].

6) Material of smooth plains (ps) forms small fields of radardark smooth-appearing terrain. It is not deformed by wrinkle ridges and typically is superposed on $p w r$.

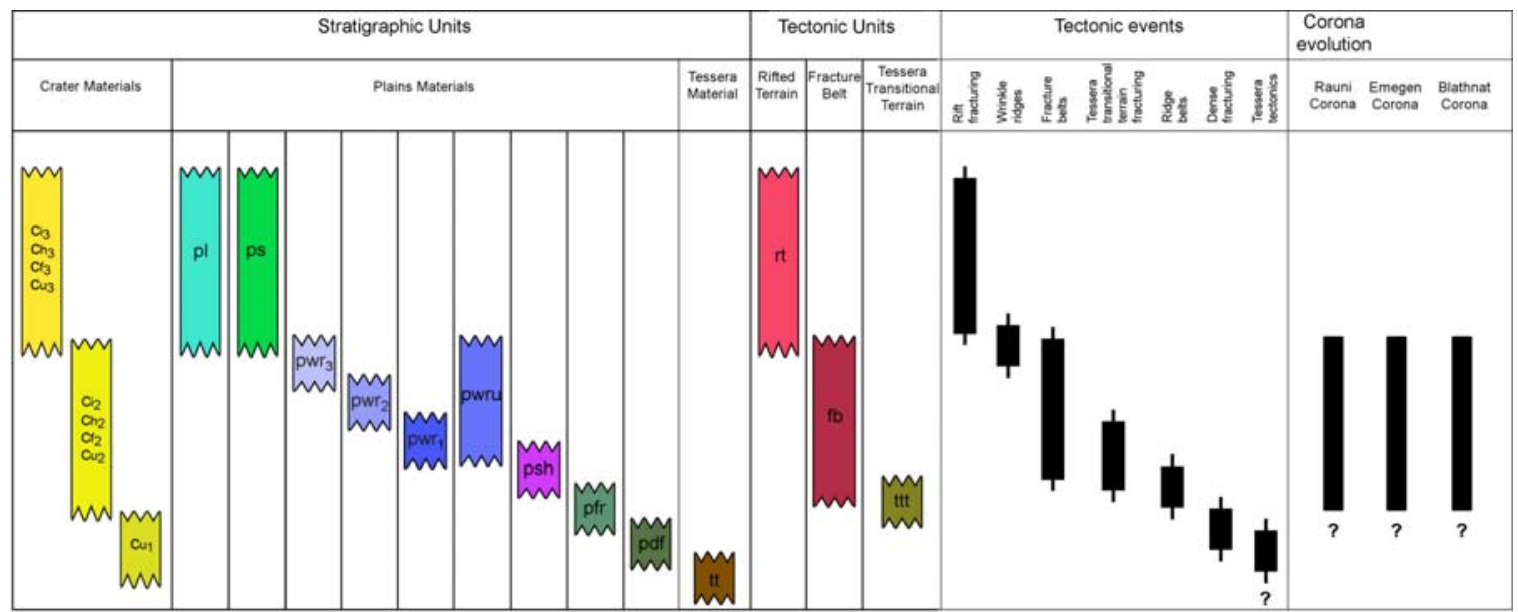

Figure 2. The V17 Beta Regio unit correlation chart. 
7) Material of lobate plains (pl) forms radar-bright flows not deformed by wrinkle ridges. The largest field of $p l$ within V17 is associated with the Theia Mons volcano superposed on the Devana rift about $100 \mathrm{~km}$ south of the southern boundary of the V17 quadrangle. There is evidence that on the global scale the rate of $p l$ emplacement was rather constant so their age in different areas may vary from the present time to $\sim \mathrm{T}[10]$.

8) Crater materials (c) compose rims, slopes, floors and ejecta, both hummocky facies and outflows. So we have mapped inside-crater material (ci), hummocky ejecta (ch), ejecta outflows (cf) and in some cases undivided crater material $(c u)$, when craters were small. Within V17 there occur 25 impact craters from 1.3 to $83 \mathrm{~km}$ in diameter [19]. As shown by several studies [e.g., 11, 13, 20] the degree of preservation of a crater-associated radar-dark halo is indicative of crater age: craters with dark parabolas (DP) have an age $<0.1-0.15 \mathrm{~T}$, craters with a clear dark halo $(\mathrm{CH})$ - from $0.1-0.15 \mathrm{~T}$ to $\sim 0.5 \mathrm{~T}(\sim 0.3 \mathrm{~T}$ if $\mathrm{D}<10 \mathrm{~km}$ ), craters with a faint halo $(\mathrm{FH})$ or with no halo $(\mathrm{NH})$ $>0.5 \mathrm{~T}(>\sim 0.3 \mathrm{~T}$ if $\mathrm{D}<10 \mathrm{~km})$

Based on the halo type and geologic relations we subdivided the V17 craters into three age subunits: $c_{3}(\mathrm{CH}$ type and those which are geologically contemporaneous to them or younger), $c_{2}$ ( $\mathrm{FH}$ and $\mathrm{NH}$ types) and $c_{1}$ (the $\mathrm{NH}$ crater Aigul, which is deformed by the $p f d$-type fracturing). From the analysis of age relations of craters with surrounding units and structures it is possible to roughly estimate ages of those units and structures. In particular, by this technique it was possible to demonstrate that the Devana Chasma rifting was still active at a time more recent than $0.5 \mathrm{~T}$ (Fig. 5).

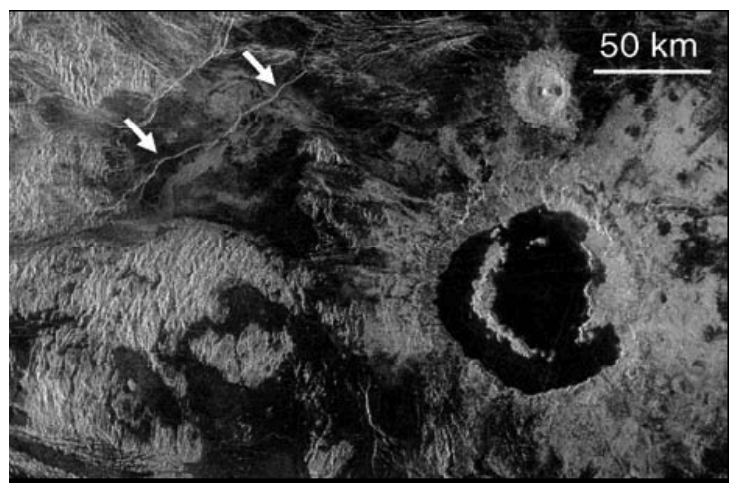

Figure 5. CH crater Sanger whose ejecta outflows are cut by the fault branching from the Devana rift (arrows).

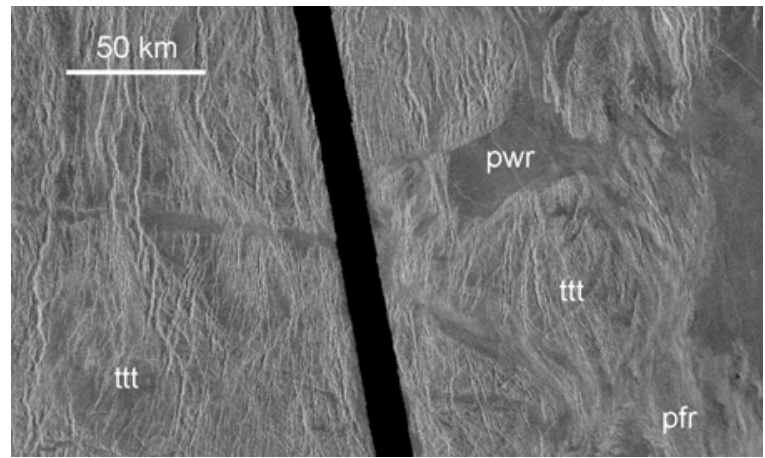

Figure 6. Unit $t t$ in the south-eastern part of the V17 quadrangle.

9) Material of tessera transitional terrain (ttt). This unit was first identified by [9]. Within the V17 quadrangle it forms areas of different size. Typically these are elongated very gently sloping highs composed of pfr plains material and crisscrossed by transverse grooves (Fig. 6). In some cases, $p d f$ material is involved in formation of $t t t$ unit.

10) Material of fracture belts (fb) forms elongated zones saturated with subparallel grooves (fractures), mostly at the northern foot of the Beta uplift. The $f b$ unit is mostly embayed by $p w r$ and younger units but some $f b$ fractures extend into $p w r$ plains deforming them. Fracture belts are considered to be ancient rift zones [e.g., 8] and some formed by dike emplacement events [21]. Arcuate fracture belts form annuli of three coronae of this quadrangle: Rauni, Emegen and Blathnat.

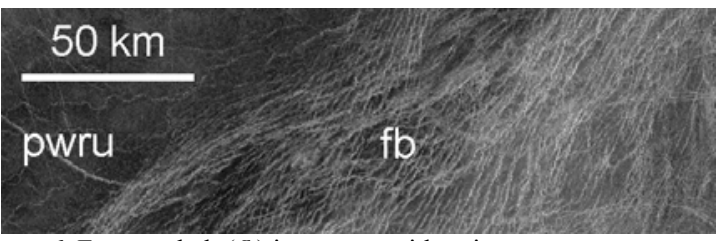

Figure 6. Fracture belt $(f b)$ in contact with unit $p w r u$.

11) Material of rifted terrain (rt) composes areas where clusters of faults and graben dominate; this is mostly concentrated in Devana Chasma. The $r t$ structures are typically anastomosing with variable width. They cut all units and are locally buried by $p l$ flows.

Structures. Eight major types of structures are identified (from older to younger): 1) Tessera-forming deformation represented by criss-crossing ridges and grooves; 2) Swarms of closely spaced grooves deforming $p d f$ material; 3) Ridges deforming the $p f r$ unit; 4) Grooves (graben) deforming pfr material thus making it the ttt unit; 5) Grooves (graben) typical of the $f b$ unit; although close or similar in age to the previous structures (type 4), these are typically longer; 6) Wrinkle ridges forming regional networks on pwr and psh units; 7) Swarms of anastomosing graben associated with the Devana rift; 8) Long linear graben mostly cutting pwr plains. It is important to note that the orientation of broad ridges typical of $p f r$ plains and networks of wrinkle ridges deforming psh and pwr plains does not show any control from the planimetric geometry of the Beta uplift, and this is different from the western Eistla structure [22] and some other structures on Venus.

A scenario of geologic history. Up until the time that the Beta uplift occurred, the geologic history of the V17 area appeared to be similar to that of many other areas of Venus: emplacement of materials of $t t, p d f$ and $p f r$ units and their deformation by the corresponding structures. Within the uplift area there is a deficit of pwr plains implying that at the time of their emplacement $(\sim \mathrm{T})$ this area was topographically higher and volcanically less active than its surrounding. However, the ridge belts and wrinkle ridges are not aligned with the Beta structure implying that significant tectonic uplift occurred later. The degree of halo preservation of craters affected by the Devana rifting and volcanism [11] suggests that at the time $\sim 0.5 \mathrm{~T}$ these processes were still active. This agrees with the results of 3D geophysical modeling of the uplift [23].

References: [1] Basilevsky (1996) LPSC 27 Abs., 65-66. [2] Basilevsky (2004) Abstracts Planet. Geol. Mapping. Flagstaff, AZ. [3] Ivanov \& Head (1996) JGR, 101, 14,861-14,908. [4] Gilmore et al. (1997) JGR, 102, 13,357-13,368. [5] Basilevsky et al. (1997) Venus II, 1047-1086. [6] Head \& Basilevsky (1998) Geology, 26, 35-38. [7] Collins et al. (1999) JGR, 104, 24,121-24,139. [8] Basilevsky \& Head (2000) PSS, 48, 75-111. [9] Ivanov \& Head (2001) JGR, 106, 17,515 17,566. [10] Basilevsky \& Head (2002) JGR, 107, 10.1029/2000JE 001471. [11] Basilevsky \& Head (2002) JGR, 107, 10.1029/2000JE 00584. [12] Basilevsky \& Head (2003) Geology, 30, 1015-1018. [13] Basilevsky et al. (2003) GRL, 10.1029/2003GL 017504. [14] Ivanov \& Head (2004) JGR, 109 10.1029/2004JE002252. [15] Solomon et al. (1992) JGR, 97, 13,199-13,256. [16] Hansen et al. (1997) Venus II, 797-844. [17] Tanaka et al. (1997) Venus II, 667-694. [18] Mc Kinnon et al. (1997) Venus II, 969-1014. [19] Schaber et al. (1998) USGS Open File Report. [20] Arvidson et al. (1992) JGR, 97, 13,199-13,256. [21] Ernst et al. (2003) Icarus, 164, 282-316. [22] Basilevsky (1994) LPSC 25 Abs., 63-64. [23] Vezolainen et al. (2004) JGR,109, 10.1029/2004JE002259.

Acknowledgements: The author acknowledges helpful discussions with Mikhail Ivanov and the technical help of Anne Côté and Peter Neivert. 
SPATIALLY ISOLATED TIME-TRANGRESSIVE VENUS EVOLTUION: AN ALTERNATE HYPOTHESIS. V.L. Hansen ${ }^{1}$, ${ }^{1}$ Dept Geol. Sci., UMD, Duluth, MN 55812 (vhansen@d.umn.edu).

Introduction: Venus resurfacing hypotheses form two groups: 1) catastrophic/episodic and 2) equilibrium/evolutionary. The former propose that global-scale, temporally punctuated, events dominated Venus evolution [1-3]; the later evoke relatively continuous volcanotectonic processes through time [46]. Results of geologic mapping provide challenges to these hypotheses. The SPITT hypothesis, which emerged from geologic mapping, calls for near steadystate crater formation and destruction on globally thin lithosphere, followed by crater accumulation with a change to thick lithosphere. Early crater destruction occurred through SPatially Isolated Time-Transgressive formation of tessera. SPITT does not depend on a particular mechanism of tessera formation (e.g., downwelling, plume, or impact-induced lava-pond), and provides tantalizing evidence that Venus records a long rich history, rather than an abbreviated view of the last $\sim 750$ Ma as currently widely accepted.

Observations: A. Venus shows few partially flooded and few faulted craters [1,3,4,7]; most craters appear 'pristine.' Studies indicate some modification [8-10]; yet, examples of near complete flooding of craters are rare. (Fig. 1 [11] shows an example of a possible $60 \mathrm{~km}$ buried crater). Thus, crater destruction was an all or nothing endeavor. Craters are either: 1) not preserved; 2) form but viscously relax, 3) completely destroyed by tectonism; 4) buried beyond recognition, or 5) preserved in near-pristine state. B. Large craters $(>100 \mathrm{~km})$ have rim-terrain heights of $\leq 650 \mathrm{~m}$ [10]; thus burial requires strata $>700 \mathrm{~m}$. Presumably ancient craters would far exceed Venus' largest crater, and likely require $>1 \mathrm{~km}$ thick strata for burial. C. Many studies indicate that huge lowland regions $\left(>10^{6} \mathrm{~km}^{2}\right)$ are covered by thin layers or flows (10's to $100 \mathrm{~m}$ thick) [12-18], and large tracts of lowland tessera show thin blanketing of strata [19-21]. D. Craters on tessera post-date deformation [22]. Tessera, which characterizes crustal plateaus, also occurs locally in lowland inliers; areally, most tessera is preserved in plateaus [23]. E. Craters record a temporal sequence of degradation in which halos are lost and troughs and interiors fill with smooth material over time $[10,24,25]$; thus, craters are divisible into broad relative age groups. Young craters display haloes and rough interiors. Old craters lack haloes and have smooth interiors. F. Crater density taken together with crater morphology (E) allows delineation of three average model surface age (AMSA) provinces [26]. Phillips and Izenberg [26] reasoned: if a surface only experienced weathering [27)], then haloes, but not associated craters, would disappear with time. However, if volcanic flows bury a surface, then a crater and its halo would be lost. Therefore old surfaces should have an abundance of craters but be statistically deficient in craters with halos; young volcanically resurfaced regions should be statistically deficient in both craters and halos. Young-
AMSA show: low crater density $\left(<1.5\right.$ craters $\left./ 10^{6} \mathrm{~km}^{2}\right)$ and a deficiency in craters with halos; intermediate AMSA show: crater density $\left(2.5-1.5\right.$ craters $\left./ 10^{6} \mathrm{~km}^{2}\right)$ without a halo deficiency; old AMSA show: high crater density ( $>2.5$ craters $/ 10^{6} \mathrm{~km}^{2}$ ), and a deficiency in impact craters with halos. Spatial correlation of geotime-dependent criteria (haloes) with crater density suggests that AMSA provinces reflect true temporal domains, not stochastic fluctuations in a random distribution [28].

Comparison of AMSA provinces with major geologic [29] features indicates that: G. Volcanic rises show no correlation with AMSA. H. Crustal plateaus correlate mostly with intermediate-AMSA. I. Many lowlands correlate with old-AMSA. J. Beta-Atla-Themis and Lada, regions of volcanotectonic activity [26,30,31], correlate with young-AMSA.

An alternate hypothesis: No previous resurfacing hypothesis addresses all observations A-J. Resurfacing must fundamentally address crater formation and removal. Assuming that craters can form over most (all) of Venus' history, destruction processes may be key. Processes apparently completely obliterate craters. Crater obliteration through wholesale lithosphere recycling cannot accommodate A-J, and crater burial by thick flows is contrary to C. Crustal plateaus, spatially correlative with intermediate AMSA, may offer critical clues. Crustal plateaus host tessera terrain, and tessera inliers, which outcrop across the lowland [23,32-34], are widely accepted as ancient plateau remnants [23,32,3538]. Divergent hypotheses for plateau formation have been proposed: downwelling, plume, and lava pondimpact. Although plateau formation is hotly debated, the common, rather than divergent, elements of these hypotheses might be most important to resurfacing. The downwelling hypothesis involves thickening by subsolidus flow and horizontal lithospheric accretion of ancient thin lithosphere associated with a focused cold mantle downwelling $[35,36,39,40]$. The plume hypothesis calls for magmatic underplating and vertical accretion due to interaction of ancient thin lithosphere with a large thermal mantle plume $[5,33,37,41,42]$. The lava pond-impact hypothesis calls for crystallization and progressive deformation of a huge lava pond, the result of massive melting of the mantle due to large bolide impact with ancient thin lithosphere [43,44]. Four critical points of agreement emerge. 1) Pre-existing craters would be completely destroyed across the area of individual plateaus $\left(2-5 \times 10^{6} \mathrm{~km}^{2}\right)$. 2) Individual plateaus formed spatially and temporally distinct from one another. 3) Plateaus formed on globally thin lithosphere, a condition presumed by many workers to exist during Venus' ancient past [5,37,45-49]. 4) Lowland tessera may represent ancient plateau remnants [23,32-34]. Thus, independent of the favored mechanism, workers agree that plateau formation 
resulted in complete crater destruction across large, but spatially isolated, areas $\left(2-5 \times 10^{6} \mathrm{~km}^{2}\right)$ time transgressively during 'early' Venus history.

SPITT: Plateau formation coupled with a transition from thin to thick lithosphere [5,37,45-49] might accommodate observations A-J. During an ancient thinlithosphere phase, crater formation and subsequent removal by spatially isolated time transgressive plateau formation could result in near a steady-state impact crater distribution. As Venus transitioned to a thicklithosphere state, new craters would accumulate. Evolution begins with a surface that accumulates craters (t1); during $\mathrm{t} 2$ an individual plateau forms by whatever mechanism completely destroying the local craters across the region that evolves into the plateau. Craters outside the aureole of the downwelling, plume, or lava pond would remain pristine. The plateau shows distinctive tectonic fabric across the region in which preexisting craters were obliterated (t3). As the plateau stabilizes, new craters form on its deformed surface (t3). A new downwelling/plume/bolide interacts with another part of the surface, obliterating all craters within its aureole (t4); this region evolves into a new plateau (t5). Over time, new plateaus form each destroying craters within their aureoles (t6, t7). The local AMSA within the area of a newly formed plateau is reduced due to plateau formation. Globally the surface would develop a near-equilibrium steady state, marked by a timeaveraged balance of global crater formation and local crater destruction (t2-t7). Local differences in crater density could occur, depending on the distribution of downwellings/plumes/bolides through time. This process could continue as long as the global lithosphere remains thin.

Lithospheric thickening would cause a marked change in surface evolution. The interaction of thick lithosphere with downwellings or large bolides would not result in plateau formation. Large thermal mantle plumes would result in the formation of a volcanic rise; local surfaces would be topographically elevated but there would be insufficient thermal energy to affect the surface rheology to destroy or modify craters. Rise formation is pertinent to the AMSA development, however; because rise formation might involve simply uplifting the existing surface, the AMSA at a rise should be older than the age of the rise itself, unless massive outpouring of lava accompanied rise formation and completely buried local craters. In this case the rise might correlate with young AMSA. Old AMSA should represent areas either completely lacking in tessera, or areas where thin flows variably cover tessera. Surfaces that were completely unaffected by plateau events, or affected by early plateau events, would accumulate craters for a significantly longer time than regions affected by more recent plateau events. Plateaus that formed just prior to the switch to thick lithosphere might sit high, having been captured (frozen in time) with the transition to thick lithosphere. Elevated plateaus should preserve relatively younger AMSA than regions affected by ancient plateau formation (e.g. lowland tessera). Volcanic rises could be associated with any AMSA because rise formation simply lifts a preexisting surface and retains the existing crater record. An individual rise could have formed anytime after the AMSA recorded on its surface. Regions marked by very young AMSA must have truly young average surface histories.

SPITT accommodates a global AMSA of $\sim 750$ $+350 /-400 \mathrm{Ma}$, and A-J. The global AMSA could record, broadly, the time of a change from near steadystate crater formation and destruction (thin lithosphere) to crater accumulation (thick lithosphere), whereas the distinct AMSA provinces occur as outlined above. The SPITT hypothesis accounts for complete local crater destruction and for 'pristine' craters (A,B), yet it accommodates the occurrence of thin, rather than thick, lava flows (C). It predicts that craters should not record tessera deformation (D), and it allows for the preservation of stages of crater degradation (E), and the occurrence of distinct AMSA provinces (F), with specific geologic relations (G-J). The SPITT hypothesis: i) embodies the spirit of the equilibrium volcanic hypothesis [3], ii) accommodates broad aspects of the view that volcanotectonic processes occurred across Venus through time, though styles and locations have change [6], and iii) incorporates a secular change in resurfacing and dynamic processes [5,37,45-49], which, iv) could address some aspects of a broadly defined geologic history that might accommodate some 'Eras' highlighted by the global stratigraphy hypothesis [25,49-50].

References: [1] Schaber et al. (1992) JGR [2] Strom et al. (1994) JGR. [3] Herrick (1994) Geol. [4] Phillips (1993) EOS. [5] Phillips \& Hansen (1998) Sci. [6] Guest \& Stofan (1999) Icarus. [7] Herrick et al. (1997) Venus II. [8] Sharpton (1994) JGR. [9] Wichman (1990) JGR. [10] Herrick \& Sharpton (2000) JGR. [11] Kreslavsky \& Basilevsky (1998) JGR. [12] Guest et al. (1992) JGR. [13] Aubele (1996) LPSC. [14] DeShon et al. (2000) JGR. [15] Addington (2001) Icarus. [16] Hansen \& DeShon (2001) USGS. [17] Brian \& Stofan (2003) USGS. [18] Stofan et al. (2005) Icarus. [19] Hansen (2005) GSAB. [20] Lang \& Hansen (2003) LPSC. [21] Lang \& Hansen (2005) USGS. [22] Gilmore et al. (1997) JGR. [23] Ivanov \& Head (1996) JGR. [24] Izenberg et al. (1994) GRL. [25] Basilevsky \& Head (2002) Geol. [26] Phillips \& Izenberg (1995) GRL. [27] Arvidson et al. (1992) JGR. [28] Campbell (1999) JGR. [29] Hansen \& Young (2005) GSA Special paper. [30] Head et al. (1992) JGR. [31] Crumpler et al. (1997) Venus II. [32] Phillips \& Hansen (1994) AREPS. [33] Hansen et al. (1997) Venus II. [34] Ghent \& Tibuleac (2002) JGR. [35] Bindschadler et al. (1992) JGR. [36] Bindschadler (1995) Geophys. Rev. [37] Hansen \& Willis (1998) Icarus. [38] Nunes et al. (2004) JGR. [39] Bindschadler \& Parmentier (1990) JGR. [40] Bindschadler et al. (1992b) JGR. [41] Hansen et al. (1999) Geol. [42] Hansen et al. (2000) JGR. [43] Hansen (2005ba) LPSC. [44] ibid (2005b). [45] Solomon (1993) Phys. Today. [46] Grimm (1994) JGR. [47] Solomatov \& Moresi (1996) JGR. [48] Schubert et al. (1997) Icarus. [49] Brown \& Grimm (1999) Icarus. [50] Basilevsky \& Head (1996) JGR. [51] (1998) ibid. 
GEOLOGIC MAP OF THE MESKHENT TESSERA QUADRANGLE (V-3), VENUS. M. A. Ivanov ${ }^{1,2}$ and J. W. Head $^{2},{ }^{1}$ Vernadsky Institute, RAS, Moscow, Russia, mikhail_ivanov@brown.edu, ${ }^{2}$ Brown University, Providence, RI, USA, james_head_iii@brown.edu.

Introduction: The Meskhent Tessera quadrangle (V3) [1] is in the northern hemisphere of Venus $\left(50-75^{\circ} \mathrm{N}\right.$, $60-120^{\circ} \mathrm{E}$ ) and is surrounded by extensive tesserae to the $\mathrm{E}$ (Fortuna and Laima) and to the S (Tellus) [2,3] and by the large basin-like lowland of Atalanta Planitia to the W. Thus, the key geological theme of the quadrangle is that it corresponds to a transition zone from uplands to lowlands. The gravity and topography of Atalanta Planitia [4-6] have been cited as evidence for large-scale mantle downwelling [4]. The topographic configuration, gravity signature, and presence of large tesserae in Ishtar Terra, Tethus Regio, and Tellus Tessera are consistent with extensive areas of thickened crust and tectonically stabilized lithosphere representing ancient and now extinct regimes of mantle convection $[7,8]$. Thus, the region of Meskhent Tessera quadrangle represents a good sample for the study of the formation and evolution of lowlands, midlands, and highlands, and possibly interaction between the downwelling and areas of thickened crust and lithosphere, the formation of associated tectonic features, and the emplacement of volcanic plains. We discuss these issues in a separate abstract [1].

General geology: The area of the V-3 quadrangle displays three major (thousands of $\mathrm{km}$ ) occurrences of tessera (Fortuna Tessera in the NW portion of the map area, Meskhent Tessera in the NE portion of the quadrangle, and Dekla Tessera in the SW corner of the quadrangle). Smaller outliers of tessera (tens to a few hundreds of $\mathrm{km}$ across) typically occur near the major tessera regions.

Other tectonic features in the $\mathrm{V}-3$ quadrangle are mostly collected in deformational belts consisting of either contractional or extensional structures. The belt of grooves (Manto Fossae) forms a giant arc that is roughly parallel to the general strike of Dekla Tessera. Another zone of groove belts is inside Dekla Tessera and oriented to the NE almost orthogonal to the orientation of the Manto Fossae zone. The other prominent zone of groove belts runs from the SE of the quadrangle (Fakahotu Corona) to the NE. Dense swarms of ridges that are $~ 5-10 \mathrm{~km}$ wide are collected in a ridge belt (Allat Dorsa) that is in contact with Dekla Tessera and follows the strike of this tessera arc. In the center of the quadrangle, fragments of ridge belts are arranged in a semicircular feature outlining a corona-like structure, Vacuna Corona. Fragments of ridge belts form parts of the rim of Fakahotu and Tusholi Coronae.

In many areas of the quadrangle, clusters of small shield volcanoes less than about $15 \mathrm{~km}$ diameter [9-15] are common in spatial association with, but overlie, tessera massifs and deformation belts. Several coronae occur within the quadrangle [16-18,13]. Two of them, Tusholi and Ops Coronae, are in a broad topographic trough between Ishtar Terra and Tethus Regio. Fakahotu Corona, in the SE portion of the map area, is at the SW extension of a chain of coronae and graben that characterize the western edge of Atalanta Planitia.

Twelve impact craters (from 4.5 to57.6 km in diameter) have been mapped in the quadrangle $[19,20]$. Two craters, La Fayette and Fedorets, have outflow deposits and craters La Fayette and Jadwiga appear to be surrounded by crater-related mantling deposits.

Stratigraphy: Although we have mapped tectonic structures independently of geologic units, in a few cases tectonic features are such a pervasive part of the morphology of the terrain that it becomes part of the definition of a unit. In the area of V-3 quadrangle we have defined and mapped the following material units.

Tessera material (t, $\sim 1.0810^{6} \mathrm{~km}^{2}$ or $\sim 14.1 \%$ of the quadrangle). This unit appears to be the stratigraphically oldest in the quadrangle. Tessera material is radar bright, consists of several sets of intersecting ridges and grooves, and is a result of tectonic deformation of some precursor terrain [2,3,21-23]. Densely lineated plains material (pdl, $\sim 0.19 \times 10^{6} \mathrm{~km}^{2}$ or $\sim 2.4 \%$ ) is among the stratigraphically oldest plains units. It is characterized by relatively flat surfaces on a regional scale and by swarms of subparallel lineaments (resolved as fractures if they are wide enough) having typical spacing of less than $1 \mathrm{~km}$. Ridged plains material (pr, $\sim 0.3510^{6} \mathrm{~km}^{2}$ or $\sim 4.6 \%$ ) is deformed by relatively broad (5-10 km wide) ridges tens of kilometers long after its emplacement. In the V-3 quadrangle this unit is arranged in linear outcrops or belts. Shield plains material (psh, $2.1410^{6} \mathrm{~km}^{2}$ or about $28.0 \%$ ) followed the emplacement and deformation of ridged plains material. This unit is characterized by abundant small shield-shaped features ranging from a few kilometers in diameter up to about 10-20 km, some of them with summit pits. Regional plains material (rp, $\sim 2.0810^{6} \mathrm{~km}^{2}$ or $\sim 27.1 \%$ ) was emplaced after formation of the earlier plains materials. This unit is composed of morphologically smooth, homogeneous plains material of intermediate-dark to intermediate-bright radar albedo complicated by wrinkle ridges. On the basis of its typical pattern of the radar backscatter, regional plains material is subdivided into two units. The lower unit $\left(\mathrm{rp}_{1}\right)$ generally has a homogeneous and relatively low radar albedo; the upper unit $\left(\mathrm{rp}_{2}\right)$ appears to have slightly higher radar albedo and, in places, is characterized by lobate boundaries. Plains materials that are younger than regional plains material are unmodified by wrinkle ridges and other structural elements. Smooth plains material (ps, $\sim 0.1410^{6} \mathrm{~km}^{2}$ or $1.8 \%$ ) is characterized by uniform and preferentially low albedo. In places, the radar albedo of the surface appears to be high. Lobate plains material (pl, $0.1610^{6} \mathrm{~km}^{2}$ or $2.1 \%$ ) has internal elements arranged in parallel to sinuous to lobate radar bright and dark strips and patches, and unit boundaries are typically lobate. Impact crater material was mapped as undivided crater material (cu) in some cases surrounded by crater outflow deposits (cf). 
Geologic history: The oldest material in the map area (tessera) forms high-standing complexly deformed areas (Fortuna, Meskhent, and Dekla Tesserae) and smaller outcrops are exposed as kipukas near the principal tessera massifs. Such a distribution suggests that tessera material exists extensively in the subsurface beneath younger plains units [24]. Densely lineated plains material is sometimes marginal to tessera and embays it. In some cases the structural fabric orientation of pdl is similar to the latest phase of deformation in tessera. This unit is interpreted to be volcanic plains material that postdated early tessera, but was deformed by the latest phases of tessera deformation. A less deformed plains unit (ridged plains material, pr) was emplaced either contemporaneously or, in part, following the formation of pdl. The most important features of $\mathrm{pr}$ are ridges (5-10 $\mathrm{km}$ wide) that are very pervasive from place to place. The material of unit $\mathrm{pr}$ and its deformation appear to have produced the second-order topography within extensive lowlands in the central and north-central portions of the Meskhent Tessera quadrangle. The unit $\mathrm{pr}$ tends to associate with tessera (Dekla) and signifies the apparent beginning of evolution of some coronae. Zones of fractures and graben (groove belts, structural unit gb) are abundant within the V-3 quadrangle. Their formation marks the episodes of extension that were both parallel and radial to the orientation of the Dekla Tessera arc. The time of formation of groove belts appears to be well constrained in the map area: they began after emplacement and deformation of ridged plains material and mostly died out before emplacement of vast plains materials such as psh and $\mathrm{rp}_{1}$.

After emplacement and deformation of ridged plains and formation of groove belts, another distinctly different plains unit (shield plains material, psh) was emplaced in many parts of the map area. The unit psh is embayed by material of regional plains. Close association of psh material with older units such as tessera, pr, and gb that make up local highs suggests that the topographic position of occurrences of the unit was an important factor in their present areal distribution [15,25]. Subsequent to the emplacement of shield plains material the style of volcanism changed again [26]. Instead of abundant small shield volcanoes, broad units of regional plains material were emplaced from sources that are now rarely visible. The wide extent of these units suggests a high-effusionrate mode of emplacement from sources that are now buried. Such a volcanic style is in distinct contrast to the widespread and abundant small shield volcanoes just preceding this phase.

Occurrences of smooth plains material (ps) and lobate plains material (pl) are closely associated with distinct source areas such as coronae and large volcanoes. Volcanism at the time of the emplacement of these materials was obviously much less abundant than during episodes of formation of psh and rp and related to a few specific sources.

Summary: The geological mapping and interpretation of relationships among the material units and structures in the map area suggest that there are clear trends in the evolution of both tectonic regimes and style of volcanism within the V-3 quadrangle. Contractional deformation changed from that associated with the compact ridge belts (pr) to that associated with smaller but pervasive wrinkle ridges. Extensional deformation appears to have an opposite trend. Fractures on the surface of the unit pdl are narrow, pervasive, and do not form belt-like concentrations. The subsequent occurrences of extensional structures are organized into belts, the individual structures of which on average become broader as a function of time.

Changes in character of volcanic activity are clearly recorded in units starting with psh. Formation of this unit is related to numerous small individual volcanic constructs. This mode of volcanism changed to massive volcanic flooding from unrecognizable sources during emplacement of the lower unit of regional plains material. Later plains units ( $\mathrm{rp}_{2}, \mathrm{ps}$, and $\left.\mathrm{pl}\right)$ were related to large distinct sources such as some coronae and intermediate and large volcanoes. Coronae within the map area display prolonged evolution. They started to form apparently early on during formation of heavily tectonized units such as $\mathrm{pr}$ and gb and continued their evolution until emplacement of young smooth and lobate plains materials.

References: [1] Ivanov M. A. and J.W. Head (2005) this issue. [2] Barsukov V. L. et al. (1986) JGR, 91, D378. [3] Sukhanov A. L. in: V. L. Barsukov et al. (editors) Venus geology, geochemistry, and geophysics, Tucson, Univ. Arizona Press, p. 82. [4] Bindschadler D. L. et al. (1992) JGR, 97, 13,495. [5] Konopliv A. S. and Sjogren W. L. (1994) Icarus, 112, 42. [6] Konopliv A. S. et al. (1999) Icarus, 139, 3. [7] Grimm R. E. (1994) Icarus, 112, 89. [8] Brown C. D. and Grimm R. E. (1999) Icarus, 139, 40. [9] Aubele J. C. and Slyuta E. N. (1990) EMP, 50/51, 493. [10] Guest J. E. et al. (1992) JGR, 97, 15,949. [11] Aubele J. C. (1994) LPSC 25, 45, 1994. [12] Aubele J. C. (1995) LPSC 26, 59. [13] Crumpler L. S. and Aubele J. C. (2000) in: Encyclopedia of Volcanoes, Acad. Press, 727. [14] Addington E. A. (2001) Icarus, 149, 16. [15] Ivanov M. A. and Head J. W. (2004) JGR, 109, NE10001, doi:10.1029/2004JE002252. [16] Stofan E. R. et al. (1992) JGR, 97, 13,347. [17] Stofan E. R. et al. (2001) GRL, 28, 4267. [18] Crumpler L. S. et al. (1993) Science, 261, 591. [19] Herrick R. R. (1997) in: R. Phillips et al., eds., Venus II, Univ. Arizona Press, p. 1015. [20] Schaber G. G. (1998) USGS OFR 98104. [21] Basilevsky A. T. et al. (1986) JGR, 91, D399. [22] Bindschadler D. L. and Head J. W. (1991) JGR, 96, 5889. [23] Solomon S. C. et al. (1992) JGR, 97, 13,199. [24] Ivanov M. A. and Head J. W. (1996) JGR, 101, 14,861. [25] Ivanov M. A. and Head J. W. (2001) JGR, 106, 17,515. [26] Head J. W. et al. (1996) LPSC 27, 525. 
GEOLOGICAL MAPPING IN THE MESKHENT TESSERA (V-3) QUADRANGLE, VENUS: EVIDENCE FOR EARLY FORMATION AND PRESERVATION OF REGIONAL TOPOGRAPHY. M.A. Ivanov ${ }^{1,2}$ and J.W. Head $^{2,}$ ${ }^{1}$ Vernadsky Institute, RAS, Moscow, Russia, mikhail_ivanov@brown.edu, ${ }^{2}$ Brown University, Providence, RI, USA, james_head_iii@brown.edu.

Introduction: The area of the Meskhent (V-3) quadrangle [1] (Fig. 1) encompasses the topographic province of midlands $(0-2 \mathrm{~km}$ above mean planetary radius (MPR)) in the transition zone from the highlands (>2 km) of Ishtar Terra and Tellus Tessera to the $\mathrm{W}$ and $\mathrm{S}$ to the large basin-like lowland $(<0 \mathrm{~km})$ of Atalanta Planitia to the E (Fig. 2). Large tessera regions (Fortuna, Laima, and Tellus Tesserae) dominate the Ishtar and Tellus areas that belong to the tessera-bearing plateau-shaped class of Venusian highlands sharply contrasting to the rifted domeshaped highlands. The topographic and gravity characteristics of the plateau-like highlands are consistent with extensive areas of thickened and isostatically compensated crust [e.g. 2]. The presence of tessera (which makes up the base of the regional stratigraphic columns in the map area and elsewhere on Venus) in these highlands suggests that they are related to ancient regimes of mantle convection that may now be extinct. What are the characteristics of the broad area of midlands between Ishtar Terra and Atalanta Planitia? What does the stratigraphic order of units and structures suggest about the possible timing and evolution of the transition zone? Does this evolution appear to consist of the processes operating in a quasi-steady-state mode? Or were they preferentially distributed toward the beginning or, alternatively, the end of the observable geologic history in the region of the V-3 quadrangle? These questions can be addressed and tested by geological mapping and the possible answers are important for the understanding of the geologic history of Venus as a whole.

Topographic position of the mapped units: The major part of the map area is within the topographic province of midlands and is mostly populated with material and structural units postdating tessera and predating regional plains material (rp1, Fig. 3). Four elevated regions separated by elongated lower-lying areas characterize the overall topography of the map area (Fig. 2). Three of them, eastern Ishtar, Tethus Regio, and in the arc of Dekla Tessera, all coincide with the large tessera occurrences that make up $\sim 14 \%$ of the map area. The fourth region in the central-eastern portion of the quadrangle corresponds to a zone of groove belts between Fakahotu Corona and Melia Mons.

The relatively old tectonized materials and deformational belts (pdl, ridge and groove belts, Fig. 3, $19 \%$ of the map area) are concentrated within regional slopes predominantly near the major tessera-bearing elevated regions. An exception is the ridge belts of Allat Dorsa north of Dekla Tessera that occur in relatively lowlying Audra Planitia. There, the belts are broadly embayed by regional plains material. The most abundant unit in the quadrangle (shield plains material, psh, Fig. 1, 28\% of the map area), postdates tessera and the deformational belts and predates regional plains (Fig. 3) and is clearly concentrated on the broad slopes away from the major elevated regions. Where the psh unit occurs within relatively low areas (for example, on the floor of Lowana Planitia) it is embayed by regional plains material. Regional plains material (rp1, Fig. 1, 24\% of the map area) occurs throughout the map area (except for the major tesserae) but preferentially occupies the elongated lowlands where it embays all previous material and structural units. The youngest and relatively non-abundant material units such as the upper unit of regional plains (rp2) and lobate/smooth plains materials (Fig. 3, 7\% of the map area) are related to distinct volcanic centers and their distribution appears to be governed by local slopes of older units.

Conclusions: The material and structural units within the V-3 quadrangle reveal not only the relative age relationships that are consistent throughout the map area but also good correlation with topography on both the local and regional scales. The older units generally occupy the higher topographic levels, which is consistent with embayment by progressively younger units. This suggests two important characteristics of the regional-scale topography within the quadrangle and, by implication, within the broader surroundings. First, the actual regionalscale topographic pattern appears to have formed relatively early on before emplacement of regional plains (rp1), in the time span from tessera to shield plains. Material of the lower unit of regional plains (rp1) follows regional topographic contours in its areal distribution, being less abundant within elevated areas and concentrated in the regional lows. Second, this regional-scale topographic configuration has remained stable since the time it was established prior to the regional plains, although the plains were warped and deformed to a relatively small extent.

References: [1] Ivanov M. A. and Head J. W. (2005) Geologic map of the Meskhent Tessera quadrangle (V-3), Venus, this conference. [2] Grimm R. E. (1994) Icarus, 112, 89.

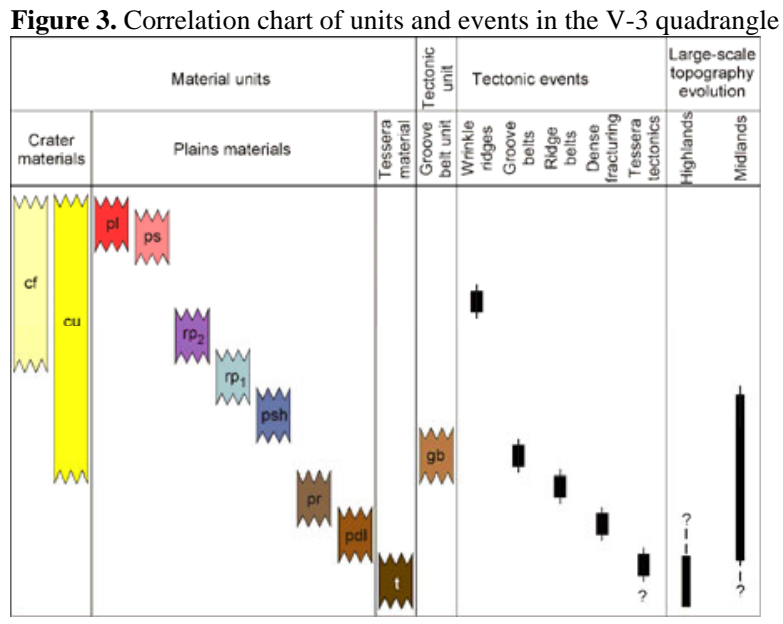


M. A. Ivanov and J. W. Head: V-3 quadrangle: early formation of regional topography

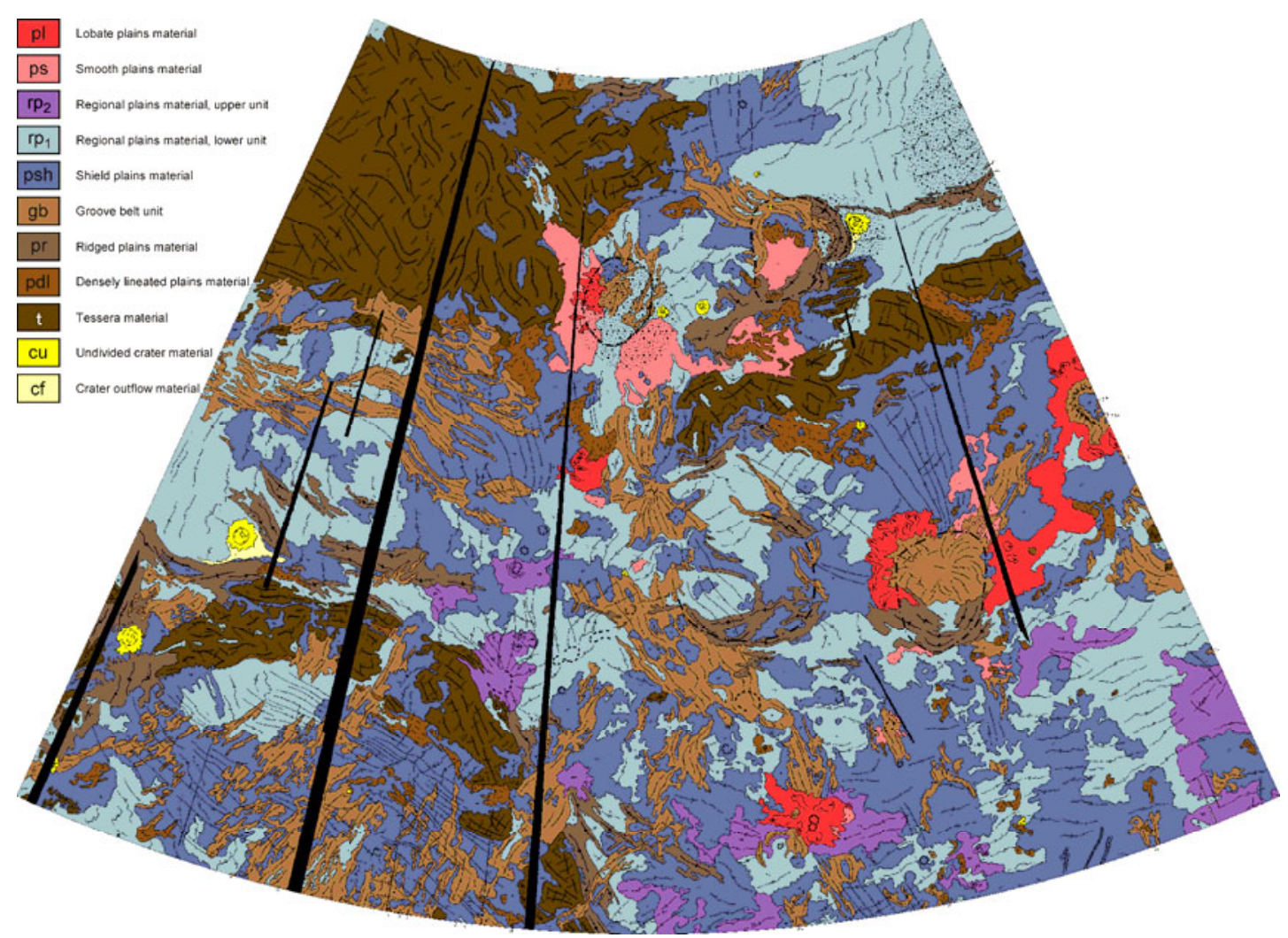

Figure 1. Geological map of the V-3 Meskhent Tessera quadrangle

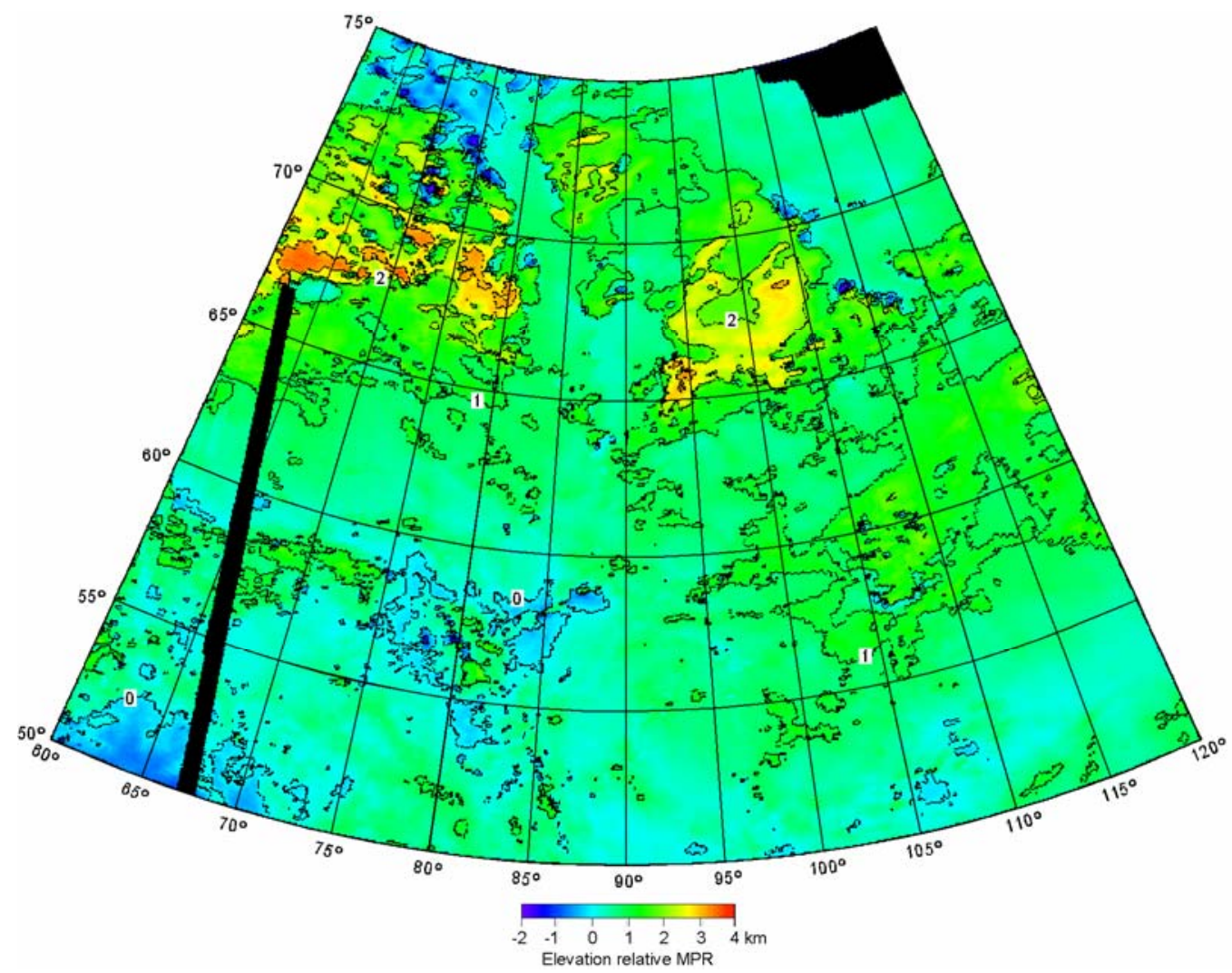

Figure 2. Regional topography for the V-3 Meskhent Tessera quadrangle 
GEOLOGICAL MAPPING OF THE LAKSHMI PLANUM QUADRANGLE (V-7), VENUS: PRELIMINARY RESULTS. M. A. Ivanov ${ }^{1,2}$ and J. W. Head ${ }^{2}{ }^{1}$ Vernadsky Institute, RAS, Moscow, Russia, mishaivn@mtu-net.ru, ${ }^{2}$ Dept. of Geological Sciences, Brown University, Providence, RI, USA, james_head_iii@brown.edu.

Introduction: Lakshmi Planum, which is about $2000 \mathrm{~km}$ across, is the most important regional-scale feature that dominates the western portion of the highland of Ishtar Terra [1]. Lakshmi Planum is a roughly circular elevated plateau $(\sim 3-4 \mathrm{~km}$ above mean planetary radius (MPR)), which is almost completely surrounded by the highest Venusian mountain ranges ( $7-8$, up to $12 \mathrm{~km}$ above MPR). Morphologically smooth plains within the planum are tilted to the south and host two large volcanic centers, Colette and Sacajawea Paterae. There are a variety of hypotheses ranging from hot spot to collision scenarios [2,3 and reference therein] that explain the unusual characteristics of Lakshmi Planum. The V-7 quadrangle covers Lakshmi Planum in the northern half of the quadrangle and the Lakshmi surroundings including vast low-lying Sedna Planitia in the southern half of the quadrangle. Thus, there are two main geological themes of the map area: 1) Lakshmi Planum with the mountain ranges and 2) the transition from the highland of Ishtar Terra to the midlands and lowlands of Sedna Planitia. The mapping in this area allows us to document specific features of Lakshmi Planum and establish the sequence of events in the formation and evolution of this major feature on Venus.

Major physiographic provinces within the V-7 quadrangle: Outer deformational zone: A broad zone of complexly deformed terrains and volcanic centers surrounds the structure of Lakshmi Planum outside of the bordering mountain ranges. In the SE corner of the quadrangle a large volcano, Muta Mons, appears to be a center emanating lava flows of Neago Fluctūs. In the south, two major scarps, Vesta and Ut Rupēs separate Lakshmi from Sedna Planitia. The major features of the transition zone there are small fragments of tessera terrain (Clotho and Moira Tesserae) and linear belts of grooves. In the $\mathrm{W}$, the large Omosi-Mama Corona, which is the source of the apparently young Djata Fluctus, is the main feature of the transition zone. Large tessera massifs, Atropos and Itzpapalotl Tesserae, make a giant arc that embraces Lakshmi Planum from the NW, N, and NE.

Inner deformational zone: The mountain ranges that almost completely outline the interior of Lakshmi form the second (inner) deformational zone around the plateau. The ranges are lowest at the southern edge of Lakshmi (Danu Montes, 1.5-2 $\mathrm{km}$ higher than the surface of Lakshmi) and are significantly higher to the $\mathrm{W}$ (Akna Montes, $3 \mathrm{~km}$ higher), $\mathrm{N}$ (Freyja Montes, 3-3.5 km higher), and especially E (Maxwell Montes, 5-10 higher). The mountain ranges consist of tightly packed elongated parallel ridges 5 to $10 \mathrm{~km}$ wide and morphologically resemble the ridge belts common elsewhere on Venus [4]. In places, there is some evidence for embayment of the mountain ranges by regional plains from the outside of Lakshmi. At the contacts with the plains that make up the interior of Lakshmi, there is abundant evidence for embayment of the mountain ranges by the plains. Along Akna and Freyja Montes, however, the interior plains are sometimes tilted toward the plateau center and appear to be slightly ridged conformal to the strike of the mountain ranges.

Interior of Lakshmi: The interior of Lakshmi is relatively flat and slightly tilted to the $\mathrm{S}$ and is covered by vast morphologically smooth lava plains moderately deformed by wrinkle ridges. Relatively small and embayed outcrops of heavily deformed materials morphologically similar to either tessera or groove belts occur within the interior of the plateau. Within the central part of the interior, there are two large volcanic centers, Colette and Sacajawea Paterae, which are sources of numerous lava flows that appear to be tectonically undeformed.

Material units and structures mapped in the V-7 quadrangle: We defined units and mapped key relations among them using the full resolution Magellan SAR data. The background for our unit definition and characterization is described in [5-11]. Within the V-7 quadrangle we defined and mapped 14 material and 2 structural units (Fig. 1,2) that have been separated into two categories (Fig. 3): 1) units that occur outside Lakshmi Planum and 2) units characterizing the mountain ranges and interior of Lakshmi. One more unit, crater materials, is present throughout the quadrangle.

Units outside Lakshmi: There are 8 material and 1 structural units in this area. From older to younger they are as follows: Tessera material ( $\mathrm{t}$ ), Densely lineated plains (pdl), Ridged plains (pr), Groove belts (structural unit, gb), Shield plains (psh), Regional plains (two units, rp1 and rp2), Smooth plains (ps), Lobate plains (pl).

Mountain ranges and interior of Lakshmi: Six material units and one structural unit characterize this area (from older to younger): Lakshmi tessera material ( $\mathrm{tL})$, Mountain belts (mt), Lakshmi groove belts (structural unit, gbL), wrinkle ridged plains (two units, $\mathrm{pwr}_{1} \mathrm{~L}$ and $\mathrm{pwr}_{2} \mathrm{~L}$ ), Lakshmi smooth plains (psL), and Lakshmi lobate plains (plL).

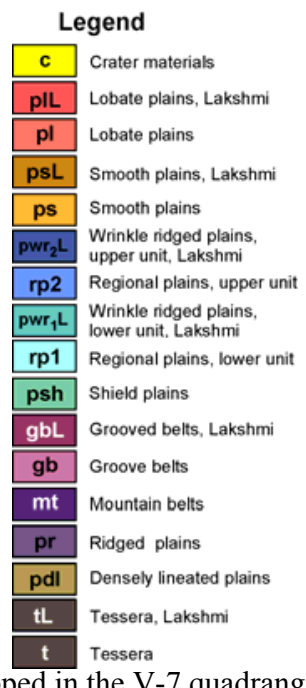

Figure 1. Units mapped in the V-7 quadrangle.

Sequence of events: Our first-order observations and preliminary mapping within the V-7 quadrangle are summarized as the following general sequence of events during the formation and evolution of Lakshmi Planum: 1) The oldest features within the area of our mapping appear to be the heavily tectonized materials, such as tessera, that are embayed by regional plains outside Lakshmi and by wrinkle ridged intra-Lakshmi plains. 2) The mountain belts and the features of the transition zone of complexly deformed terrains around Lakshmi may be somewhat younger, but very detailed mapping is necessary to establish an order of events between these features. 3) The mountains and the transition zone are embayed by vast regional plains both from inside (within Lakshmi Planum) and outside (in Sedna Planitia). Neither in Lakshmi Planum nor outside is there direct evidence for the sources of these plains. 4) The latest activity within the map area was volcanism at several distinct centers that produced the lava flows of Neago Fluctūs and Djata Fluctus to the southeast and west of Lakshmi and around Colette and Sacajawea Paterae within Lakshmi Planum.

References: [1] Barsukov V. L. et al. (1986) JGR, 91, D399. [2] Kaula W. M. et al. (1992) JGR, 97, 16,085. [3] Kaula W. M. et al. (1997) in: Venus II, S. W. Bougher et al. eds., 789. [4] Banerdt W. B. et al. (1997) in: Venus II, S. W. 
Bougher et al. eds., 901. [5] Tanaka K. L. (1994) USGS Open File Report 94-438, 50 p. [6] Basilevsky A. T. and Head J. W. (1995a) EPM, 66, 285. [7] Basilevsky A. T. and Head J. W. (1995b) PSS, 43, 1523. [8] Basilevsky A. T. et al. (1997) in: Venus II, S. W. Bougher et al. eds., 1047. [9] Ivanov M. A. and Head J. W. (1998) LPSC 29, 1419. [10] Ivanov M. A. and Head J. W. (2001a) Geologic Map of the Lavinia Planitia (V55) Quadrangle, U.S. Geological Survey Miscellaneous Investigations Series Map I-2684, scale 1:5,000,000. [11] Ivanov M. A. and Head J. W. (2001b) JGR, 106, 17,515.

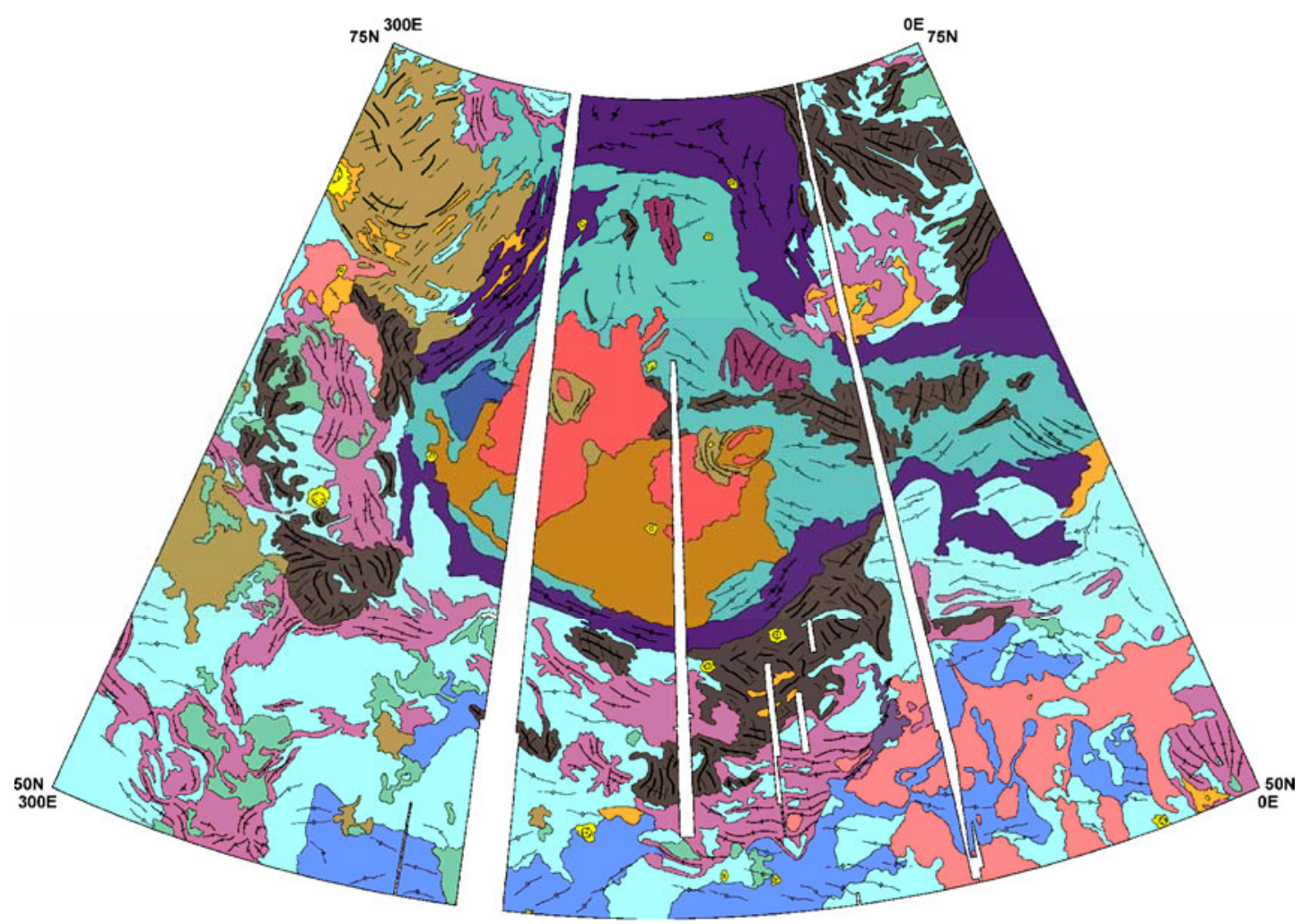

Figure 2. Preliminary geological map of the V-7 quadrangle.

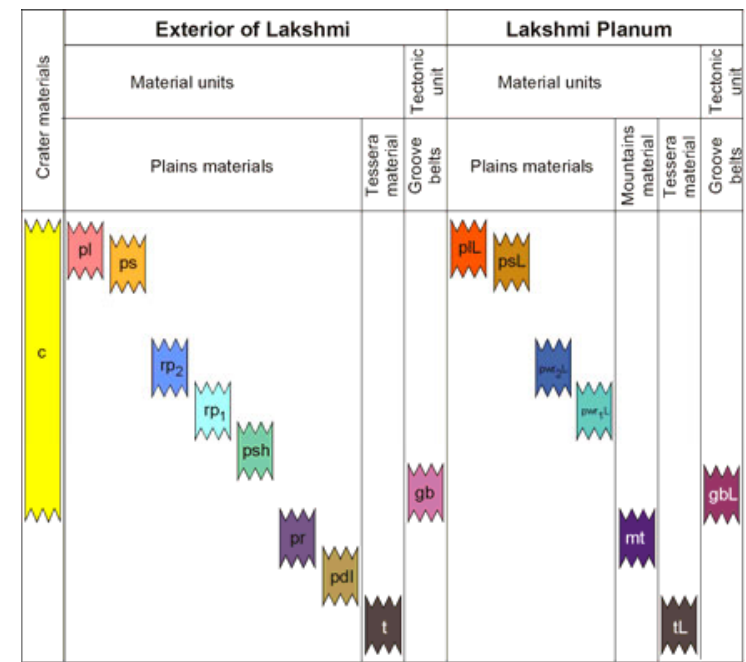

Figure 3. Correlation chart of units mapped in the V-7 quadrangle. 
GEOLOGICAL MAPPING OF THE FREDEGONDE QUADRANGLE (V-57), VENUS: PRELIMINARY RESULTS. M. A. Ivanov ${ }^{1,2}$ and J. W. Head ${ }^{2}{ }^{1}$ Vernadsky Institute, RAS, Moscow, Russia, mishaivn@mtu-net.ru, ${ }^{2}$ Dept. of Geological Sciences, Brown University, Providence, RI, USA, james_head_iii@brown.edu.

Introduction: The Fredegonde quadrangle (V-57, 50-75S, $60-120 \mathrm{E})$ covers the transition from Lada Terra in the west to relatively small (several hundreds of $\mathrm{km}$ across) lowland basins in the east. The edge of Lada Terra is characterized by several large coronae interconnected by swarms of grooves that form large corona-groove chains extending for several thousands of kilometers. The chains resemble in many aspects the corona-rift zones at the margins of large equidimensional basins such as Lavinia (V55) and Atalanta (V4) Planitiae [1,2] and typically are accompanied by extensive young lava flows and prominent belts of linear deformation. The mapping in this quadrangle offers the opportunity to characterize the transitional zones between midlands and lowlands and establish the sequence of events within the corona-groove zones and to assess the relative timing among them and other features, such as volcanic plains, ridge belts, and edifices.

Material units and structures mapped in the V-57 quadrangle: We defined units and mapped key relations among them using the full resolution Magellan SAR data. The background for our unit definition and characterization is described in [3-9]. Within the V-57 quadrangle we defined and mapped 6 material and 1 structural units of endogenous origin (Fig. 1,2). Two more units represent materials of the floors, walls, and continuous ejecta (c) and outflows (cf) of impact craters. There are 8 material and 1 structural units in the area of the Fredegonde quadrangle. From older to younger they are as follows: Tessera material (t), Densely lineated plains (pdl), Ridged plains (pr), Groove belts (structural unit, $\mathrm{gb}$ ), Shield plains (psh), Regional plains (two units, $\mathrm{rp}_{1}$ and $\left.\mathrm{rp}_{2}\right)$, Smooth plains (ps), Lobate plains (pl).

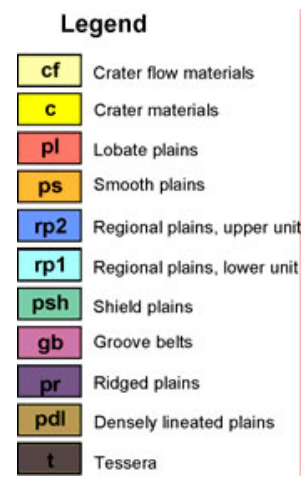

Figure 1. Units mapped in the V-57 quadrangle

Major features of the V-57 quadrangle: The area of the quadrangle covers the transition from the upland of Lada Terra to the west to the extensive elongated lowland of Aino Planitia to northeast. The eastern portion of Lada Terra within the map area almost lacks occurrences of tessera and the oldest units exposed there are densely lineated plains and ridge belts. Small fragments of these units heavily embayed by regional plains occur in the central, central-northern, and centralsouthern portions of the quadrangle. Elongated occurrences of ridge belts correspond to distinct topographic ridges that are oriented in NW and N directions. The most important features in the quadrangle are several large coronae interconnected by swarms of grooves. The coronae and groove belts make up large corona-groove chains that form prominent ridge-andtrough topographic complexes and extend for several thousands of kilometers in a NE direction toward the lowland of Aino Planitia. The general strike of the corona-groove chains is almost orthogonal to the preferential orientation of the ridge belts. In many aspects the corona-groove chains within the map area are similar to zones at the margins of large equidimensional basins such as Lavinia (V55) and Atalanta (V4) Planitiae. Near the basins of Lavinia and Atalanta Planitiae, the corona/groove zones tend to be roughly parallel to the edges of the basins. In the case of the eastern portion of Lada Terra, however, the deformational belts are oriented perpendicular to the general elongation of Aino Planitia. Individual structures of the groove swarms (groove belts) are embayed by regional plains and thus are older. Regional plains deformed by wrinkle ridges occur in the middle part of the regional stratigraphic column, form the most extensive material unit within the map area, and cover the majority of the surface of the quadrangle including both the surface of the upland of Lada Terra and the lowland of Aino Planitia. Large fields of shield plains, fragments of which are mostly embayed by regional plains, occur in places within the quadrangle. The coronae from the corona-groove zones appear to be distinct sources of relatively young volcanism. Vast lava flows that form the upper unit of regional plains $\left(\mathrm{rp}_{2}\right)$ and lobate plains occur in close spatial association with Dunne-Musun and Ambar-ona Coronae that occupy a broad topographic high in the center of the quadrangle. Another locus of young volcanism is associated with Xaratanga Chasma and several large coronae in the NW corner of the quadrangle.

Sequence of events: Our first-order observations and preliminary mapping within the $\mathrm{V}-57$ quadrangle are summarized as the following general sequence of events during the formation and evolution of the transition from Lada Terra to the lowlands of Aino Planitia. 1) The oldest materials form a massif of tessera at the northern edge of the quadrangle. Apparently in the post-tessera time, plains materials were emplaced in the central, central-northern, and SE portions of the map area. Densely spaced fractures or broad ridges later deformed these materials. 2) The most extensive deformational zones of groove belts postdate emplacement and deformation of tessera, densely lineated plains, and ridge belts. Many coronae in the quadrangle appear to begin their evolution during this period. 3) Vast plains units such as shield plains and regional plains embay structures of groove belts and, thus, are younger. Pervasive networks of wrinkle ridges deform these plains units. 4) At the end of the apparent geologic history of the quadrangle, extensive lava flows that are almost undeformed tectonically, and embay wrinkle ridges, were emplaced from several distinct sources such as some coronae. Thus, the corona/groove belt zones appear to be long-lived complexes the evolution of which began before emplacement of regional plains and continued to the time of deformation of regional plains by wrinkle ridges.

References. [1] Ivanov M. A. and Head J. W. (2001) USGS Geol. Inv. Ser., Map I- 2684. [2] Ivanov M. A. and Head J. W. (2003) USGS Geol. Inv. Ser., Map I-2792. [3] Tanaka K. L. (1994) USGS Open File Report 94-438, 50 p. [4] Basilevsky A. T. and Head J. W. (1995a) EPM, 66, 285. [5] Basilevsky A. T. and Head J. W. (1995b) PSS, 43, 1523. [6] Basilevsky A. T. et al. (1997) in: Venus II, S. W. Bougher et al. eds., 1047. [7] Ivanov M. A. and Head J. W. (1998) LPSC 29, 1419. [8] Ivanov M. A. and Head J. W. (2001a) Geologic Map of the Lavinia Planitia (V55) Quadrangle, U.S. Geological Survey Misc. Invest. Series Map I-2684, scale 1:5,000,000. [9] Ivanov M. A. and Head J. W. (2001b) JGR, 106, 17515. 


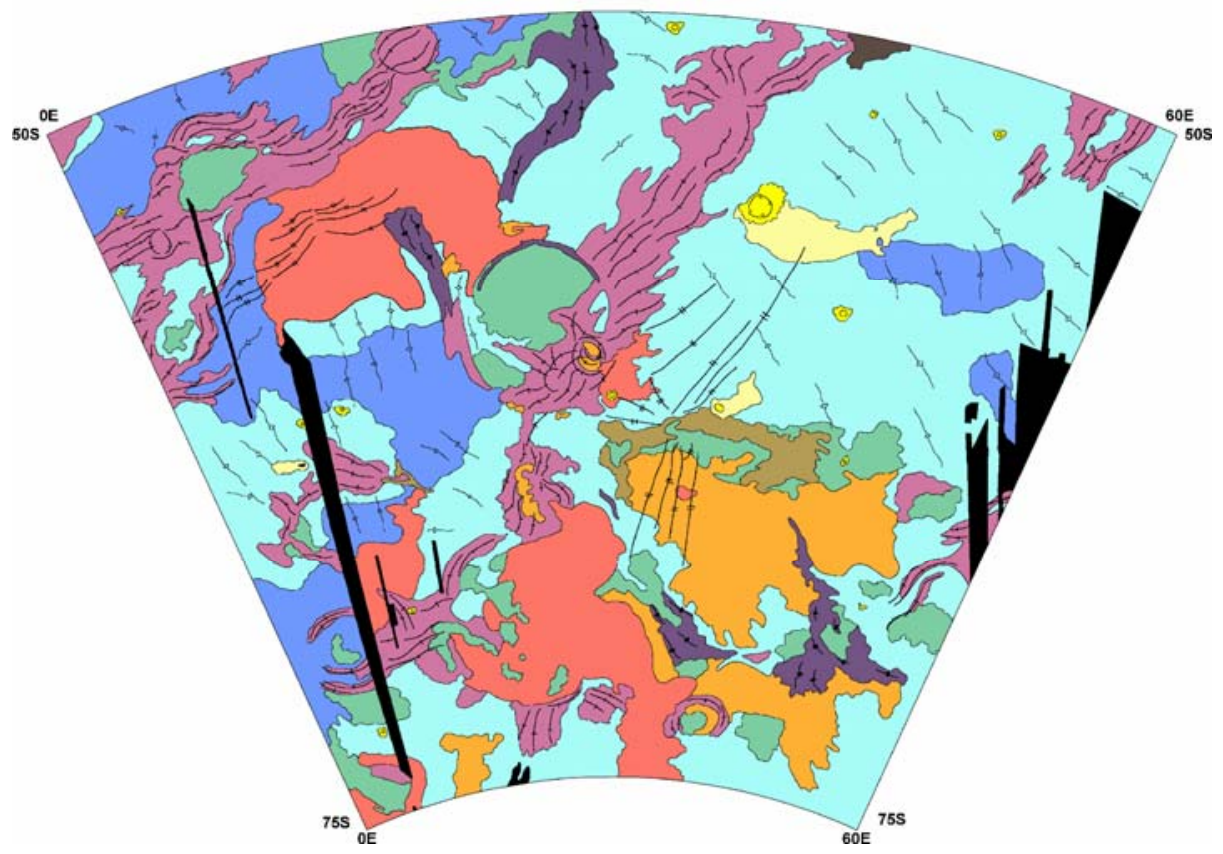

Figure 2. Preliminary geological map of the V-57 quadrangle

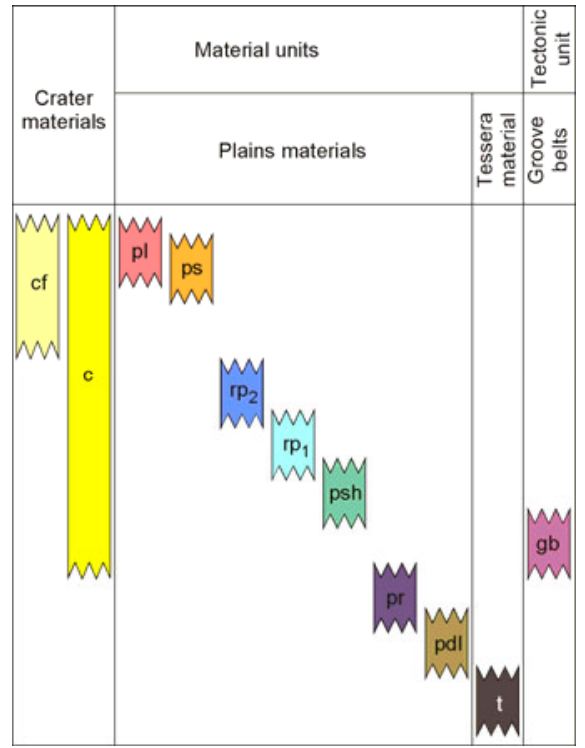

Figure 3. Correlation chart of units mapped in the V-57 quadrangle 
GEOLOGIC MAP OF THE GREENAWAY QUADRANGLE (V-24), VENUS: A PROGRESS REPORT. N.P. Lang ${ }^{1}$ and V.L. Hansen ${ }^{1},{ }^{1}$ University of Minnesota, Duluth, Duluth, MN 55806; lang0604@tc.umn.edu.

Introduction: The Greenaway quadrangle occupies an $\sim 8,400,000 \mathrm{~km}^{2}$ equatorial swath of lowlands and highlands (fig. 1). The map area is bounded by crustal plateau Thetis Regio to the south, Rusalka Planitia to the east, and Gegute Tessera to the west. The northern three-fourths of the quadrangle comprises parts of Niobe and Llorona Planitiae, which are part of the vast lowlands that cover $\sim 80$ percent of Venus' surface [1]. Southern V-24 marks the northern edge of Aphrodite Terra (including Thetis Regio), boasting the highest topography in the quadrangle with elevations reaching $>1 \mathrm{~km}$ above the Mean Planetary Radius (MPR: 6051.84 km). Northern Aphrodite Terra abruptly slopes north to Niobe and Llorona Planitiae. A broad northeast-trending topographic arch pocked with coronae divides Niobe and Llorona Planitiae within V-24 into two northeast-trending elongate basins that served as depot centers for shield and coronae-sourced materials; both basins drop to elevations of $>1 \mathrm{~km}$ below MPR. In addition to these major features, V-24 hosts thousands of small volcanic constructs (shields), seven coronae, tessera terrain, suites of faults, fractures, and wrinkle ridges, 21 impact craters, and one craterless splotch.

The goal of geologic mapping of the Greenaway quadrangle was to determine the geologic history for this region, which in turn provides insights into volcanic and tectonic processes that shaped the Venusian lowlands. Map relations illustrate that aerially expansive shield terrain (unit st) [see 2,3] played a primary role and coronae played a secondary role in volcanic resurfacing across $\mathrm{V}-24$.

Data: Mapping was conducted using cycles 1, 2, and 3 of NASA Magellan synthetic aperture radar (SAR) imagery and Magellan altimetry datasets. We compiled the map on a digital C-1MIDR (Compressed Once Mosaiced Image Data Record) 225-m/pixel SAR base; however we mapped using full-resolution hard copy images and full-resolution digital $(75 \mathrm{~m} /$ pixel) normal and inverted (negative) SAR image bases. Synthetic stereo imagery, created by merging altimetry data with cycle 1 SAR [4] using NIH-Image macros developed by D.A. Young, proved useful in resolving the interactions of flows, primary and secondary structures, and topography. Adobe Illustrator ${ }^{\mathrm{TM}} 9$ and 10, in association with Avenza MAPublisher ${ }^{\mathrm{TM}} 4$, comprised the primary mapping and GIS tools; we enhanced radar images using Adobe Photoshop ${ }^{\mathrm{TM}} 5$. We obtained digital full-resolution SAR image bases from the USGS MAP-A-PLANET website (http://pdsmaps.wr.usgs.gov).
Geologic overview: Geologic units in the Greenaway quadrangle include three terrains, 17 material units, and a stratigraphically incoherent background unit. Terrains characterize most of the map area and include a regionally expansive shielddominated unit (unit st), tessera terrain (unit ttu), and a potentially regionally extensive basal unit (unit btu) pervasively cut by northwest-trending lineaments. Interspersed with the terrains are material units associated with individual coronae and impact craters. Coronae-related materials include coronae-sourced flow material and shield fields. Impact crater materials are mapped as undivided ejecta (unit $\mathrm{cu}$ ), fluidized outflow (unit co), and crater fill (unit cf). The stratigraphically incoherent background unit (unit fu) covers much of the northeast part of the map area, consists of presumably volcanic material with no obvious source(s), and is veiled by impact crater-related halos.

The map area also hosts an array of secondary structures. Secondary structures occur at a variety of scales and include fractures, folds, ridges, and lineaments. Multiple suites of structures locally occur together to structurally define larger scale features such as coronae, and they occur in suites defining features such as fracture zones. Wrinkle ridges trend mostly east-northeast across the northern one-third of the quadrangle cutting all map units in the region. Local wrinkle ridge variations are apparently associated with local features. Southeastern V-24 lacks regional wrinkle ridge suites, although local ridges define an easterly trend.

The geology and topography of V-24 are grossly linked. Crustal plateau (high-standing, flat-topped, quasi-circular regions interpreted as supported by thickened crust [5-7]) tessera terrain comprises the highlands along the western and southern boundaries of the map area. Local topographic highs up to $\sim 100$ s of meters in elevation are spread across the quadrangle and mark kipukas of tessera terrain and unit btu. Shield terrain dominates most of the lowland where it embays units ttu and btu. A northeast trending topographic arch marked by four coronae divides the lowland into two topographic basins. The western basin, which comprises part of Niobe Planitia, hosts local outcroppings of unit btu as well as three separate units of corona-sourced flow material (units fcA, fcB, and $\mathrm{fcR}$ ) that broadly parallel the basin trend. The eastern basin, which comprises part of Llorona Planitia, hosts extensive outcroppings of unit btu. Corona-sourced flow material is present along the northeastern margin of the eastern basin. Coronae along the topographic 
arch source flow material that has embayed kipukas of unit ttu located along the arch flanks.

Geologic history: Geologic unit correlation is the process of interpreting mutual time relations of local stratigraphic sections, and it attempts to synthesize local stratigraphic sections into a composite time scheme applicable to a wider region [8]. The surest means to correlate units involves one or more criteria: fossil content, isotopic data, stratigraphic position in relation to a widespread geologically instantaneous marker bed $[9,10]$, and significant and robust impact crater statistics $[11,12]$. The inability to robustly ascertain any of these criteria on Venus makes geologic unit correlation highly suspect. Therefore, following [13], we develop a Sequence of Map Units (SOMU) chart for the Greenaway quadrangle where embayment and crosscutting relations constrain relative timing, and allow for an interpretation of a geologic history.

The geologic history of V-24 supports the interpretation that, as is the case with most of Venus, volcanism and tectonism are the two dominant processes that have shaped the map area. Tessera terrain (unit ttu) and basal terrain (unit btu) are the two oldest recorded units in the Greenaway quadrangle. The emplacement history and timing of deformation of these two basal units is unconstrained. The temporal relation between the two units is also unconstrained, but it is possible that units ttu and btu are genetically related, which would infer that these two units are closely related in time. Thus, all other map units in V-24 were most likely emplaced on the basal units ttu and btu. Warping of the Gegute Tessera inlier postdated unit ttu formation, but timing cannot be further constrained; there is no evidence that any other map units were concurrently warped. Following, and possibly even concurrent with, formation of units ttu and btu was the formation of unit st. Map relations suggest that unit st formation is a long occurring process that may expand almost the entire history of the map area temporally overlapping with emplacement with all other map units. Scattered outcrops of units ttu and btu along the topographic arch indicate that arch formation likely postdates units ttu and btu with the uplift of the arch responsible for local preservation of the two basal units. Formation of the topographic arch and archrelated coronae (including the anastomosing fracture zone linking the coronae) formed synchronously. To suggest differently would require explanation for the parallelism of the arch and coronae along the arch crest. Initiation of arch coronae volcanism is unconstrained, however. Some coronae flow material extends down the arch flanks indicating that coronaerelated volcanism occurred, at least locally, after arch formation. Initiation of the emplacement of units fcA, fcBo, and fcR is also unconstrained. However, their broad parallelism with the Niobe basin trend implies that these three coronae-flow units postdate formation of the topographic arch. Further, because units fcR and fcBl embay unit ttu, Rosmerta and Blai coronae most likely locally postdate formation of unit ttu. The timing of units fcI and fCm are unconstrained, but unit fcI must at least locally postdate unit btu. Wrinkle ridges cut most units in the lowlands, consistent with the interpretation that wrinkle ridges are some of the youngest features in the map area. However, initiation of wrinkle ridge formation is difficult to constrain. The initial age of imposition of a wrinkle ridge fabric may predate its current geomorphic expression implying that there is ideally no stratigraphic constraint on wrinkle ridge timing; material units can only be said to predate the very last phase of wrinkle ridge formation.

References: [1] Masursky, H. and others (1980) JGR, 85, 8232-8260. [2] Aubele, J. (1996) LPSC XXVII. [3] Hansen, V. (2005) GSAB, 117, 808-812. [4] Kirk, R. and others (1992) JGR, 92, 16,37116,380. [5] Bindschadler, D. and others (1992) JGR, 97, 13,495-13,532. [6] Phillips and Hansen (1994) AREPS, 22, 597-654. [7] Hansen, V. and others (1997) Venus II, 794-844. [8] Dunbar and Rogers (1957) Principles of Stratigraphy, Wiley and Sons, 356 p. [9] Compton, R. (1985) Geology in the field, Wiley and Sons, 398 p. [10] Prothero, D. (1990) Interpreting the stratigraphic record, W.H. Freeman and Company, 410 p. [11] Hauk, S. and others (1998) JGR, 103, 13,635-13,642. [12] Campell, B. (1999) JGR, 104, 1897-1916. [13] Hansen, W. (ed) (1991) Suggestions to authors of the reports of the United States Geological Survey, $7^{\text {th }}$ ed.: U.S. Gov. Printing Office, 289 p.

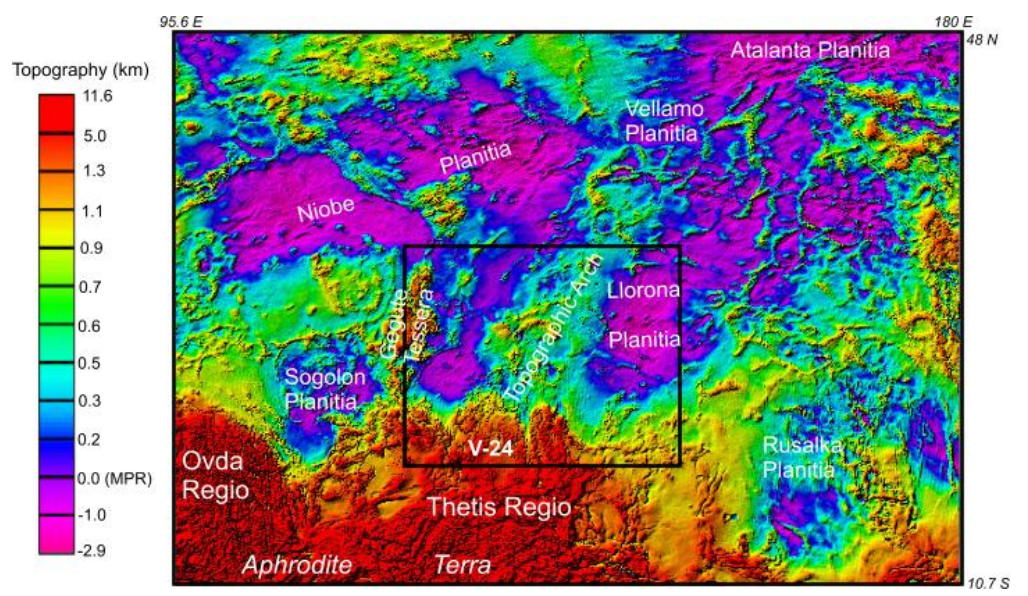

Figure 1: Topographic context for V-24 (black box), in Mercator projection. The northern edge of Thetis Regio comprises the southern edge of the map area and the topographic arch divides the northern three-fourths of V-24 into two northeast-trending topographic basins.

MPR=Mean Planetary Radius (6051.84 km). Topographic base taken from the Planetary Interactive GIS on-the-Web Analyzable Database (PIGWAD) (http//webgis.wr.usgs.gow/pigwad.htm). 
MAPPING OF V28 AND V53. E. R. Stofan ${ }^{1,2}$, J. E. Guest ${ }^{2}$ and A. W. Brian ${ }^{2}{ }^{1}$ Proxemy Research, 20528 Farcroft Lane, Laytonsville, MD 20882, ellen@proxemy.com, ${ }^{2}$ Department of Geological Sciences, University College London, UK.

Introduction: Geologic maps of Hecate Chasma (V28) and Themis Regio (V53) quadrangles have been completed at the1:5,000,000 scale as part of the NASA Planetary Geologic Mapping Program. Each quadrangle covers a portion of a chasma system, and has extensive rifting, numerous coronae, and abundant volcanism [1]. We mapped these regions to better define the relationship between corona formation and rifting, to study the relationship between rifting and volcanism, including coronae, and to determine the stratigraphic relationship of plains-forming units.

Quadrangle Overviews, V28: The Hecate Chasma Quadrangle (V28) extends from $0^{\circ}$ $25^{\circ} \mathrm{N}$. latitude, $240^{\circ}-270^{\circ} \mathrm{E}$. longitude. The overall topography of V28 consists of lowlying plains located slightly below Mean Planetary Radius (MPR, 6051.84, [3]). Hecate Chasma is a rift system over $2000 \mathrm{~km}$ long [2], which extends across a lowland region (Hinemoa Planitia). Hecate Chasma is actually made up of several, branching rift systems. The region covered by V28 contains low-lying plains units, coronae, moderate and large volcanoes, shields, domes and cones. The intermediate to large volcanoes include Nazit, Wyrd and Polik-mana Montes and Paoro, Nipa and Pajan Yan Tholi. There are fourteen coronae in the quadrangle, the largest of which is the $525 \mathrm{~km}$ diameter Taranga Corona. There are eight impact craters in the V28 quadrangle.

We have mapped ten plains materials units in V28, nine associated with Hinemoa Planitia and one associated with Asteria Regio. Most of the plains units are not in contact and not very extensive, producing a very horizontal stratigraphic column. Of the fourteen coronae in the quadrangle, ten have associated mappable deposits, with several having multiple units. The other four coronae either deform plains units or are embayed by plains, volcano or other corona units.

Fifteen units associated with named volcanic edifices have been mapped, along with flow materials emanating from unnamed or unknown sources. Eleven units associated with coronae have been mapped, with several coronae having no associated materials units. In addition, two small outcrops of tessera and impact crater materials have been mapped.

The overall stratigraphy of V28 indicates a geologic history of the region characterized by interleaved episodes of plains-forming volcanism, corona formation, and formation of intermediate to large volcanic edifices. The rift system is relatively young, but appears to have formed in stages. The map is complete and the text will be completed by August.

V53: The Themis Regio Quadrangle (V53) extends from $25^{\circ} \mathrm{S}-50^{\circ} \mathrm{S}$. latitude, $270^{\circ}$ $300^{\circ}$ E. longitude, and includes the Themis Regio highland, surrounding plains, and the southernmost portion of Parga Chasmata. V53 consists of low-lying plains lying slightly below Mean Planetary Radius (MPR, 6051.84, [3]). The topographically lowest points in the quadrangle (about $2 \mathrm{~km}$ below MPR) are within the Parga Chasmata rift and in the troughs around several coronae.

Six plains units have been mapped in V53. The plains farthest from the rift appear to be a regional-scale plains unit, unlike the more patchy units mapped in V28. Nine units associated with specific named volcanic edifices have been mapped; most of these units are not in contact with each other, or with consistent plains or corona units, making an overall stratigraphy difficult to determine. Multiple materials units associated with un- 
named or unknown sources have also been mapped and combined into a single unit, although they may have similar morphology but formed at different times. Twenty corona materials units are mapped. There are 12 impact craters within the quadrangle.

Some age relationships can be determined between some of the coronae and volcanic edifices, with no clear pattern observed. Some coronae predate rifting, some postdate it, while most are interpreted to have formed largely synchronously with rifting. The map for V53 is complete, and the text is being finalized.

Conclusions: In V28 and V53, more plains materials units have been mapped than in our previously mapped quadrangles, V46 and V39. The scale of plains units are on the order of 100's of kms rather than 1000's of kms. In V28, all of the plains materials units to the south of the rift have an unusually high concentration of volcanic edifices.

In both sections of the two chasmata we mapped, coronae are located along the rift, as well as to the north and the south of the rifts. Coronae in both quadrangles exhibit all forms of corona topographic shapes [4], including depressions, rimmed depressions, plateaus and domes. Most of the coronae formed synchronously with the rifting, although some clearly predate the rifts and others postdate extensional deformation.

A strong association between volcanism and coronae along rifts has been noted elsewhere on the planet [5]. In V28 and V53, some coronae along the rift do not have much associated volcanism; coronae with the most associated volcanism in these quadrangles are located at least $500 \mathrm{~km}$ off the rifts or on the Themis Regio highland. While extension clearly plays a role in the amount of volcanism associated with coronae [5], it is not the only contributing factor. Coronae at Themis Regio may have greater than average associated volcanism owing to the possible mantle plume beneath the rise.
The large number of plains units, coronae and volcanoes in these two quadrangles results in a very horizontal stratigraphic column, as few units are in direct contact. The scale of resurfacing in these quadrangles is on the scale of 100's of kilometers, consistent with the fact that they lie in the most volcanic region of Venus.

References: [1] Crumpler, L. S. et al. (1997) In Venus II, eds. Brougher, S. W., Hunten, D. M. \& Phillips, R. J., University of Arizona Press, Tucson, 697756. [2] Hamilton, V. E. and E. R. Stofan (1996) Icarus, 121, 171-194. [3] Ford, P. G., and Pettengill, G. H. (1992) Journal of Geophysical Research, v. 97, no. E8, p. 13,103-13,114. [4] Smrekar, S. E. and E. R. Stofan (1997) Science, 277, 1289-1294. [5] Magee, K. P. and J. W. Head (1995) J. Geophys. Res. 100, 1527-1552. [6] Stofan, E. R., S. E. Smrekar, D. L. Bindschadler, and D. A. Senske (1995) J. Geophys. Res. 100: 23, 317-23,327. [7] Hansen, V. L. and R. J. Phillips (1993) Science 260, 526-530. 
MAPPING GANYMEDE AT 1:15M: A PROGRESS REPORT. G. Wesley Patterson ${ }^{1}$, James W. Head ${ }^{1}$, Geoffrey C. Collins ${ }^{2}$, Robert T. Pappalardo ${ }^{3}$, Louise M. Prockter ${ }^{4}$, and Baerbel K. Lucchitta ${ }^{5},{ }^{1}$ Department of Geological Sciences, Brown University, Providence, RI, 02912 (Gerald_Patterson@brown.edu), ${ }^{2}$ Wheaton College, Norton, MA, 02766, ${ }^{3}$ LASP, University of Colorado, Boulder, CO, 80309, ${ }^{4}$ Applied Physics Laboratory, Laurel, MD, 20723, ${ }^{5}$ USGS, Flagstaff, AZ, 86001.

Introduction: The Galilean satellites represent a series of bodies that all formed from the same protoJovian nebula but are distinctly different in their physical properties, surface geology, and thermal evolution [1-4]. The explanation for many of these disparate characteristics is likely related to the radially varying conditions of the nebula during the earliest period of their formation [5-6]. However, an explanation for the differences in the geological evolution of Ganymede and Callisto, given their similar size, density, and bulk composition, remain one of the most fundamental questions in comparative planetology [6, 7]. Understanding the global distribution of geologic units on Ganymede in space and time can offer constraints on our ideas of how and why this icy satellite evolved to its present state.

The Voyager mission provided important information about the nature of the surface of Ganymede at moderate resolution and these data were used to produce a series of geologic maps covering the imaged surface at the 1:5M scale [e.g., 8-10]. The Galileo mission has provided a host of new data (highresolution monochromatic, color, and stereo imagery, polarimetry, near-infrared spectral imagery, etc.) and we are compiling a global geologic map of Ganymede (at the $1: 15 \mathrm{M}$ scale) that will represent the most recent understanding of the satellite on the basis of this data. This contribution builds on important previous accomplishments in the study of Ganymede [11-15] and seeks to further clarify: 1) the major geological processes operating on Ganymede, 2) the characteristics of the geological units comprising its surface, 3) the stratigraphic relationships of geological units and structures, 4) the geological history inferred from these relationships, 5) the crater size-frequency distributions on key geological units and structures, and 6) the cratering chronology of Ganymede, which can be used to compare to other Solar System bodies. Here we summarize our progress toward the completion of this global mapping project.

Unit definitions: The first task we undertook in developing a global geologic map of Ganymede was to reassess the units identified at Voyager resolution using Galileo resolution data [16, 17]. The result of this reassessment was a revised Description of Map Units (DOMU) in which the units have been divided into five terrain types: 1) light, 2) dark, 3) reticulate, 4) palimpsest, and 5) crater material.
Light material: This material has been subdivided into four units: grooved, subdued, irregular, and undivided. The grooved unit (lg) is arranged in domains characterized by parallel, roughly evenly spaced grooves and ridges oriented in a single dominant direction. The subdued unit (ls) is similar to the grooved unit but appears smooth or finely grooved at Galileo and/or Voyager resolution except where secondary craters and crater chains are superposed. The irregular unit (li) is similar to the subdued unit but contains isolated grooves with no preferred orientation. The undivided unit (l) represents all materials of sufficiently low resolution for which morphological properties and/or age relationships cannot be determined.

Dark material: This material has been subdivided into three units: cratered, lineated, and undivided. The cratered unit (dc) represents large areas of low albedo material with moderate to high crater density commonly occurring as polygons bounded by bright units. The lineated unit (d) is similar in character to the bright grooved unit but with lower albedo and depressions tending to be more sinuous and shallower. The undivided unit (d) represents all materials of sufficiently low resolution that their material properties cannot be determined. This also may include irregularly shaped large patches and small slivers of low albedo material interspersed within light terrain of indistinct morphology or areas too small to be identified by morphologic criteria other than albedo.

Reticulate material (r): This terrain consists of a single unit. It is often associated with and surrounded by bright grooved, bright subdued, and/or dark lineated units but can be distinguished from them by its variable albedo and presence of grooves with two dominant directions (typically orthogonal to each other).

Palimpsest material: This material consists of two units: palimpsests and palimpsest interior plains. The palimpsest unit (p) is characterized by flat, generally circular to elliptical structures occurring predominately (but not exclusively) on dark terrain units. These structures lack rims but can have internal, concentric ridges. The palimpsest interior plains unit (pi) is characterized by smooth, circular to subcircular patches of high albedo material commonly found at or near the center of palimpsests.

Crater material: This terrain consists of seven units: bright craters, partly degraded craters, degraded 
craters, secondary craters, dark crater material, basin rugged material, and basin smooth material. The first three units separate craters into a stratigraphic sequence ( $\mathbf{c}_{\mathbf{1}}, \mathbf{c}_{2}$, and $\mathbf{c}_{3}$ from oldest to youngest respectively) based on degradation state, which we feel can be more clearly determined than for palimpsests. The secondary crater unit (cs) is characterized by fields of uniform, small pits surrounding large bright craters, partly degraded craters, and some palimpsests. Dark crater material (cd) appears to be predominately associated with bright craters and forms dark patches on their floors or rims. The basin rugged material (br) and basin smooth material (bs) units are used to define the prominent Gilgamesh basin.

Mapping strategy: Using the revised DOMU described herein, we are in the process of compiling the global geologic map. To accomplish this task we are broadly mapping the boundaries of terrain types (e.g., dark material, craters, etc.) and superimposed structures (i.e. furrows) across the surface of Ganymede. We are also doing detailed mapping of geologic units (e.g., light grooved, dark cratered, palimpsest interior plains, etc.) in $60^{\circ} \times 60^{\circ}$ quadrangles. The assigned unit boundaries are reviewed and modified as necessary within each quadrangle before proceeding to the next. The minimum dimension we have established for mapping a feature as a unit is $30 \mathrm{~km}$ (2 mm on the map). After completing the detailed mapping of geologic units on the surface, we will review the results with all participating researchers to discuss and reconcile any discrepancies or issues before finalizing the map. This map is being produced entirely in GIS format for analysis and combination with other datasets.

Progress: To date, we have mapped the boundaries for dark materials and craters and have also completed a map of furrows for the entire surface of Ganymede. Furthermore, we have completed the detailed mapping of six quadrangles spanning from $30^{\circ} \mathrm{S}$ to $30^{\circ} \mathrm{N}$ and $180^{\circ} \mathrm{W}$ to $180^{\circ} \mathrm{E}$. The units mapped cover all terrain types described except basin materials and span a wide range of resolutions and lighting conditions. In addition, we have tentatively added another unit definition to the dark materials terrain. The dark irregular unit (di) is characterized by isolated grooves with no preferred orientation similar to the light irregular unit but having an albedo characteristic of dark materials (Fig. 1).

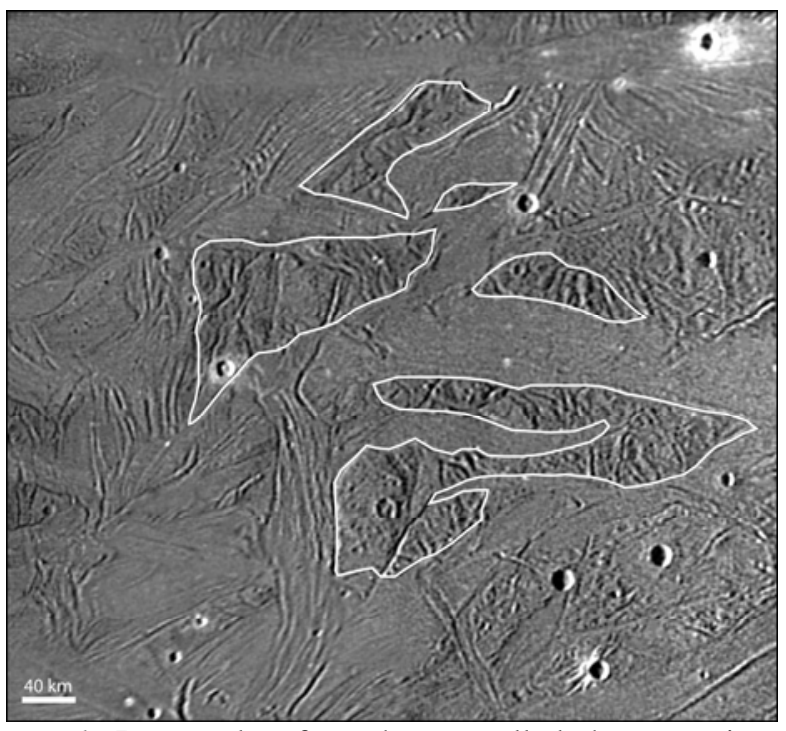

Fig. 1. Image taken from the controlled photomosaic of Ganymede (I-2034). Features defined as dark irregular unit are outlined in white and located in a region centered on $5^{\circ} \mathrm{N}$ and $135^{\circ} \mathrm{E}$.

References: [1] R. Greeley (1999) The New Solar System, 253-262. [2] R. T. Pappalardo (1999) The New Solar System, 263-276. [3] W. B. McKinnon and E. M. Parmentier (1986) Satellites, 718-763. [4] G. Schubert et al. (1986) Satellites, 224-292. [5] D. J. Stevenson et al. (1986) Satellites, 39-88 [6] T.V. Johnson (2004) Physics Today, 57, 77-83. [7] D. J. Stevenson (2004) Physics Today, 57, 43-48. [8] J. E. Guest et al. (1988) USGS Map I-1934. [9] D. E. Wilhelms (1997) USGS Map I-2242. [10] B. K. Lucchitta et al. (1992) USGS Map I-2289. [11] B. K. Lucchitta (1980) Icarus, 44, 481-501. [12] E. M. Shoemaker et al. (1982) Sats. of Jupiter, 435. [13] S. Murchie et al. (1986) JGR, 91, E222-E238. [14] R. T. Pappalardo et al. (1998) Icarus, 135, 276-302. [15] L. M. Prockter et al. (1998) Icarus, 135, 317. [16] G. C. Collins et al. (2003) PGG Planetary Mappers Meeting. [17] G. W. Patterson et al. (2003) PGG Planetary Mappers Meeting. 
PROGRESS IN GEOLOGIC MAPPING OF EUROPA. K. L. Tanaka ${ }^{1}$, P. H. Figueredo ${ }^{2}$, R. Greeley ${ }^{3}$, T. M. Hare $^{1}$, K. F. Mullins ${ }^{1}$, D. A. Senske ${ }^{4}$, and E. J. Kolb ${ }^{3},{ }^{1}$ U. S. Geological Survey, Flagstaff, AZ, ktanaka @usgs.gov, ${ }^{2}$ Exxon, Houston, TX, ${ }^{3}$ Arizona State University, Tempe, AZ, ${ }^{4}$ Jet Propulsion Laboratory, Pasadena, CA.

Introduction: Our objective is to complete the first global geological map of Europa, and to interpret the surface history of the satellite. This project includes geologic mapping of an updated, post-Galileo global photomosaic of Europa (which combines Galileo and Voyager data), and the search for possible correlations of the surface geology with maps of surface temperatures and ice contaminants as published by $[1,2]$ respectively, that were determined from the Galileo Photopolarimeter-Radiometer (PPR) and Near Infrared Mapping Spectrometer (NIMS) instruments.

Through the geologic map, we intend to synthesize the current knowledge of the surface evolution of Europa. In addition, the map will constitute a geological framework for the ongoing analysis of Galileo data and for planning future missions to Europa. Such missions are unlikely to be launched for more than a decade, and the proposed map would serve as a critical base for geological, geophysical, and astrobiology investigations of Europa in the interim.

The map is being produced and edited in Geographic Information Systems (GIS) software for digital manipulation of map information. GIS software permits spatial co-registration and comparison of all geographically referenced datasets, including spectral, chemical, and geologic-feature maps.

Background: Greeley et al. [3] presented guidelines for geologic mapping of Europa and characterized many of the major units, subunits, and structures identifiable at global, regional, and local scales. In addition, they proposed a system of nomenclature, symbols, and color conventions, and suggested a preliminary stratigraphic framework. This work sets the stage for the global geological mapping and synthesis undertaken here.

The most extensive geological mapping from Galileo data consists of two pole-to-pole maps across the leading and trailing hemispheres of Europa by Figueredo and Greeley [4]. In general, the geological histories derived from these maps indicate early formation and modification of background plains, subsequent cross-cutting and emplacement of an intricate network of bands and ridges, followed by chaotic disruption of the surface (locally, older chaos is recognized). More recently, Riley et al. [5] analyzed a region near the south pole and determined a more non-directional resurfacing history. However, there has been no attempt to correlate these local or regional relationships into a global stratigraphic record.
Base map: Our initial intent was to use the USGS published global photomosaic of Europa at 1:15,000,000 scale (USGS Map I-2757) as the map base on which to compile the global geologic map of Europa. This map was controlled and mosaicked using the best medium resolution images from the Galileo orbiter Solid-State Imaging (SSI) camera and the Voyager 1 and 2 spacecraft. Lower resolution data were used to complete the coverage. However, during the creation of the global mosaic, many of the medium resolution images were down-sampled from higher resolutions images to 500 meters per pixel, resulting in degradation of observable features. Moreover, some images were deleted due to the need for moderate emission/incidence angles to help reduce differences between the images. To derive a photomosaic that used the highest resolution data available, we generated a new mosaic using the entire collection of original controlled and radiometrically calibrated images at full resolution, which we are now using as the base map for publication.

Lineament-based stratigraphy: We mapped over 1,600 major Europan lineaments thus far, and currently we are determining their formational sequence using GIS software in conjunction with a customized GIS temporal sorting tool built by our team. GIS-based mapping allows the recording of specific attributes for each lineament and unit outcrop in an associated database table. Feature datafields under which data were recorded include the feature's unique identification value, center longitude and latitude, mean azimuthal orientation, and datafields that record age relative to uniquely identified lineaments and geologic unit outcrops. The stratigraphic placement information of each feature was constrained by up to 10 relationships (five older and five younger) that are recorded into the database. If a particular feature had stratigraphic relationships with more than 10 features, we determined the 10 most relevant ones that constrain the sequence of formation. The sorting tool provided error-checking capabilities including the detection of duplicate or contradictory sequence attributes within a feature's older- and younger-than datafields. Given the uneven resolution of the basemap images, a confidence value was entered for each of the 10 identified age relationships. The sorting tool uses this information to build an initial framework and to identify inconsistencies in the data.

An algorithm within the sorting tool employs the relative age attributes for all the lineaments to generate 
a complex correlation chart in which horizontal lines represent the lineaments and vertical lines represent the crosscutting relationships between intersecting lineaments. Their stratigraphic position is shown from youngest to oldest, top to bottom. We emphasize that this is a "work in progress," which we are using to develop a self-consistent stratigraphic framework for Europa. With this framework in place, the correlations will be simplified to show the sequence of lineament formation (with uncertainty ranges), which will be used to correlate map units as well. The relative-age data will be used to determine if there are distintictive periods within Europa's geologic history. For a given pair of non-intersecting lineaments, their position on the chart with respect to the time axis does not show their relative emplacement timing. Relative age relationships between non-intersecting lineaments can only be established through a third common lineament. The plotted location of non-intersecting lineaments with respect to the time axis is solely a function of available chart space and chart readability.

While all lineaments in the chart are connected to at least another feature, lineaments 'floating' within their bounding vertical lines introduce a good deal of uncertainty. Only those lineaments interconnected by continuous ascending or descending 'steps' can be temporally constrained. The relationships between these lineaments will not change if all or portions of the chart are extended or collapsed in the time axis. Despite the mentioned restrictions, the chart shows some degree of correlation between far-apart areas, even in opposite hemispheres. Thus some degree of global correlation is achievable. Once we have determined the stratigraphic position of each major lineament (or group of lineaments) that collectively comprise the global network, we will be able to bracket using lineament cross-cutting relations the ages of major events and units in the geologic record.

Crater and chaos mapping: Our geologic map shows the distribution of impact craters on a global scale, building on the work of Turtle and Pierazzo [6], and placing these areas into a global geologic context. Contact relationships documented on current regional geologic maps [4, 7, 8] are being extrapolated to global scales to enable the use of major lineaments as stratigraphic markers.

Thus far, we have mapped $~ 1175$ sites of chaos and domes. Mapping the distribution of chaos and dome morphologies and sizes and their ages can address models of chaos formation that involve local to global heat sources and kinematic models of Europa's icy crust involving melting, ductile flow, convection, diapirism, a possible subsurface ocean, and sill intrusion [9-16]. In particular, uncertainty exists over whether Europa ex- perienced a sequential history of plains and chaos development and lineament formation [4, 8, 10] versus one of more continual, diachronous development of various structures via crustal melt-through and tectonic cracking [5, 17].

References: [1] Spencer J. R. et al. (1999) Science 284, 1514-1516. [2] McCord T. B. et al. (1999) J. Geophys. Res. 104, 11827-11851. [3] Greeley R. et al. (2000) J. Geophys. Res. 105, 22,559-22,598. [4] Figueredo P. H. and Greeley R. (2004) Icarus 167, 287312. [5] Riley J. et al. (2005) Lunar Planet. Sci. XXXVI, Abstract \#1516. [6] Turtle E. P. and Pierazzo E. (2001) Science 294, 1326-1328. [7] Prockter L. M. et al. (1999) J. Geophys. Res. 104, 16531-16540. [8] Kadel S. D. et al. (2000) J. Geophys. Res. 105, 22,657-22,669. [9] Carr M. H. et al. (1998) Nature 391, 363-365. [10] Pappalardo R. T. et al. (1998) Nature 391, 365-368. [11] Spaun N. A. et al. (1998) Geophys. Res. Lett. 25, 4277-4280. [12] Greenberg R. et al. (1999) Icarus 141, 263-286. [13] Collins G. C. et al. (2000) .J. Geophys. Res. 105, 1709-1716. [14] Riley J. et al. (2000) J. Geophys. Res. 105, 22,599-22,615. [15] Hoppa G. V. et al. (2001) Icarus 151, 181-189. [16] Greenberg R. et al. (2003) Icarus 161, 102-126. [17] Figueredo P. H. et al. (2002) J. Geophys. Res. 107, doi: 10.1029/ 2001JE001591. 
GLOBAL GEOLOGIC MAPPING OF IO USING GALILEO AND VOYAGER DATA. David A. Williams, Department of Geological Sciences, Arizona State University, Box 871404, Tempe, Arizona, 85287 (David.Williams@asu.edu); Laszlo Keszthelyi, Astrogeology Team, U.S. Geological Survey, Flagstaff, Arizona; David Crown, Planetary Science Institute, Tucson, Arizona.

Introduction: This spring we began a new threeyear project to produce a global geologic map of Io using Galileo and Voyager images. The objective is to complete a global reconnaissance of Jupiter's volcanic moon, which is now possible because of the extensive spatial and temporal coverage of Io's antijovian hemisphere that was obtained during the Galileo Mission at Jupiter (1995-2003). The Galileo images complement the excellent Voyager coverage of the subjovian hemisphere. The goals of our project, funded by the NASA Outer Planets Research Program, are to 1) create a tool that integrates the new discoveries from the Galileo Mission with the lessons learned from Voyager about the geologic activity and evolution of Io;2) create a framework for the continuing analysis of Galileo data; 3 ) create an aid for the correlation of ongoing groundbased telescopic observations of Io with known sites of active volcanism; and 4) create a basemap that will be useful for planning spacecraft observations of Io from future missions. In this abstract we discuss our work plan and approach during Year 1, which focuses on the strategies needed to produce the global Io map, based on the insights learned from our previous regional mapping.

Approach and work plan: During FY '05 the USGS will produce the global mosaics $(500 \mathrm{~m} / \mathrm{px}$ resolution) of Io required to complete this project. These mosaics include Galileo Solid-State Imager (SSI)-only monochrome and low-phase color global mosaics, a monochrome Galileo-Voyager global mosaic, and the combined mosaic merged with the lowphase SSI color. Mosaics are being produced by Paul Geissler and Tammy Becker of the USGS (Flagstaff) with a planned delivery date of October 2005.

During the time that the global mosaics are being made, the PI (DAW) and Co-Is (LPK, DAC) are developing the techniques required to produce the global map. Our approach is to build on our experience from geologic mapping of regional Io mosaics using Galileo SSI images (DAW and LPK) and global mapping using Voyager images (DAC). Each of us is independently mapping the Amirani-Gish Bar region of Io (Figure 1), using Galileo SSI monochrome mosaic I24AMSKGI01 $(470-510 \mathrm{~m} /$ pixel) merged with the color data from observation C21COLOR01 (1.4 $\mathrm{km} / \mathrm{pixel}$ ) [1]. This mosaic covers a large area in the $\mathrm{NE}$ antijovian hemisphere, from $\sim 8-35^{\circ} \mathrm{N}$ and 80 $135^{\circ} \mathrm{W}$. This merged mosaic is very close to the resolution of the global mosaics being generated (500 $\mathrm{m} / \mathrm{pixel}$ ), and serves as a good tool to calibrate our mapping techniques. By having the PI and Co-Is independently map the same region, the broadest range of mapping skills and interpretations are being brought to the problem, so that the most useful techniques will be identified for the global map production.

Strategies for global mapping: Our mapping approach is to use traditional planetary mapping techniques [2] and build on the experience gained from the Voyager-era maps of the subjovian hemisphere [3] and our regional mapping using Galileo SSI images. There are two key considerations that need to be recognized when developing a strategy for global Io mapping. First, as noted by Geissler et al. [4, 5], the bulk of the surface changes on Io due to volcanism are centered around a few very active vents. Large areas of the surface $(83 \%)$ had no discernable changes during the Galileo mission. This observation was reinforced during our regional mapping of the Chaac-Camaxtli [6], Culann-Tohil [7], and Zamama-Thor regions [8], each of which is dominated by one or more sites of active volcanism. This observation also suggests a mapping approach centered on formations, i.e., sets of related geologic units focused on a specific source of activity (patera, fluctus, mons, etc.).

Second, because the Galileo and Voyager imaging coverage of Io [1,9] is not uniform (i.e., much global $(>1 \mathrm{~km} / \mathrm{px})$ imaging, limited regional $(0.1-1 \mathrm{~km} / \mathrm{px})$ imaging, and rare local $(<100 \mathrm{~m} / \mathrm{px})$ imaging, all at a range of phase angles and lighting conditions), the number of material units that can be defined and characterized for the global map may be limited. Based on our regional mapping [6-8], and the experience of the Voyager-era mappers [3], Io has 5 primary types of material units: plains, flows, patera floors, mountains, and diffuse deposits. The plains materials have various textures and degrees of layering, resulting from a complex history of deposition and erosion of sulfurous [10] and silicate explosive and effusive volcanic deposits, volcanic vent and mountain formation, and perhaps other as yet unidentified processes [6-8]. Patera floor materials have a wide range of colors, albedos, and textures that depend upon the composition and eruption styles of the volcanic materials that cover them. Lava flow materials also have a range of colors and albedos from dark to bright; dark flows are thought to be mafic or ultramafic silicate lavas and bright flows are thought to be sulfur and/or sulfur dioxide $\left(\mathrm{SO}_{2}\right)$ flows [11]. Mountain materials resulted from uplift of crustal blocks [12, and references therein], mantling by plume deposits, and erosion by mass movement [13]. Diffuse deposits, which Galileo images show exist in five basic colors (white, black, yellow, red, and green), are produced when material ejected in explosive plume eruptions settles on the surface. These deposits likely 
consist of both pyroclastic fragments and frozen gases, and are traditionally mapped both on the Voyager-era maps and our Io maps [3, 7-8]. Interestingly, unlike all other imaged bodies in the Solar System, there are no visible impact craters on Io. The point is that the number of subunits of these 5 primary unit types that can be created and used on the global map will have to be carefully considered. Likewise, use of multiple images under various lighting conditions will be necessary to identify scarps of layered plains and mountains, and possibly other tectonic features.

Implications of work: New insights on Io's volcanism have been gained during the Galileo era, such as: 1) more accurate color imaging in the visible spectrum, and the association of specific colors of volcanic deposits to particular compositions and styles of eruption [4]; 2) recognition of the volcano-tectonic relationship between paterae and montes in many areas [12]; and 3) definition of discrete eruption styles (Promethean, Pillanian, Lokian).

The Galileo observations of Io from 1996-2001 have led to discoveries with profound implications for the nature of Io's interior and surface, and for the development of models of Io's geologic evolution to its present state (e.g., [15]). Global geologic mapping is one critical element that is required for incorporating these new observations to refine our models of Io. Mapping Io is a unique challenge because of the rate of surface change. Despite the fact that $83 \%$ of Io's surface has not changed during Galileo, we will have to make special adjustments to standard mapping techniques to deal with temporal changes. We are using GIS to record these changes (the Amirani-Gish Bar mapping by LPK is being done in GIS), which would be more difficult to capture on a traditional paper map. The systematic characterization of Ionian surface fea- tures and their distribution in time and space is essential for identifying the volcanic and tectonic processes working on and within Io. Some specific outstanding questions (that we may or may not be able to answer): are the flow and the patera floor materials the same material? What are the mountains made of (dominantly pyroclastics or coherent rock)? Is there a global pattern to the tectonics on Io? How closely are tectonism and volcanism linked?

References: [1] Keszthelyi et al. (2001) JGR 106(E12), 33,025-33,052. [2] Shoemaker and Hackma, (1962) in The Moon, Z. Zopal and K.Z. Mikhailov (eds.), Academic, San Diego, CA, 289-300; Wilhelm, (1972) USGS Interagency Report, Astrogeology, 55; Wilhelms (1990) in Planetary Mapping, Greeley and Batson (eds.), Cambridge Univ. Press, New York, 208-260; Tanaka et al. (1994) USGS Open File Rep., 94-438, 66 pp. [3] Crown et al. (1992) USGS Misc. Invest. Series Map I-2209, 1:15,000,000; Greeley et al, (1988) USGS Misc. Invest. Series Map I-1949, 1:2,000,000; Moore (1987) USGS Misc. Invest. Series Map I-1851, 1:1,003,000; Schaber et al. (1989) USGS. Geol. Invest. Series Map I-1980, 1:5,000,000; Whitford-Stark et al. (1991) USGS Misc. Invest. Series Map I-2055, 1:5,000,000. [4] Geissler et al, (1999) Icarus 140, 265-282. [5] Geissler et al. (2004) Icarus 169/1, 29-64. [6] Williams et al. (2002) JGR 107(E9), 5068, doi:10.1029/2001JE001821. [7] Williams et al. (2004) Icarus, 169/1, 80-97. [8] Williams et al., in press. [9] Turtle et al. (2004) Icarus, 169/1, 3-28. [10] Douté et al. (2001) Icarus 149, 107-132 (2002) Icarus 158, 460-482 (2004) Icarus 169/1, 175-196. [11] McEwen et al. (2000) Science 288, 1193-1198. Williams et al. (2001) JGR 106(E12), 33,16133,174. [12] Schenk et al. (2001) JGR 106(E12), 33,20133,222; Jaeger et al. (2003) JGR 108(E8), 5093, doi:10.1029/2002 JE001946. [13] Moore et al. (2001) JGR 106(E12), 33,223-33,240. [14] Lopes et al. (2004) Icarus 169/1, 140-174. [15] Keszthelyi et al. (2004) Icarus 169/1, 271-286.

Figure 1. The Amirani-Gish Bar region, which is being mapped as preparation for using the global mosaics. Names followed by an asterisk are provisionally approved by the International Astronomical Union.

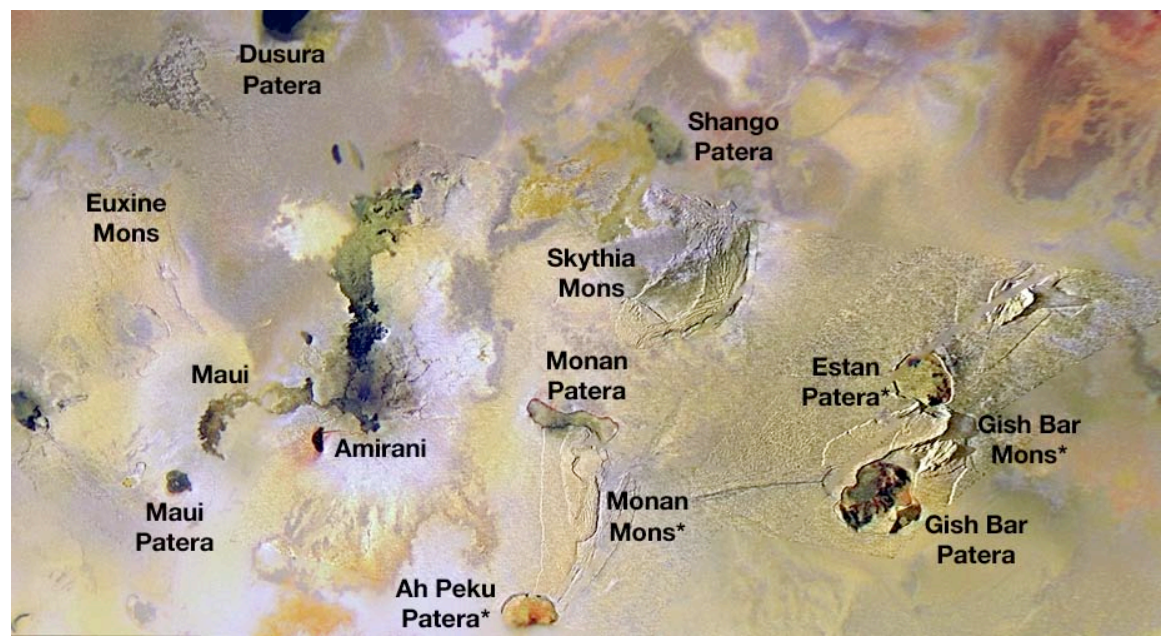


COPERNICUS 1:2.5M SCALE MAPPING: DATASETS, METHODS, AND RESULTS OF THE LUNAR GEOLOGIC MAPPING PILOT PROJECT. L.R. Gaddis ${ }^{1}$ (lgaddis@usgs.gov), J.A. Skinner ${ }^{1}$, Jr., T.M. Hare ${ }^{1}$, and B.R. Hawke ${ }^{2},{ }^{1}$ Astrogeology Team, U.S. Geological Survey, Flagstaff, AZ 86001; ${ }^{2}$ Hawaii Institute of Geophysics and Planetology, University of Hawaii, Honolulu, HI 96822.

Introduction: Lunar geosciences have been significantly advanced since the first systematic geologic maps were produced at regional and global scales during the 1960's [1-3]. These advancements have occurred through the acquisition and analysis in recent years of digital data such as Lunar Orbiter (LO) photographs as well as multispectral, elemental, topographic, and earthbased spectral and radar data. To demonstrate the utility of these data for lunar geologic mapping, we are using the full complement of available data to complete a 1:2.5M scale pilot geologic map that centers on Copernicus crater [4].

The Copernicus quadrangle $\left(0^{\circ}-30^{\circ} \mathrm{N}, 0^{\circ}-45^{\circ} \mathrm{W}\right)$ contains impact craters and ejecta material of Copernicus (94 km dia.) and Eratosthenes (58 km dia.) craters, two type localities of not only dispersed crater-related materials, but more importantly lunar time-stratigraphic units that are traceable over broad regions of the planet $[3,5]$. The quadrangle contains Lower Imbrian basin-related materials (Alpes and Fra Mauro Fms.), Upper Imbrian mare basalts and pyroclastic deposits (Mare Insularum, Sinus Aestuum, and marginal Mare Imbrium), Eratosthenian mare basalts (central Mare Imbrium) and crater materials, and Copernican impact and related deposits. Preliminary results of our mapping of morphologic and compositional units are described below.

Data: Basemaps for this map include a LO-IV photomosaic (60 m/px, [6]), Clementine UVVIS (415, 750, 900, 950, 1000-nm; $100 \mathrm{~m} / \mathrm{px}$, [7]) and NIR data (110, 1250, 1500, 2000, 2600, 2780-nm; $500 \mathrm{~m} / \mathrm{px}$, [8]) and UVVIS 'standard' color ratios $(\mathrm{R}=750 / 415 \mathrm{~nm}$; $\mathrm{G}=750 / 950 \mathrm{~nm} ; \mathrm{B}=415 / 750 \mathrm{~nm}$ ), Clementine topographic data (1 km/px, [9]), Earth-based $3.8 \mathrm{~cm}$ radar (3.1 $\mathrm{km} / \mathrm{px},[10])$, as well as Clementine derived optical maturity (OMAT, [11]) data. We also use high (9 m/px) and very-high $(1.3 \mathrm{~m} / \mathrm{px})$ resolution LO-IV frames that cover the Copernicus crater floor, wall, and central peak.

Methods: We processed, orthorectified, and coregistered data using both image processing (ISIS) and GIS (ArcMAP) platforms to assess the capabilities of these different environments for lunar geologic mapping with digital data. All geologic digitization is being completed in an ESRI "geodatabase" format for ease of data compilation, vector attribution, topological cleaning, interlayer analyses and data sharing; geodatabase feature classes are easily converted to alternate GIS files types. Moreover, both ISIS and ArcMAP have the capability to render and analyze raster data, such as band mixing, false-color image production, and advanced band math. The geologic unit-based extraction and plotting of spec- tral data on two- and three-axis plots provide a powerful tool to reveal clustering of reflectance behaviors, allowing us to distinguish among geologic units by color and to infer stratigraphic associations. These lunar data and the digital framework in which we process and render them provide a previously unparalleled environment for the production of high-quality geologic maps based on unit morphology, texture, and color [e.g., 12].

\section{Copernicus Quadrangle Mapping Observations:}

Stratigraphy. The goal of stratigraphy in mapping is to place definable units into horizons of time using areally extensive units (or structures) that have a discernible, discreet absolute or relative age [e.g., 13]. The stratigraphy of Wilhelms [5] formed the starting point for our stratigraphic mapping and interpretations. Our work builds extensively on the use of derived parameters, including composition and soil maturity [11], from Clementine multispectral reflectance data at UVVIS and NIR wavelengths. While lunar geologic units and events were dated where possible using returned rock and soil samples, measurements of crater size-frequency distributions have been used to extend these data well beyond the small number of units sampled [e.g., 12]. Color and maturity data from Clementine offer a valid stratigraphic marker for materials belonging to the Copernican System. An assessment of the utility of these data to lunar stratigraphy is a major goal of this pilot mapping project.

Highland units. Past geologic maps of the Copernicus region delineated pre-Imbrian crater massifs associated with the Imbrian multi-ring impact basin (Montes Carpatus and Apenninus) as well as scattered Imbrian-age highlands units of Sinus Aestuum and Sinus Medii. These units were broadly interpreted to have formed as a result of uplifted (and subsequently mass-wasted) prebasin materials and scattered, elevated remnants of Imbrium basin ejecta [1-2], based on the morphologic character of the surface units (e.g., knob roundness, distribution of coarse material), crater counts, and cross-cutting relationships. The Clementine color and OMAT data allow us to examine the spectral signatures of these highland units and to constrain unit boundaries and cross-cutting relationships.

We find mappable color differences among preImbrian highland units that comprise both the Sinus Aestuum and Sinus Medii highlands to the southeast and the arcuate highland outcrops of the southern Imbrium basin. While these highland units have a common reflectivity in single-band (e.g., 750-nm) UVVIS and comparable OMAT values ( 0.13 to 0.15 ), variation in the 950/750 nm ratio suggests that these materials have dif- 
ferent ferrous iron contents [4]. Color data thus reveal previously unmapped, complex compositional units that have likely been excavated from depth. For example, the central peak of Copernicus has an olivine-rich composition [14] that would likely not have been identified in the absence of color data.

Mare units. In combination with extensive cratercounting efforts, Clementine color data have been used to identify and delineate major mare units of different ages and stratigraphic sequences [12]. We build on these results to map the upper Imbrian and Eratosthenian age mare basalts and their relation to local highland units as well as Eratosthenian and Copernican impact craters and crater-related materials.

Clementine UVVIS and color ratio as well as OMAT data show that some mare basalts previously mapped as continuous units have significant variations in color, ferrous iron and titanium contents, and/or maturity. Based on these variations, stratigraphic boundaries, geologic units, surface ages, and eruptive histories of the Mare Imbrium and Oceanus Procellarum that are included in the Copernicus quadrangle can be better differentiated.

Crater units. Materials related to Copernicus and Eratosthenes craters were mapped previously based on telescopic albedo and morphology [1-2]. The resultant geologic maps identified the extents of comminuted and redistributed impact material based largely on reflectivity of a single spectral band. Clementine color and ratio data show substantial variation in reflectance and morphology among these crater-related deposits, particularly at the 2780-nm NIR wavelength, and in optical maturity. We use these data to more accurately map both the extent and type of excavated materials. For instance, the northwest crater wall and ejecta of Copernicus have significantly elevated $750-\mathrm{nm}$ values, suggesting local excavation and redistribution of a relatively bright, ironpoor material, possibly derived from Imbrium basin massifs. Eratosthenes crater, which partly overlies Imbrium basin massif materials, shows a similar (though more subdued) color variation, suggesting that the northernmost ejecta may consist of excavated preImbrian basement rocks. Ejecta from smaller craters that impacted mare basalts, particularly near mare/highland boundaries, also show distinct color and optical maturity properties. Color data such as these provide clues to the depth of origin and the diversity of materials that were excavated.

The ability to identify and map redistributed target materials provides a tremendous advance to lunar geologic mapping, requiring careful identification of geologic contacts and detailed geologic unit descriptions. These efforts mark a substantial improvement in our ability to identify, characterize, and analyze geologic units on the Moon and thus to address significant scien- tific issues. Using stratigraphic tools and terminology developed and implemented for terrestrial planets [1517], we have produced a preliminary geologic map that aims to remove subjective bias in unit delineation and characterization. These mapping approaches will incorporate recent advances in the use of optical maturity values to characterize stratigraphic boundaries and sequences $[18,19]$, and will result in a clearer definition of the nature and timing of the Copernican/Eratosthenian boundary.

Other materials. A fourth major material unit in the Copernicus quadrangle is comprised of significant distributions of "dark mantle" pyroclastic materials [e.g., 12]. Clementine color and ratio data indicate that these materials are very high in titanium content. Moreover, these deposits have high OMAT values, pointing to both long-term surface exposure and a high abundance of Ferich rocks, consistent with a volcanic origin. Yet some local dark-halo deposits mapped by [1] are not readily detected in the color data, nor do they display morphologies largely different from local impacts. Some of these low-albedo deposits may be either satellitic craters associated with the Copernicus impact or subsequent discreet impact craters.

Preliminary Results: Our preliminary mapping shows a substantially more diverse-both compositionally and temporally - series of geologic units than have been previously mapped in the Copernicus quadrangle. As a result of this work, we expect to identify mapping parameter values in our digital data that are appropriate for future geologic mapping by us and others across the Moon. Results will be compiled into a formal USGS SIM-series geologic map. Among our final results will be a lunar mappers' guide (likely published as a USGS Open File Report), with evaluations and recommendations for digital data acquisition and dissemination, relative utility for unit identification, characterization, and mapping, basemap construction, and useful tools and tips for future mappers.

References: [1] Schmitt et al. (1967) USGS I-515. [2] Wilhelms and McCauley (1971) USGS I-703. [3] Shoemaker and Hackman (1962) Symp. 14 IAU, 289. [4] Gaddis et al. (2005) LPSC XXXVI, \#2021. [5] Wilhelms (1987) USGS Prof. Paper 1348, 302 pp. [6] Becker et al. (2005) LPSC XXXVI, \#1836. [7] Eliason et al. (1999) PDS_CL_4001 to_4078. [8] Gaddis et al. (2005) NIR PDS archive, in prep. [9] Rosiek et al. (2002) LPSC XXXIII, \#1792. [10] Zisk et al. (1974) Moon, 10, 17. [11] Lucey et al. (2000) JGR 105, 20377. [12] Hiesinger et al. (2003) JGR 108(E7). [13] Hansen (2000) Earth Plan. Sci. Lett. 176, 527-542. [14] Pieters et al. (1999) Science 266, 18441848. [15] North American Stratigraphic Code (1983) AAPG Bull. 67, 841-875. [16] Skinner and Tanaka (2003) LPSC XXXIV, \# 2100. [17] Wagoner et al. (1988) SEPM Spec. Pub. No. 42. [18] Grier et al. (2001) JGR 106, 32847-32862. [19] Hawke et al., this volume. 
THE ORIGIN OF LUNAR CRATER RAYS: IMPLICATIONS FOR THE COPERNICANERATOSTHENIAN BOUNDARY. B.R. Hawke ${ }^{1}$, L.R. Gaddis ${ }^{2}$, D.T. Blewett ${ }^{3}$, J.M. Boyce ${ }^{1}$, B.A. Campbell ${ }^{4}$, T.A. Giguere ${ }^{5}$, J.J. Gillis ${ }^{1}$, P.G. Lucey ${ }^{1}$, C.A. Peterson ${ }^{1}$, M.S. Robinson ${ }^{6}$, and G.A. Smith ${ }^{1},{ }^{1}$ Hawaii Institute of Geo- $^{2}$ physics and Planetology, University of Hawaii, Honolulu, HI 96822, ${ }^{2}$ U.S. Geological Survey, Astrogeology Program, 2255 N. Gemini Drive, Flagstaff, AZ 86001, ${ }^{3}$ NovaSol, 733 Bishop Street, Honolulu, HI 96813, ${ }^{4}$ Center for Earth and Planetary Studies, National Air and Space Museum, Washington, D.C. 20560, ${ }^{5}$ Intergraph Corporation, P.O. Box 75330, Kapolei, HI 96707, ${ }^{6}$ Center for Planetary Sciences, Northwestern University, Evanston, IL 60208.

Introduction: Lunar rays are filamentous highalbedo features that are radial or subradial to impact craters. The nature and origin of lunar rays have long been the subjects of major controversies. We are investigating the origin of lunar crater rays in support of the new Lunar Geologic Mapping Program.

The Origin of Selected Lunar Rays: We used a variety of remote sensing data to study selected rays. Clementine UVVIS images were used to produce highresolution $\mathrm{FeO}, \mathrm{TiO}_{2}$, and optical maturity (OMAT) derived maps for these rays [after Lucey et al.; 1, 2]. In addition, near-IR spectra and 3.8- and 70-cm radar maps were used.

Messier Crater Complex. Messier (14 km in long dimension) and Messier A (11 km dia.) are located in Mare Fecunditatis. Major rays extend north and south from Messier and west from Messier A. Near-IR spectra and 3.8-cm radar, $\mathrm{FeO}, \mathrm{TiO}_{2}$, and OMAT maps show that rays south and west of the Messier complex are dominated by fresh mare material [3]. These rays are prime examples of "immaturity" rays. They are bright because they contain immature basaltic debris. Highlands material is not present in these rays.

Tycho Ray (Nectaris). A major ray from Tycho crater crosses much of Mare Nectaris. We focused on that portion of the ray that extends $\sim 40 \mathrm{~km} \mathrm{NE}$ of Rosse crater and includes a Tycho secondary crater cluster. Analyses of near-IR spectra, $\mathrm{FeO}, \mathrm{TiO}_{2}$, and OMAT images and radar data indicate that Tycho ray is dominated by fresh mare material excavated and emplaced by secondary craters [3, 4]. While some highlands material is likely present, the major factor that produces the brightness of the ray is the immature mare basalt.

Tycho Ray (Southern Highlands). We examined a continuation of the Tycho ray discussed above in the highlands SW of Mare Nectaris. This ray has the same range of $\mathrm{FeO}$ values (5.5-7.0 wt.\%) as that of the adjacent highlands terrain. The OMAT map shows that brighter portions of this ray are composed of immature material. The high albedo of this ray is totally due to the immaturity of the highlands debris.

Lichtenberg Crater Rays. The FeO map of the Lichtenberg region indicates that ejecta and rays $\mathrm{N}$ and
NW of the crater show relatively low $\mathrm{FeO}$ abundances. These deposits are dominated by low-FeO highlands debris. The OMAT image shows that these highlandsrich deposits are fully mature. Hence, the Lichtenberg rays show a relatively high albedo because of their composition.

Olbers A Ray. This Copernican-aged impact crater (43 km dia.) is located in the highlands on the Moon's western limb and exhibits an extensive ray system in Oceanus Procellarum. A number of ray segments are distinct in the OMAT image and are enriched in immature material relative to adjacent terrain. Reduced $\mathrm{FeO}$ and $\mathrm{TiO}_{2}$ values are also associated with these segments. Therefore, both composition and immaturity are important in producing the brightness of these ray segments [3]. These ray segments are good examples of "combination" rays.

In summary, lunar rays are bright because of compositional contrast with surrounding terrain, the presence of immature debris, or a combination of the two effects.

Implications for Calibration of the Lunar Stratigraphic Column: It has long been thought that craters that exhibit rays were formed more recently than $1.1 \mathrm{Ga}$ [e.g., 5]. However, it has now been shown that the rayed crater Lichtenberg is older than $1.68 \mathrm{Ga}$, perhaps far older [6]. In addition, McEwen et al. [7] used counts of craters superposed on large rayed-crater ejecta to determine that Hausen and Pythagoras have $\sim 3.0 \mathrm{Ga}$ or greater ages. The working distinction between the Eratosthenian and Copernican Systems is that Copernican craters larger than a few kilometers in diameter still have visible rays whereas Eratosthenianaged craters do not $[5,8,9]$. Since compositional rays can persist for $3 \mathrm{Ga}$ or more, the mere presence of bright rays is not a reliable indicator that a crater was formed during the Copernican Period [e.g., 3, 7, 10, $11,12]$. It is clear that a new method is required to distinguish Copernican from Eratosthenian craters. Several workers $[3,11,12]$ have suggested that the OMAT parameter be used to define the C-E boundary. OMAT values for fresh crater ejecta decrease with age [2]. With increasing age, OMAT values for ejecta and rays are indistinguishable from the background value, 
which is the optical maturity index saturation point [2, 12]. The time required for a fresh surface to reach this saturation point could be defined as the Copernican Period. Surfaces that have reached full optical maturity would then be of Eratosthenian (or greater) age. The time required for a surface to reach full optical maturity has not been firmly established. However, Grier et al. [11, 12] noted that if ejecta of Copernicus were slightly more mature it would be indistinguishable from the background in an OMAT image. Hence, the saturation of the optical maturity index may occur at about $0.8 \mathrm{Ga}$, the commonly accepted age of Copernicus $[13,14,15]$.

A Reevaluation of Lunar Crater Ages: We have studied rays associated with several lunar craters to determine their compositions and maturity states and to assess the ages of parent craters in light of the new criteria for identifying the C-E boundary.

Aristillus (dia. $=55 \mathrm{~km}$ ) and Autolycus (dia. $=39$ $\mathrm{km}$ ) are located NW of the Apollo 15 site in Imbrium basin. Both have been mapped as Copernican craters based on the presence of rays $[5,16]$. The high-albedo rays of Aristillus and Autolycus contain highlands material and are bright because of compositional contrast with the surrounding mare terrain. The rays and ejecta of both craters have reached full optical maturity [12, 17]. Hence, Aristillus and Autolycus are older than Copernicus and should be mapped as Eratosthenian-aged craters. Support for an Eratosthenian age for these craters was presented by Ryder et al. [9]. They indicated that Aristillus and Autolycus have absolute ages of 1.3 and $2.1 \mathrm{Ga}$, respectively, based on the results of radiometric dating of Apollo 15 samples. These ages are greater than that of Copernicus ( 0.8 $\mathrm{Ga})$.

Taruntius (56 km dia.; $5.6^{\circ} \mathrm{N}, 46.5^{\circ} \mathrm{E}$ ) has been mapped as a Copernican-aged crater $[5,16]$. The high-albedo rays which surround Taruntius are compositional rays. They are optically mature and appear bright only because they contain relatively large amounts of highland debris. Taruntius is older than Copernicus and should be mapped as an Eratosthenian-aged crater. It has been suggested that the localized pyroclastic deposits on the interior of Taruntius were very young because of the Copernican age of the host crater. However, it now appears that these pyroclastic deposits are Eratosthenian.

Taruntius $\boldsymbol{H}$ (8 km dia.) and Taruntius $\boldsymbol{P}$ (7 km dia.) are located SE of Taruntius in Mare Fecunditatis. Since these craters lack well-defined rays, they are mapped as Eratosthenian craters [18]. The OMAT image of these craters clearly shows that their ejecta deposits are immature. They are younger than Coper- nicus and should be assigned a Copernican age.

O'Day (71 km dia.; 30.6 ${ }^{\circ} \mathrm{S}, 157.5^{\circ} \mathrm{E}$ ) has been mapped as a Copernican crater [5]. However, the ejecta blanket and rays of O’Day are fully mature [12] and the rays in Mare Ingenii contain a highlands component. O'Day should be mapped as an Eratosthenianaged crater.

Eudoxus (67 km dia.; 44. $3^{\circ} \mathrm{N}, 16.3^{\circ} \mathrm{E}$ ) has been mapped as a Copernican-aged impact structure $[5,16]$. Our results show that Eudoxus has compositional rays. Since both ejecta and rays of Eudoxus are fully mature [12], this crater should be assigned an Eratosthenian age.

Summary and Conclusions: Since compositional rays can persist for $3 \mathrm{Ga}$ or more, the mere presence of bright rays is not a reliable indicator that a crater was formed during the Copernican Period. The OMAT parameter could be used to define the C-E boundary. The time required for a fresh surface to reach the optical maturity index saturation point could be defined as the Copernican Period. A reevaluation of the ages of Aristillus, Autolycus, Taruntius, O’Day, and Eudoxus indicated that these craters should be assigned an Eratosthenian age. This approach can be used for geologic mapping of the Moon.

References: [1] Lucey P. et al. (2000) J. Geophys. Res., 105, 20,297. [2] Lucey P. et al. (2000) J. Geophys. Res., 105, 20,377. [3] Hawke B. et al. (2004) Icarus, 170, 1. [4] Campbell B. et al. (1992) Proc. Lunar Planet. Sci., 22, 259. [5] Wilhelms D. (1987) U.S.G.S. Prof. Pap., 1348. [6] Heisinger H. et al. (2003) J. Geophys. Res., 108, _E7). [7] McEwen A. et al. (1993) J. Geophys. Res., 98, 17207. [8] Shoemaker E. and Hackman R. (1962) The Moon-Sym. 14 of the I.A.U., 289. [9] Ryder G. et al., (1991) Geology, 19, 143. [10] Pieters C. et al. (1985) J. Geophys. Res., 90, 12,393. [11] Grier J. and McEwen A. (2001) Accretion of Extraterrestrial Material throughout Earth History, 403. [12] Grier J. et al., (2001) J. Geophys. Res., 106, 32,847. [13] Eberhardt P. et al. (1973) Moon, 8, 104. [14] Bogard D. et al. (1994) GCA, 58, 3093. [15] Stoffler D. and Ryder G. (2001) Space Sci Rev., 96, 9. [16] Wilhelms D. and McCauley J. (1971) U.S.G.S.Map I-703. [17] Blewett D. and Hawke B. (2001) Meteorit. Planet. Sci., 36, 701. [18] Olson A. and Wilhelms D. (1974) U.S.G.S. Map I-837. 
MARTIAN HIGHLAND/LOWLAND BOUNDARY ZONES: GEOLOGIC MAPPING IN DEUTERONILUS MENSAE AND HELLAS PLANITIA. David A. Crown, Leslie F. Bleamaster III, and Frank C. Chuang, Planetary Science Institute, 1700 E. Ft. Lowell Rd., Suite 106, Tucson, AZ 85719, crown@psi.edu.

Introduction: Geologic mapping studies coupled with geomorphic analyses are being used to characterize geologic processes that have shaped the Martian highlands and, in particular, to evaluate landforms and deposits resulting from modification of highland terrains by volatile-driven degradation. Highland-lowland boundary zones are being investigated in Deuteronilus Mensae along the dichotomy boundary of northern Arabia Terra and in Hellas Planitia along the eastern margin of Hellas basin. The current mapping studies build on previous mapping in eastern Hellas [1-10] and recent analyses of debris aprons in eastern Hellas and along the dichotomy boundary [11-13]. The current work is designed to provide new constraints on the styles and timing of the diverse processes that have contributed to the complex geologic record preserved in these highland-lowland boundary zones.

Hellas Planitia: MTM quadrangles -40277, -45277 , and -45272 cover the distal regions of Dao and Harmakhis Valles and adjacent parts of Hellas Planitia. Here, highly degraded highland terrains of the Hellas rim contact the floor deposits of Hellas basin. The map area includes valles and their floor deposits, remnants of rugged basin rim materials, dissected channeled plains, and the basin floor deposits. Recent studies using MOC and THEMIS images coupled with MOLA data suggest that the eastern basin rim is a large depositional shelf, with a series of elongate, sinuous channels extending toward Hellas Planitia and a concentration of finely-layered outcrops along a distinct scarp that separates the basin floor from the surrounding rim [14-15]. The later stages of Dao and Harmakhis Valles are interpreted to be dominated by collapse and sapping in a volatile-rich substrate [16]. These observations and progressive highland terrain degradation from the highlands inward toward the basin margin are consistent with ancient lakes in the basin interior [17], as proposed earlier based on analyses of western Hellas [18].

Specific research objectives for geologic mapping of eastern Hellas Planitia include: a) to reconstruct fluvial systems that dissect the Hellas rim; b) to characterize the extensions of Dao and Harmakhis Valles onto the basin floor and to identify sediments contributed to Hellas Planitia; c) to investigate the nature of the boundary between the east rim and Hellas Planitia in order to infer its mode of origin, age, and history of modification; and d) to use small-scale surface morphology and small crater populations to examine finely layered deposits, local erosion and redistribution of materials by the wind, and burial/mantling/exhumation of surfaces. This new mapping facilitates comparisons between the geologic history of the east rim and Hellas Planitia.

Deuteronilus Mensae: MTM quadrangles 35337, 40337, and 45337 include the transition from the highlands of Arabia Terra to the northern plains of Acidalia Planitia. MTM quadrangle 35337 consists of cratered terrain exhibiting $\sim 8$ craters $\geq 15 \mathrm{~km}$ in diameter, including the $125 \mathrm{~km}$-diameter crater Cerulli and its well preserved ejecta blanket. Large craters show a range of preservation states but are mostly moderately to highly degraded. McGill [19] mapped 3 Noachian highland units that may extend into this quadrangle. MTM quadrangles 40337 and 45337 contain the transition from relatively continuous highland surfaces into the fretted terrain where highland surfaces are preserved in mesas surrounded by low-lying plains and debris aprons. Also included are parts of fretted terrain valley systems (including Mamers Valles), the large low-lying expanse containing Deuteronilus Colles, and the angular mesas and surrounding lowlands of Deuteronilus Mensae proper. Crater Lyot is located to the NE and its ejecta should have at one time covered the area exposed in MTM 45337. Parker et al.'s [20] analysis of Deuteronilus Mensae west of the map area suggests the presence of two gradational boundaries that may be associated with ancient Martian northern oceans.

Specific research objectives for mapping in Deuteronilus Mensae include: a) to identify lobate debris aprons, lineated valley fill, and other potentially ice-rich mass-wasting features; b) to examine lowlying plains for evidence of melting of ice and related drainage and possible connections to debris aprons and lineated valley fill; $\mathrm{c}$ ) to characterize highland surfaces present both on continuous plains and on mesas; d) to examine in detail the geomorphic and topographic characteristics of debris aprons for comparison to the eastern Hellas population; and e) to use small-scale morphology and populations of small craters to look for evidence of ice-related deformation, examine recent resurfacing history, and help evaluate ages of features in the map area. This research will address key scientific questions regarding the geologic history of the lowland-highland boundary, sequences of highland degradation, and the emplacement of debris aprons and other potentially ice-rich features.

References: [1] Crown D. A. et al. (1992) Icarus, 100, 125. [2] Mest S. C. and Crown D. A. (2001) Icarus, 153, 89110. [3] Leonard G. J. and Tanaka K. L. (2001) USGS Geol. Invest. Ser. Map I-2694. [4] Tanaka K. L. and Leonard G. J. (1995) JGR, 100, 5407-5432. [5] Greeley R. and Guest J. E. (1987) USGS Geol. Invest. Ser. Map I-1802B. [6] Mest S. C. and Crown D. A. (2002) USGS Geol. Invest. Ser. Map I-2730. [7] Mest S. C. and Crown D. A. (2003) USGS Geol. Invest. Ser. Map I-2763. [8] Price K. H. (1998) USGS Misc. Invest. Ser. Map I-2557. [9] Mest S. C. and Crown D. A. (2005 in press) USGS. [10] Crown D. A. and Greeley R. (2005 in review) USGS. [11] Pierce T. L. and Crown D. A. (2003) Icarus, 163, 46-65. [12] Mangold N. (2003) JGR, 108, doi: 10.1029/ 2002JE001885. [13] Chuang F. C. and Crown D. A. (2005 in press) Icarus. [14] Crown D. A. et al. (2004) in 2nd Conf. on Early Mars, \#8027. [15] Crown D. A. et al. (2005) LPSC XXXVI, \#2097. [16] Crown D. A. et al. (2004) LPSC $X X X V$, \#1185. [17] Crown D. A. et al. (2005 in review) JGR. [18] Moore J. M. and Wilhelms D. E. (2001) Icarus, 154, 258276. [19] McGill G. E. (2002) USGS Geol. Invest. Ser. Map I2746. [20] Parker T. J. et al. (1989) Icarus, 82, 111-145. 
MTM QUADRANGLES -15257 \& -20257: WESTERN HESPERIA PLANUM, MARS. Melissa A. Farley ${ }^{1}$, Tracy K.P. Gregg ${ }^{1}$, and David A. Crown ${ }^{2}$, ${ }^{1}$ Dept. of Geology, 876 Natural Sciences Complex, University at Buffalo, Buffalo, NY 14260-3050, mafarley@acsu.buffalo.edu, tgregg@geology.buffalo.edu, 2Planetary Science Institute, Tucson, AZ, dcrown@psi.edu.

Introduction: Hesperia Planum, Mars plays two significant roles in Martian geology and stratigraphy. First, it is considered to be the type location for Martian ridged plains [1]; second, its crater size-frequency distribution derived from Viking Orbiter (VO) images marks the base of the Hesperian system [2]. The volcano Tyrrhena Patera is located within the western portion of Hesperia Planum and is characterized by broad, low relief flanks that are dissected by numerous radial channels. Detailed investigations of the summit region [3] agree with earlier, regional studies [4], which suggest that Tyrrhena Patera shield materials are pyroclastic in nature. However, the youngest materials erupted from Tyrrhena Patera appear to be lava flows associated with a large $(\sim 1000 \mathrm{~km}$ x $250 \mathrm{~km})$ lava flow field that extends southwest of the summit [3]. Geologic mapping and impact crater statistics [3] reveal that a significant part of the region previously mapped as Hesperia Planum [1] is either Late Noachian-Early Hesperian-aged shield materials or Amazonian-aged lava flows associated with Tyrrhena Patera. MTM Quadrangles -15257 and -20257 (Fig. 1) harbor the contact between what was once considered Hesperia Planum materials $[1,3]$ and the Noachian-aged highlands to the west. Using MOLA, MOC, and THEMIS data in conjunction with VO images, we have identified four key results from photogeologic mapping of western Hesperia Planum. First, Tyrrhena Patera shield materials extend all the way to the Noachianaged highlands west of Hesperia Planum, with a maximum extent of $\sim 700 \mathrm{~km}$ northwest of the summit. Shield deposits located at distances on the order of $10^{2} \mathrm{~km}$ are likely the result of pyroclastic flows [3,4,5]. Given Mars' current atmosphere, airfall deposits are unlikely to have reached more than a few tens of kilometers from the summit [5]. The presence of pyroclastic flow deposits is further supported by the lack of primary flow features within the shield materials. Second, the shield materials are layered, suggesting multiple eruptive or cooling units. Third, no lava-flow features or volcanic source vents have been identified within the Martian ridged plains of Hesperia Planum. Fourth, THEMIS data (both thermal and visible) reveal much more fluvial erosion in this region than was visible in VO data.

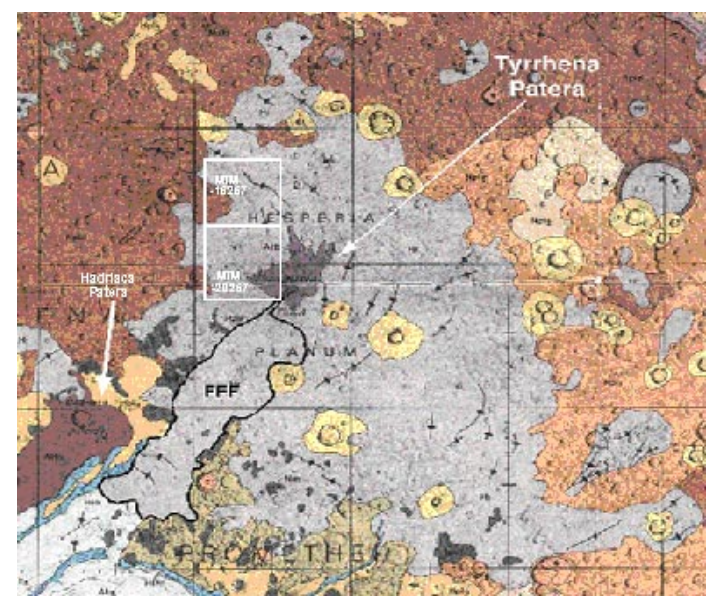

Figure 1. MTM Quadrangles -20257 and -15257 (white boxes) on the 1:15M geologic map of Mars [1]. Regions shaded light gray represent the Hesperia Planum ridged plains; the dark gray area is Tyrrhena Patera. An Amazonian-aged lava flow field (FFF), associated with Tyrrhena Patera, is also shown.

Tyrrhena Patera shield materials: Dissected shield materials have been identified up to $\sim 700 \mathrm{~km}$ NW from the summit region and embay the Noachian highlands to the west. Recent investigations of Tyrrhena Patera deposits [6,7] reveal that the shield materials cover about a fourth of what was originally mapped as Hesperia Planum [1]. Shield materials are characterized by a smooth to locally hummocky surface, typically bound by steep erosional scarps. However, as the distance from the summit increases, the height of the bounding scarps decreases. Several locations within the shield deposits have stacked or stairstepping scarps, which are interpreted to indicate multiple eruptive or cooling units of pyroclastic flows. The easily eroded nature of the shield materials, combined with extremely low flank slopes ( $<1$ degree), suggest that the edifice is composed of pyroclastic materials [3,4]. At least four shield layers have been identified using the elevation and location of bounding scarps. Given the available data, material differences between the four shield units are not visible. Generally, the scarps are continuous and show consistent elevation variations between steps, making scarps a useful and reliable factor in shield unit identification. 
Hesperia Planum: Previous 1:500K mapping of the Tyrrhena Patera summit region [3] classified a region north of the summit caldera complex as "ridged and etched plains." These materials are also found in MTM Quadrangles -20257 and -15257. THEMIS images reveal that this unit is actually comprised of interfingered plains materials, some of which appear to be variably eroded shield materials erupted from Tyrrhena Patera. Other portions appear to be lobate flow deposits, which originated somewhere north of Tyrrhena Patera and flowed southwards to embay the shield materials. A sedimentary origin rather than a volcanic origin is favored, because no volcanic vents north of Tyrrhena Patera have been identified.

Channels and Erosion: Investigation of THEMIS data has revealed numerous channels not visible in the VO images. A region northwest of the Tyrrhena Patera summit consists of cross cutting, orthogonal channels, which bound $<100 \mathrm{~m}$ tall mesas of Tyrrhena Patera shield materials (Fig. 2). Smooth-sided ledges $(<50 \mathrm{~m}$ tall) surround the mesas and mimic their overall shape. In many places the ledges form the walls of the channels, producing the observed orthogonal channel pattern (Fig. 2). A smooth channel-fill material lies within the orthogonal channels and is interpreted to be reworked shield material transported downlsope by both fluvial and mass wasting processes. The ledges exist within a material that has thermal properties similar to the smooth channel-fill and may represent stream terraces. This area has been informally called "peanut-butter cookie terrain" and is interpreted to be the erosional remnants of Tyrrhena Patera shield materials. The nature of the erosion remains under investigation but current evidence suggests that the erosive agent may be water. Channel heads here are morphologically similar to terrestrial sapping channels $[8,9,10]$ and the orthogonal pattern suggests strong structural control.

Several first-order sinuous channels (up to $\sim 200 \mathrm{~km}$ long) with widths of $\sim 1 \mathrm{~km}$ have been identified within the low-lying plains that surround the Tyrrhena Patera shield materials. Locally, the channels exhibit terraces and crosscut wrinkle ridges. The sinuous channels may represent one of the youngest geologic events in the region.

Summary: Many regions previously mapped as Hesperia Planum ridged plains material $[1,3]$

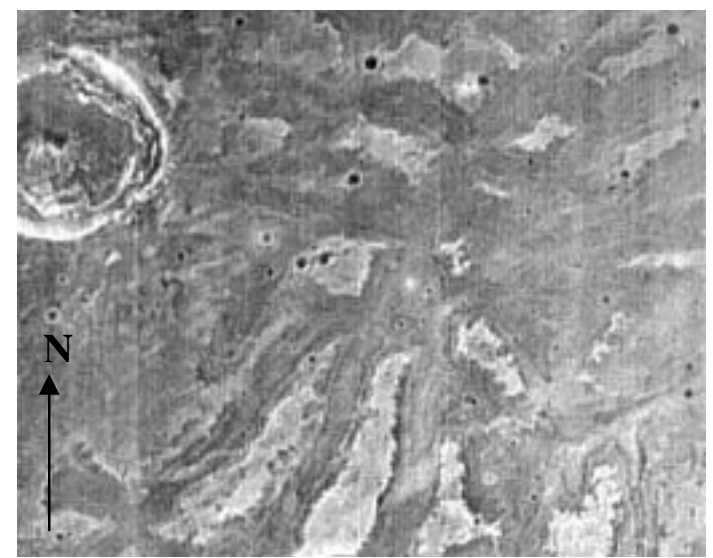

Figure 2: THEMIS-Nighttime IR mosaic of I06407014 and I06045006. Images show "peanut butter cookie terrain” with orthogonal channels and channel-parallel ledges. Mosaic width is approximately $35 \mathrm{~km}$ for scale.

actually consist of layered shield materials associated with Tyrrhena Patera and smooth channel-fill material transported via channel networks. At least four shield deposits have been identified based on the location and elevation of bounding scarps, and are interpreted to be pyroclastic flow deposits. After the emplacement of shield materials, numerous channels formed on the on the flanks of Tyrrhena Patera, and may be the result of lava flows, volcanic density currents, or surface runoff. However, these channels now have broad, flat floors, with theater-shaped heads suggesting modification by groundwater sapping. The shield materials were dissected and redeposited as smooth-channel fill material within many lowlying regions of Hesperia Planum. Regional stresses produced wrinkle ridges across Hesperia Planum, which controlled the orientation of many channel networks. However, some narrow, sinuous channels appear to cross-cut large wrinkle ridges, suggesting that erosion and tectonism were long-lived, concurrent events.

References: [1] Greeley, R. and Guest, J. E. (1987) USGS Misc. Invest. Ser. Map I-1802-B. [2] Tanaka, K. (1986) LPSC 17 ${ }^{\text {th }}$, Houston, March 17-21, 1985, Proceedings: Part I, JGR, 91, suppl., E139-E158. [3] Gregg, T. K. P., et al. (1998) USGS Misc. Invest. Ser. Map I-2556. [4] Greeley, R. and Crown, D. A. (1990) JGR 95, B5, 71337149. [5] Glaze, L. S. and Baloga, S. (2002) JGR, 107, 1-11. [6] Gregg, T. K. P., et al. (2000) GSA abstracts, 32, 7, 500. [7] Farley, M. A., et al. (2004) PGG Mappers Meeting abstract. [8] Higgins, C. G. (1984) Groundwater as a geomorphic agent, 18-58. [9] Laity, J. E. and Malin, M. C. (1985) Bull. Geol. Soc. Amer. 96, 203-217. [10] Gulick, V. C. and Baker, V. R. (1990) JGR 95, B9, 14325-14344. 
LOIRE VALLES TO NEWCOMB CRATER: “TRACING” THE VALLEYS BACK TO THEIR SOURCES. C.M. Fortezzo ${ }^{1}$, K.K. Williams ${ }^{1}$, J.A. Grant ${ }^{1},{ }^{1}$ Center for Earth and Planetary Studies, National Air and Space Museum, Washington, D.C., 20013-7012,fortezzoc@si.edu.

Introduction: Mapping of MTMs -20012 and -25012 in southeast Margaritifer Terra, Mars [1-4] is complete, but questions still remain about the origin and temporal extent of the dense valley networks of Paraná Valles. Newly funded mapping of 4 additional MTM quads (-20007, $-25007,-20002,-25002)$ to the east, headward of Paraná Valles, may better constrain the origin and timing of the hydrologic history in the region.

Examining the relationship between valley networks on the flanks of Newcomb crater in the east and those of Paraná Valles in the west as both a continuous basin and as separate sub-basins may reveal more information about the processes and timing that shaped the geomorphology of the region.

MTM -20012 \& -25012: Three areas within the completed mapping region are of particular interest because of their unique features.

A $\sim 35 \mathrm{~km}^{2}$ deltaic deposit (Figure 1a) with multiple channel features within a breached $\sim 30 \mathrm{~km}$ wide crater (centered at 23.5S, 347.75E) preserves two episodes of flow. The most recent well-preserved valley cuts the delta, meanders south and flows along the southern margin of the original deposit before becoming indistinguishable from the crater floor resurfacing deposit. Another less well-preserved channel runs across the delta and around a group of small knobs mapped as an island of positive relief chaotic terrain. This crater is breached on the northern rim and has a valley flowing out into Paraná basin and its chaotic terrain.

The $\sim 7000 \mathrm{~km}^{2}$ of positive relief chaotic terrain (Figure 1b) in the center of the map area (22S, 348.5E) consists of closely spaced elongate plateaus, buttes, knobs and linear ridges of similar heights separated by troughs which lack an apparent preferred orientation. Although this area is termed chaotic, it has been interpreted as erosional remnants, most likely associated with standing water or groundwater discharges, or an alteration caused by deflation in some areas.

Formed by drainage on the western flank of Paraná basin, Loire Valles (Figure 1c) is a large valley comprised of dense, well-integrated, small valley network tributaries. Catastrophic discharge of Paraná basin caused the rapid downcutting and headward erosion of the main branch of Loire Valles. Drop in base level followed by rapid incision of the tributaries and subsequent piracy of the once eastern draining tributaries formed the current preserved morphology.
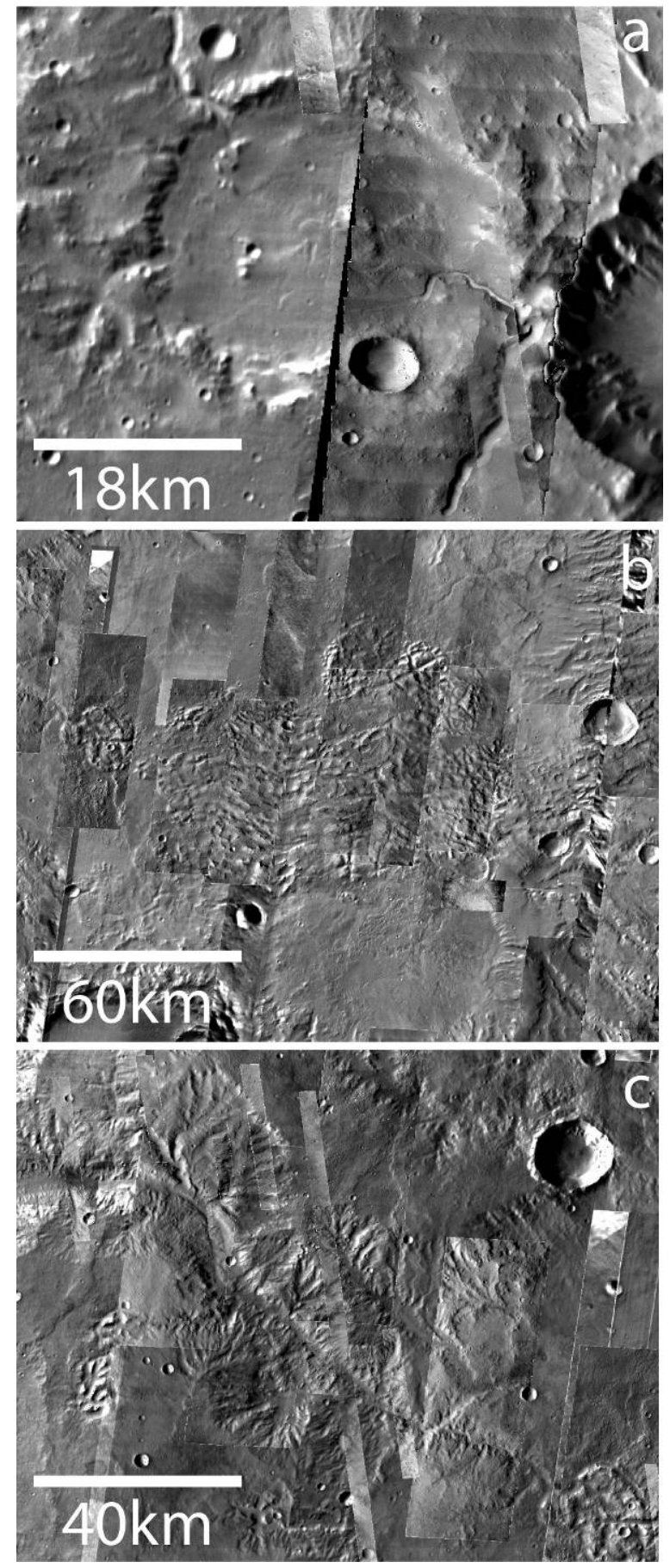

Figure 1: Three mosaics of MDIM, THEMIS daytime IR and MOC Narrow Angle images. a) Deltaic deposit in a breached crater. b) Chaotic terrain in the Paraná basin. c) Head and highly dissected valley of Loire Valles. 
New Mapping Area: The Newcomb-Paraná area (MTMs -20002, -20007, -25002, and -25007; Figure 2) covering $0^{\circ}$ to $10^{\circ} \mathrm{W}$ and $17.5^{\circ}$ to $27.5^{\circ} \mathrm{S}$ will be mapped to determine the relative ages of resurfacing events in upper Paraná Valles to examine how valleys either incise or are mantled by resurfacing deposits within the Newcomb-Panará region. In addition to traditional crater counting methods for large areas, crater counting techniques designed for calculating the ages of narrow, linear features $[5,6]$ will be used to establish comparative ages of the valley networks relative to each other. Tanaka [5] noted that although counting fewer small craters results in errors of $\sim 30 \%$ for N1, N2 and N3 cumulative ages (ages most likely calculated for this study), this amount of error is not overly detrimental to determinations of relative age. With higher resolution data (i.e. THEMIS Daytime IR and Visible images), higher counts of craters with diameters $<5 \mathrm{~km}$ will be possible, thus leading to less error. This analysis will be performed on the Paraná Valles network and the network on the western flank of Newcomb crater, and the results will be compared to determine their ages relative to each other. Cumulative crater densities will then be calculated for sub-basins within the dense valley networks to compare the timing of activity among sub-basins. Determining the formational timing of valley networks relative to each other may further constrain the role and persistence of water in the region.

If the results of crater counts show that valley networks formed simultaneously, it would suggest that groups of basins and sub-basins over a region are related, which suggests an areally extensive period of water-driven erosion. However, Paraná Valles and the valley network on the west flank of Newcomb crater do not currently display linked valleys at the surface but it is possible that they were linked hydrologically in the past. One possible scenario is that the valley networks could have been connected when they were active but evidence of their connection is obscured by later resurfacing events (i.e. volcanic resurfacing or crater impactslejecta). The second scenario is that the valleys are not linked at the surface but are linked by a groundwater network. For example, precipitation pools and infiltrates into the subsurface in catchments upslope then seeps out along steeper slopes, such as crater rims, as the groundwater stair-steps down the regional relief toward the Martian lowlands.

Alternatively, if the results of the mapping and crater counting show that basins were not active contemporaneously, it may indicate that valley forming processes were local events that shaped different basins at different times. Resurfacing events may have redistributed active valleys or halted flow in one basin and/or caused the emergence of new basins in an adjacent region.

References: [1] Grant J. A. and D. A. Clark (2002) Planetary Mappers Meeting (abst.). [2] Williams, K. K. and J. A. Grant (2003) Planetary Mappers Meeting (abst.). [3] Fortezzo, C. M. and J. A. Grant (2004) Planetary Mappers Meeting (abst.). [4] Grant, J. A., K. K. Williams, and C. M. Fortezzo (2005) see this volume. [5] Tanaka, K. L. (1982) NASA Tech. Memo., 85127, 123-125. [6] Wichman, R. and P. H. Schultz (1987) NASA Tech. Memo., 89810, 474-475.

Figure 2: MTM location map. Four black squares in the southeast show the new Newcomb-Panará mapping area

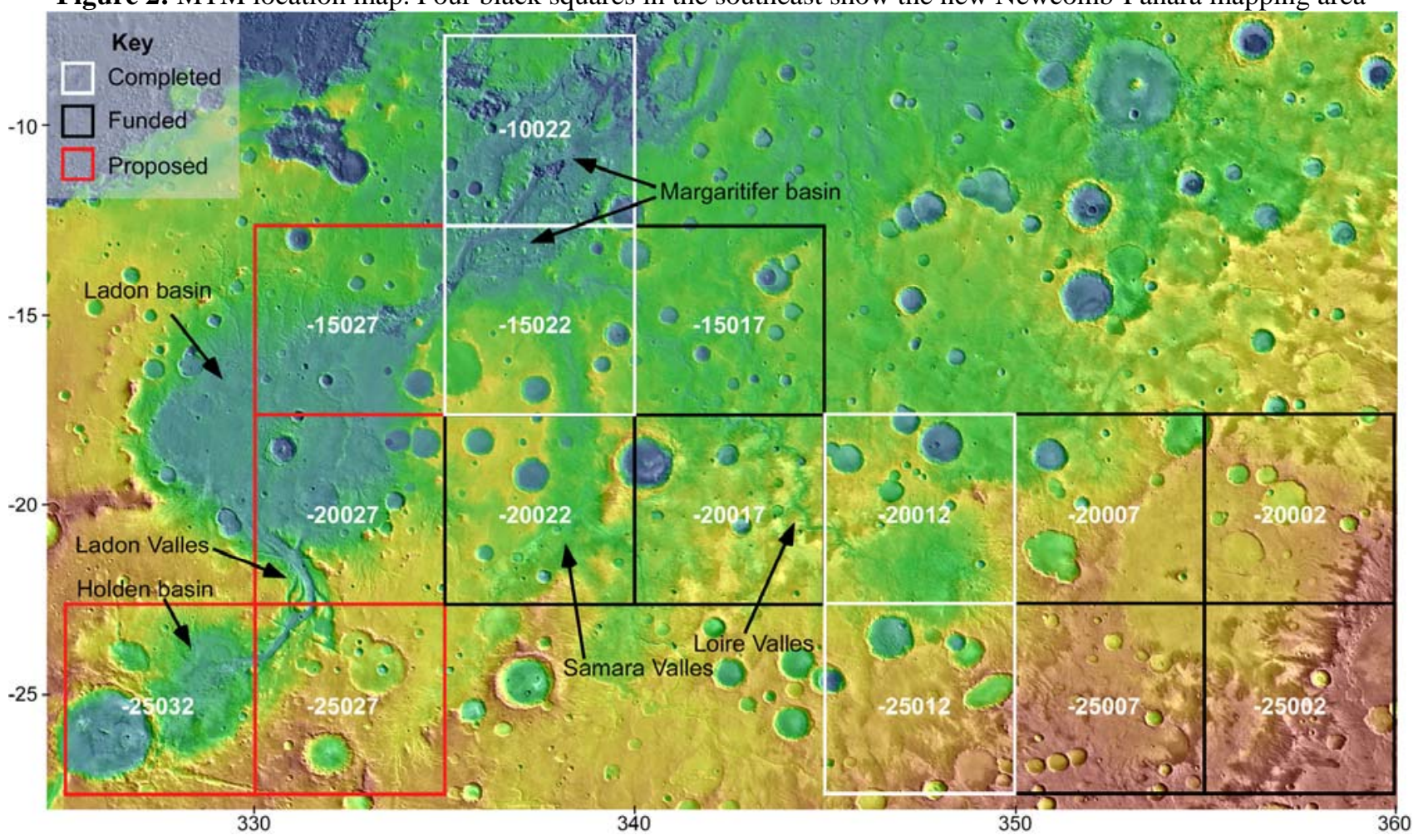


MAPPING IN MARGARITIFER TERRA: COMPLETED, UNDERWAY, AND PROPOSED. J. A. Grant ${ }^{1}$, K. K. Williams ${ }^{1}$, and C. M. Fortezzo ${ }^{1},{ }^{1}$ Center for Earth and Planetary Studies, National Air and Space Museum, Smithsonian Institution, Washington, D.C. 20560.

Introduction: Margaritifer Terra (Fig. 1) records a complex geologic history [1-6] along the flanks of the Chryse trough [7]. Completed mapping at 1:500,000 (Figs. 2-4) details a complex history of water transport, storage, and release along the Uzboi-Holden-LadonMargaritifer (UHLM) northward-flowing mesoscale outflow system on the west side of the trough [2] and the Samara and Paraná-Loire valley systems on the east side of the trough [3-5] that merge in Margaritifer basin near the head of Ares Vallis [5].

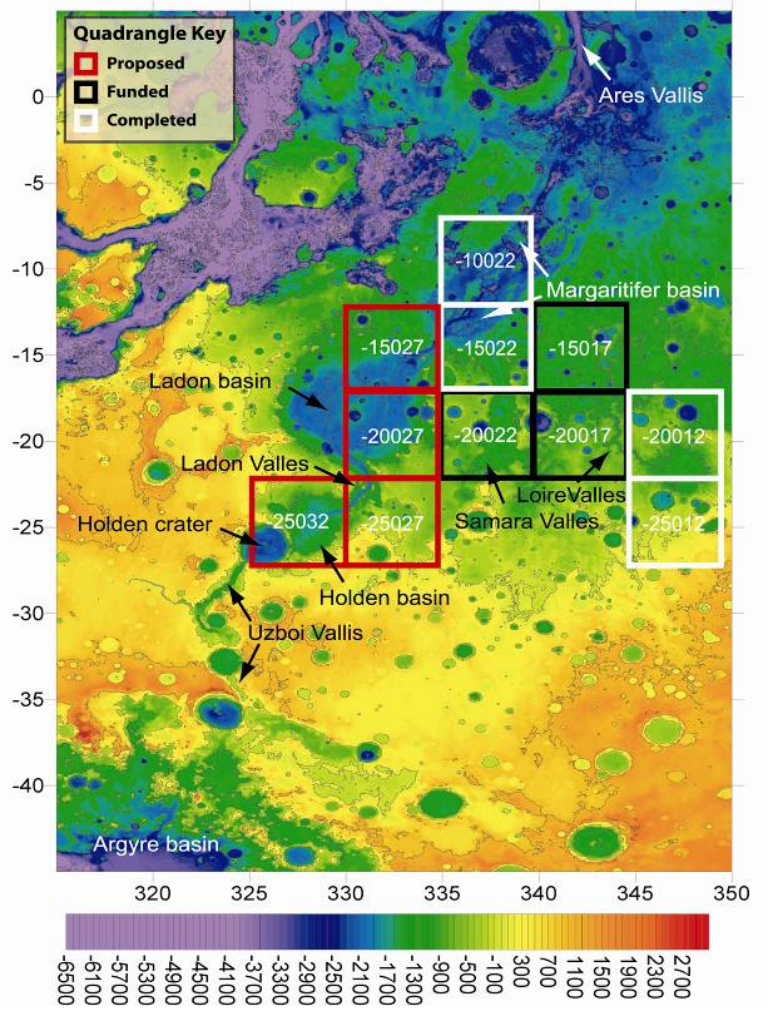

Figure 1. MOLA Topography of Margaritifer Terra region. Completed MTM maps (white boxes), funded maps (black boxes) and proposed maps (red boxes) are shown. Contour interval is $1 \mathrm{~km}$ and north is towards the top of the image.

Mapping (Figs. 2-4) identifies the degraded Ladon and Holden multi-ringed impact basins [8] as the oldest features in Margaritifer Terra whose formation was followed by evolution of the cratered upland surface and widespread resurfacing events that deposited materials interpreted to be of mostly volcanic origin on the basis of wrinkle ridges and occasionally lobate morphology [5]. The first two events occurred during the early to middle Noachian with the second ending at an N5 age of around 1000 (number of craters $>5 \mathrm{~km}$ in diameter per $1,000,000 \mathrm{~km}^{2}$ ). The third resurfacing event began in the late Noachian (N5 age 300) was coincident with waning highland volcanism. A final, more localized resurfacing event began in the middle Hesperian (N5 age 130) and emplaced material that usually embays many valleys and channels. Additional mapping of the Samara and Paraná-Loire and adjacent drainages is underway (Fig. 1) that should help place additional constraints on the timing and extent of valley formation. Nevertheless, most drainage along the UHLM and valley systems extended into the midHesperian (N5 150), but apparently concurrent late flow and local volcanic activity occurred along and near the UHLM system into the early Amazonian (N5 40) after the last resurfacing event.

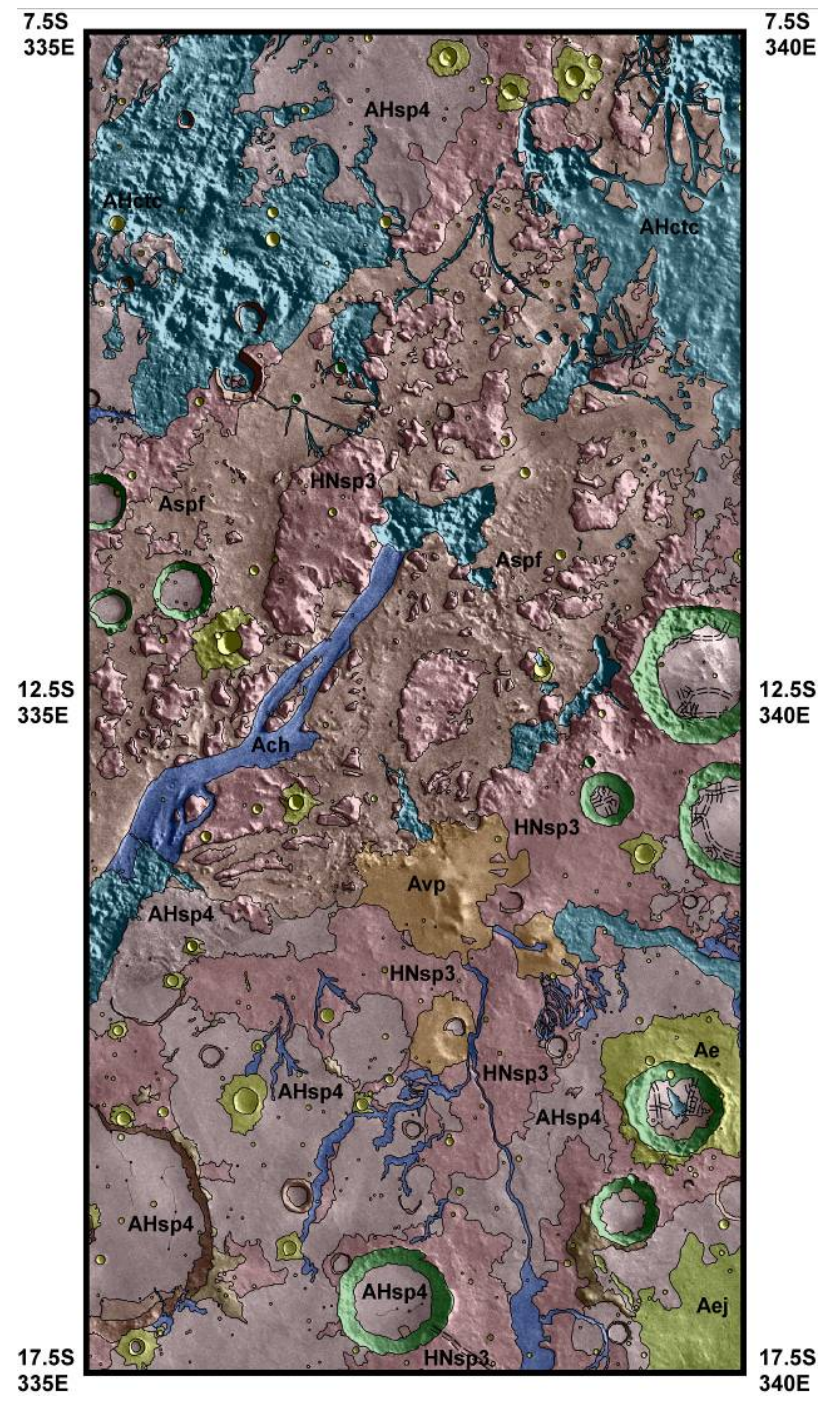




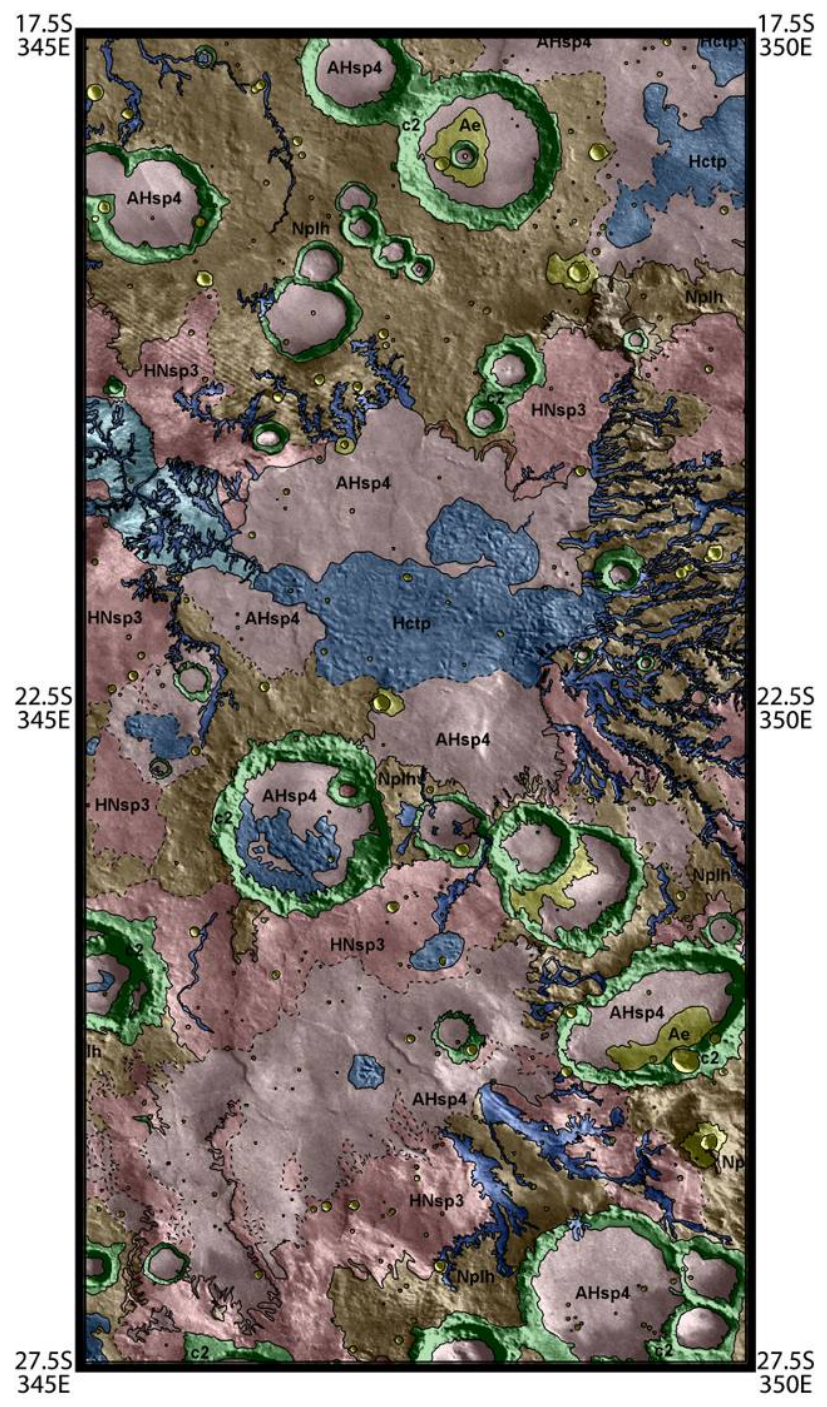

Figures 2 and 3. Completed 1:500,000 maps of MTM -10022, -15022 (on previous page) and -20012 and -25012 (above) covering the Margaritifer basin confluence of the UHLM, Samara, and Parana-Loire systems and the headward reaches of the Parana-Loire systems, respectively. Mapped units are described in Figure 4.

Margaritifer basin (Fig. 2) received discharge from UHLM and Samara and Paraná-Loire Valles. Smooth plains embay most adjacent surfaces (except those cut by chaos) and characterize the basin floor whose northeastern extent is indistinct due to collapse of Margaritifer and Iani Chaos [9]. The plain extends at least to the head of Ares Vallis and water discharged into Margaritifer basin likely resulted in considerable ponding, subsurface infiltration, and storage of water that was followed by collapse to form Margaritifer and Iani Chaos (Fig. 2), re-release of stored water, and incisement of Ares Vallis. Nevertheless, the source and role of late stage discharge from the UHLM system that may have triggered formation of Ares Vallis remains unresolved. Additional maps of the Holden crater and Ladon basin areas (Fig. 1) are being proposed in order to evaluate possible sources and causes for late discharge through the UHLM system.

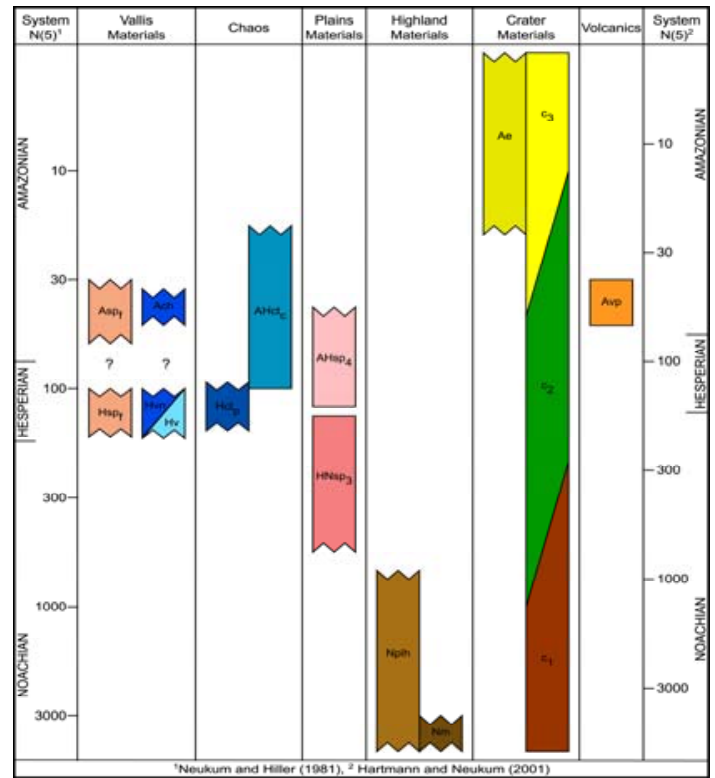

Figure 4. Correlation of mapped units in Figures 2 and 3. Relative ages are expressed as the number of craters larger than $5 \mathrm{~km}$ in diameter per 1,000,000 $\mathrm{km}^{2}$ and were derived via comparison to [10] and [11] on the left side and right side, respectively. Ae and $c_{3}$ are Amazonian ejecta and well preserved craters. Avp are Amazonian volcanic/pyroclastics. $A s p_{f}$ are Amazonian fluvial deposits. Ach are Amazonian channels. $A H_{c t}$ are Amazonian/Hesperian collapsed chaotic terrain. $\mathrm{AHsp}_{4}$ are the Amazonian/Hesperian smooth plain resurfacing event. $c_{2}$ are moderately degraded craters. $H s p_{f}$ are Hesperian fluvial deposits. $H v n$ and $H v$ are Hesperian valley network and valley units. Hct $_{p}$ are Hesperian positive relief chaotic terrain. $\mathrm{HNsp}_{3}$ are the Hesperian/Naochian smooth plains. $c_{3}$ are highly degraded craters. $\mathrm{Nplh}$ and $\mathrm{Nm}$ are the Noachian hilly plateau unit and mountainous unit.

References: [1] Saunders, S. R, (1979) USGS Map I1144. [2] Parker, T. J. (1985) MS Thesis, Cal. State Univ., LA. [3] Grant, J. A. (1987) NASA Tech. Memo. 89871, 1268. [4] Grant, J. A. (2000) Geology, 28, 223-226. [5] Grant, J. A., and Parker, T. J. (2002) J. Geophys. Res., 107, 10.1029/2001JE001678. [6] Hynek, B. M., and R. J. Phillips (2001) Geology, 29, 407-410. [7] Phillips, R. J., et al. (2001) Science, 291, 2587-2591. [8] Schultz, P. H., et al. (1982) J. Geophys. Res., 87, 9803-9820. [9] Rotto, S. and K. L. Tanaka (1995) USGS Map I-2441. [10] Neukum, G. and Hiller K. (1981) J. Geophys. Res., 86, 3097-3121. [11] Neukum, G. and B. A. Ivanov (2001) Lunar Planet. Sci. Conf. XXXII, Abs. 1757, LPI, Houston, TX. 
Geologic Mapping of Hesperia Planum, Mars. Tracy K.P. Gregg ${ }^{1}$ and D.A. Crown ${ }^{2}$, ${ }^{1}$ Dept. of Geology, 876 Natural Sciences Complex, University at Buffalo, Buffalo, NY, 14260, tgregg@geology.buffalo.edu, ${ }^{2}$ David A. Crown, Planetary Science Institute, Tucson, AZ, crown@psi.edu.

Introduction: Hesperia Planum, Mars, characterized by a high concentration of mare-type wrinkle ridges and ridge rings [1-4], encompasses a region of over 2 million square kilometers in the southern highlands (Fig. 1). The most common interpretation is that the plains materials were emplaced as "flood" lavas that filled in low-lying regions [5-10]. Deposit thickness, based on partially buried craters, is $<3 \mathrm{~km}$ [4]. Its stratigraphic position and crater-retention age [e.g., 9, 11, 12] define the base of the Hesperian system. In addition, the maretype wrinkle ridges on its surface make Hesperia Planum the type locale for Martian "Hesperian-aged ridged plains" [e.g., 9]. In spite of this significance, there are still many unresolved issues surrounding the formation and evolution of Hesperia Planum.

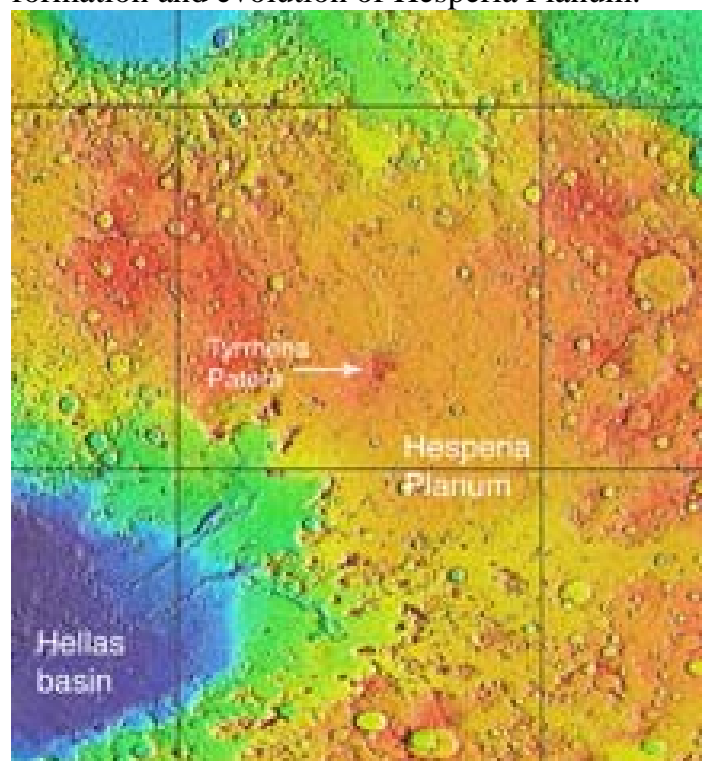

Figure 1. MOLA DEM indicating the location of Hesperia Planum, the smooth region to the northeast of Hellas basin. The volcano Tyrrhena Patera is indicated.

Recent investigations have focused on the deposits of Tyrrhena Patera, a low-relief, central-vent volcano located within Hesperia Planum near the western boundary between Hesperian ridged plains and Noachian-aged highlands (as mapped by Greeley and Guest [9]). Greeley and Crown [13] determined that a significant portion of what had been mapped as Hesperia Planum is actually volcanic deposits from Tyrrhena Patera. They mapped a young lava flow field extending from the Tyrrhena Patera summit $\sim 1000 \mathrm{~km}$ to the southwest. Subsequent mapping and crater size-frequency distributions suggested an Amazonian age for this flow field [14]. Further analyses [13-16] suggested that easily eroded volcanic deposits (interpreted to be pyroclastic deposits, probably flows) from Tyrrhena Patera extend several hundred kilometers to the northwest. Thus, only about one-third of what had originally been identified as Hesperia Planum ridged plains remains as such. In addition, Mest and Crown [17] map a dissected plains unit to the south of Tyrrhena Patera that may be a portion of Hesperia Planum modified by fluvial activity, and Crown and Mest [18] note significant drainage from Hesperia Planum to the south, both in the source region of Reull Vallis and to the east.

Hesperia Planum Deposits: It has been proposed [1, 7] that Hesperia Planum is composed of fluid-probably basaltic_lavas. However, aside from Tyrrhena Patera, no obvious volcanic vents have been found [cf. 4, 13, 15, 17-19]. Detailed mapping of the upper reaches of Dao, Harmakhis and Reull Valles have revealed that although fluvial channels can be observed in or near the southern portions of Hesperia Planum, no lava flow lobes or lava channels can be seen [20]. This is also the case in southeastern Hesperia Planum [21]. Investigation of available THEMIS data, in both infrared and visible wavelengths, does not reveal any volcanic vents or obvious volcanic flows. (Note that volcanic flows can be observed in VO, MOC, MOLA and THEMIS data within the Tyrrhena Patera lava flow field [e.g., 4].) This calls into question the interpretation of Hesperia Planum as being exclusively volcanic in origin. Even on the ancient lunar maria, lava flow lobes and channels have been observed [e.g., 22]. It is useful, therefore, to critically evaluate other possible origins for Hesperia Planum, including (but not limited to) aeolian, sedimentary, or pyroclastic deposits. It is possible that a number of different geologic processes contributed to Hesperia Planum materials through time and space. The channels in the upper reaches of Reull Vallis [17, 18] and those to the east, for example, suggest at least a partial sedimentary component to parts of the ridged plains.

Other Hypotheses: Pyroclastic deposits from Tyrrhena Patera. Current mapping of Tyrrhena Patera indicates that layered, easily eroded materials 
can be traced from the Tyrrhena Patera summit as far as $700 \mathrm{~km}$ to the northwest. The deposit characteristics are consistent over this distance, except that observed layers within the material become thinner distally. This is consistent with the behavior of pyroclastic flow deposits. Results from recent modeling [21] indicate that, all eruption conditions being equal, a Martian pyroclastic flow should be able to travel $3-4$ times farther than an identical flow on Earth. A difficulty with this hypothesis is that Hesperia Planum materials appear to embay the construct of Tyrrhena Patera on the eastern flanks of the volcano.

Lacustrine Deposits. Materials in western Hesperia Planum are layered and relatively flat-lying, with a regional slope of $<0.1^{\circ}$. Layers are not observed in the eastern portion of Hesperia Planum, but the eastern portion contains a greater number of more closely spaced wrinkle ridges. Available evidence suggests that the formation of wrinkle ridges is enhanced in layered materials [4]. Sediments deposited in a standing body of water would generate flat-lying, layered sequences. No obvious shoreline has yet been identified, but we are examining Mars Obiter Laser Altimeter data to determine if the boundaries of Hesperia Planum deposits are at the same elevation. If so, this would be consistent with a lacustrine origin for at least some of the Hesperia Planum deposits [cf. 22]. However, this observation would not preclude flood lavas.

Reworked Volcanic Deposits. The layered materials in western Hesperia Planum are associated with Tyrrhena Patera. It is possible that they are reworked and redeposited volcanic deposits, rather than primary pyroclastic flow deposits. Water would be the most likely reworking agent, although the abundant dunes observed within Hesperia Planum indicate that wind is (or has been) an effective erosion and transport agent in the region.

Hypotheses Testing: The hypotheses presented will be difficult to distinguish without careful mapping of the region and characterization of the Hesperia Planum deposits. Furthermore, materials in western Hesperia Planum appear to have a distinct origin from those in the east. Western Hesperia Planum deposits are layered and eroded, with few wrinkle ridges; eastern Hesperia Planum materials do not display obvious layers or erosional scarps, and contain abundant, orthogonal and intersecting wrinkle ridges. If the layered Hesperia Planum materials are lacustrine sediments, the proximity of Tyrrhena Patera makes it likely that the sediments would be composed of volcanic materials from that volcano.
We have been funded to generate a geologic map of the Hesperia Planum region (Figure 2) to address these issues.

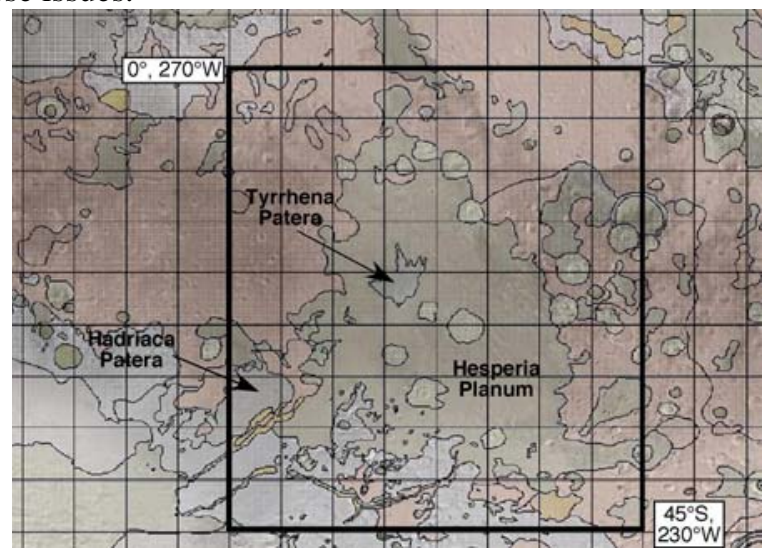

Figure 2. Global geology of Hesperia Planum, as mapped by Greeley and Guest [1987], superposed on Viking Mars Digital Image Mosaic. Proposed map area outlined in black. Large brown region is Hesperian Ridged Plains (unit $\mathrm{Hr}$ ). Grid is $5^{\circ}$. (Modified from PIGWAD.)

References: [1] Scott, D. A. and M. Carr (1978) USGS Misc. Series I-1083. [2] Chicarro, A. F., P. H. Schultz and P. Masson (1985) Icarus 63:153. [3] Watters, T. and D. J. Chadwick (1989), NASA Tech. Rpt. 89-06:68. [4] Goudy, C. and T. Gregg (2002) LPSC 33 Abstract \#1135. [5] Potter, D. B. (1976) USGS Misc. Series I-941. [6] King, E. A. (1978) USGS Misc. Series I-910. [7] Greeley, R. and P. Spudis (1981) Rev. Geophys. 19:13. [8] Scott, D. A. and K. Tanaka (1986) USGS Misc. Series I-1802A. [9] Greeley, R. and J. Guest (1987) USGS Misc. Series I-1802B. [10] Leonard, J. G. and K. Tanaka (2001) USGS Misc. Map Series I-2694. [11] Tanaka, K. (1986). [12] Tanaka, K. (1992) in Mars, U. Arizona Press, p. 345. [13] Greeley, R. and D. A. Crown (1990) J. Geophys. Res. 95:7133. [14] Gregg, T. K. P., D. A. Crown and R. Greeley (1998) USGS Misc. Series I-2556. [15] Crown, D. A., R. Greeley and K. Price (1992) Icarus 100:1. [16] Gregg, T. K. P. and D. A. Crown (2004) IAVCEI General Assembly Abstract. [17] Mest, S. and Crown, D. A. (2001) Icarus 153:89. [18] Crown, D. A. and S. Mest (2004) USGS Open File Rpt. 2004-1289. [19] Farley, M. A., T. K. P. Gregg and D. A. Crown (2004) USGS Open File Rpt. 2004-1100. [20] Schaber, G., J. M. Boyce and H. J. Moore (1976) Proc. LPSC 7:2783. [21] Gregg, T. K. P. and D. A. Crown (2004) IAVCEI General Assembly. [22] Head, J. W., D. Smith and M. Zuber (1998) Meteor. Planet. Sci. 33(4):A66. 
GEOLOGIC MAP OF THE MTM 85200 QUADRANGLE, PLANUM BOREUM REGION OF MARS.

K. E. Herkenhoff and J. A. Skinner, Jr., U. S. Geological Survey, 2255 N. Gemini Dr., Flagstaff, AZ 86001 (kherkenhoff@usgs.gov).

Introduction: The polar deposits on Mars likely record and display the climate history of Mars over the last $10^{7}$ to $10^{9}$ years [1]. To fully appreciate this history, we require a clear delineation of the geologic character of the polar layer deposits. Recent topographic and spectral reflectance datasets provide not only diverse content, but also a broad slice of spatial resolution that can tremendously improve the vertical and lateral delineation of layered sequences within the polar deposits.

The area of this 1:500,000-scale map includes polar layered deposits and polar ice, as well as dunes of Olympia Undae. This quadrangle was mapped in order to study the relations among erosional and depositional processes on the north polar layered deposits and to compare them with the results of previous 1:500,000-scale mapping of the south polar layered deposits [2-3]. The MTM 85200 quadrangle extends from 140 to $180^{\circ} \mathrm{E}$ longitude and from 82.5 to $87.5^{\circ} \mathrm{N}$ latitude and covers $\sim 61,000 \mathrm{~km}^{2}$ of the north polar plateau. Within the boundaries of the study area are ancient, eroded basal units overlain by more recent layered deposits, aeolian mantles, and seasonal frost.

The polar ice cap, areas of partial frost cover, the layered deposits, and two nonvolatile surface units-the dust mantle and the dark material--were mapped in the south polar region [4] at 1:2,000,000 scale using a color mosaic of Viking Orbiter images. During reconnaissance studies, we constructed Viking Orbiter (VO) color mosaics (revs 726, 768 and 771, acquired taken during the northern summer of 1978) and used them to identify similar color/albedo units in the north polar region, including the dark, saltating material that has a low thermal inertia [6] and appears to source from within the layered deposits [5]. Because the resolution of the color mosaics is not sufficient to map the color/albedo units in detail at 1:500,000 scale, contacts between them were recognized and mapped using higher resolution black-and-white VO images.

No craters are identified in the north polar layered deposits or polar ice cap in the map area [7-8]. The observed lack of craters larger than $300 \mathrm{~m}$ implies that the surfaces of these units are no more than 100,000 years old or that they have been resurfaced at a rate of at least $2.3 \mathrm{~mm} / \mathrm{yr}$ [8]. The recent cratering flux on Mars is poorly-constrained, so inferred resurfacing rates and ages of surface units are uncertain by at least a factor of 2 .

Datasets and Methods: Geologic mapping has begun in earnest with the very significant addition of
Mars Global Surveyor (MGS) and Mars Odyssey (MO) datasets, which supplement original, VO-based reconnaissance mapping results. The original basemap image components were acquired during the 1978 northern summer and were compiled specifically for the purposes of geologic mapping. MGS datasets used in this study consist of the MOLA gridded topography dataset and MOC narrow-angle images. The MOLA dataset covers the entire quadrangle at a resolution of $512 \mathrm{pixel} /$ degree (115 m/pixel). Derived MOLA products include point-to-point slope maps and high-pass filtered (slope detrended) images to reveal local topographic variations and surface morphologies. MOC narrow-angle images are invaluable in the identification and mapping of individual and packages of layered sequences. There are 257 MOC images with a pixel resolution of $<100$ meters that collectively cover $27 \%$ of the entire MTM 85200 quadrangle. The primary MO dataset that has been adapted and used in this study is the THEMIS image catalog, which contains visible and daytime and nighttime infrared images at resolutions of 18 to $40 \mathrm{~m} /$ pixel and $100 \mathrm{~m} /$ pixel respectively. As of the April 2005 data release, there are 185 visible images (92\% quad coverage), 55 daytime infrared images (86\% quad coverage), and 104 nighttime infrared images (87\% quad coverage). THEMIS visible images are the most useful in identifying geologic contacts and surface characteristics. The MGS and MO datasets nicely supplement VO image mosaics in both their spectral band widths as well as their resolutions. As a result, we currently have tremendous strength in providing a high quality map product to the planetary community.

The geologic mapping is being completed using ESRI's ArcMAP software and related spatial tools. We compiled all raster datasets and vector map features into a project-specific geodatabase in order to use the full capability of the Arc product, including data dissemination and multi-layer analysis.

Stratigraphy and structure: The layered deposits (unit $\mathrm{Al}$ ) are recognized by their distinct bedded appearance, red color and lower albedo relative to the polar ice cap and frost deposits. In both polar regions, layers are apparent at least partly because of their terraced topography, especially where accented by differential frost retention [13-14]. MOC images show that layered deposit exposures are commonly rough, with evidence for deformed beds and unconformities [16]. Angular unconformities have been found in various locations within this map area, and are mapped using 
hachures on the side of the contact where layers are truncated.

The partial frost cover (unit Af) is interpreted as a mixture of frost and defrosted ground on the basis of its albedo, color, and temporal variability. Bass and others [17] found that frost albedo reaches a minimum early in the northern summer, then increases during the rest of the summer season. The increase in albedo is interpreted as resulting from condensation of $\mathrm{H}_{2} \mathrm{O}$ from the atmosphere onto cold traps in the north polar region [17]. Because the images used for the base and for mapping were taken in mid-summer, the extent of the high-albedo units shown on this map is greater than during early summer.

The albedo of the residual polar ice cap (unit Ac) is higher than all other units on this map. The contact with the partial frost cover (unit Af) is gradational in many areas, most likely because unit Af represents incomplete cover of the same material $\left(\mathrm{H}_{2} \mathrm{O}\right.$ frost $)$ that comprises unit Ac. The summer extent of the north polar cap was the same during the Mariner 9 and Viking missions [17], which suggests that it is controlled by underlying topography. Albedo patterns in these summertime images are correlated with topographic features seen in springtime images. Areas of the highest albedos must be covered by nearly pure coarsegrained ice or dusty fine-grained frost [18-19]. The presence of perennial frost is thought to aid in the long-term retention of dust deposits [20], so areas covered by frost all year are the most likely sites of layered-deposit formation. It is not known whether net deposition is currently occurring in the map area.

Dark dunes (unit Ad) appear to have sources within the polar layered deposits, where a dark, platy basal unit of possible Early Amazonian age is exposed within the map area [21]. The dunes overlie the layered deposits in places and a large volume of dark, saltating material covers Olympia Undae in the southern part of the map area. This material may have been deposited as dunes before the currently-exposed north polar layered deposits were laid down over them, perhaps recording an ancient climate that did not allow a perennial north polar cap to form.

Expected results: We expect the geologic mapping efforts of MTM85200 to reveal substantial information concerning both Early Amazonian basal unit geology and Late Amazonian, lower and upper layered deposit sequencing and characteristics. Moreover, the southern boundary of the quadrangle contains thick aeolian deposits of the north polar erg and appears to have unique, interlayered lateral relationships with adjacent deposits. GIS-based mapping proceeds rap- idly once all datasets have been incorporated. We intend to have significantly advanced the geologic mapping by the end of the year and present map-related topical studies at LPSC 2006.

Acknowledgements: Joel Viers (USGS volunteer) prepared an ArcView project and assisted in the mapping of this quadrangle. This work was supported by the NASA Planetary Geology and Geophysics Program.

\section{References:}

[1] Thomas P. et al. (1992) Polar deposits on Mars, in Mars, University of Arizona Press, 767-795.

[2] Herkenhoff K. E. and Murray B. C. (1992) USGS Misc. Inv. Series Map I-2304; Herkenhoff K. E. and Murray B. C. (1994) USGS Misc. Inv. Series Map I-2391; Herkenhoff K. E. (2001) USGS Misc. Inv. Series Map I-2686.

[3] Herkenhoff K. E. (1998) USGS Misc. Inv. Series Map I-2595.

[4] Herkenhoff K. E., and Murray B. C. (1990) JGR, 95, 1343-1358.

[5] Thomas P. C. and Weitz C. (1989) Icarus, 81, 185215.

[6] Herkenhoff, K. E. and A. R. Vasavada (1999) J. Geophys. Res., 104, 16,487.

[7] Cutts J. A. et al. (1976) Science, 194, 1329-1337.

[8] Herkenhoff K. E. and Plaut J. J. (2000) Icarus, 144, 243-253.

[9] Zuber M. T. et al. (1998) Science, 282, 2053-2060.

[10] Smith D. E. et al. (1999) Science, 284, 14951503.

[11] Murray B. C. et al. (1972) Icarus, 17, 328-345.

[12] Cutts J. A. (1973) JGR, 78, 4231-4249.

[13] Howard A. D. et al. (1982) Icarus, 50, 161-215.

[14] Herkenhoff K. E. and Murray B. C. (1990) JGR, 95, 14,511-14,529.

[15] Blasius K. R. et al. (1982) Icarus, 50, 140-160.

[16] Edgett K. S. and Malin M. C. (1999) LPS XXX, Abstract \#1029; Malin M. C. and Edgett K. S. (2001) JGR, 106, 23,429-23,570.

[17] Bass D. S. et al. (2000) Icarus, 144, 382.

[18] Clark R. N. and Lucey P. G. (1984) JGR, 89, 6341-6348.

[19] Kieffer H. H. (1990) JGR, 95, 1481-1493.

[20] James P. B. et al. (1979) Icarus, 68, 422-461.

[21] Byrne, S., and B. C. Murray (2002) JGR, 107, 10.1029/2001JE001615; Edgett, K. S. et al. (2002) Geomorphology 52, 289-297; Tanaka, K. L. et al. (2003) JGR, 108, doi:10.1029/ 2002JE001908; Fishbaugh, K. E. and J.W. Head III (2005) Icarus 174, 444-474. 
GEOLOGIC MAPPING OF OLYMPUS MONS CALDERA, MARS. Peter J. MouginisMark, Hawaii Institute of Geophysics and Planetology, University of Hawaii, Honolulu, Hawaii, 96822.

Olympus Mons is one of the best known landforms on Mars, and it has been extensively described, mapped, and analyzed. Previous U.S. Geological Survey maps include two 1:5,000,000 scale maps based on Mariner 9 images [1, 2], a Viking-based 1:2,000,000 scale map of the Tharsis region [3], and a 1:1,000,000 map [4]. There have also been numerous research studies that consider either the physical volcanology of the volcano [e.g., $5-11$ ] or the cratering history of the volcano [12-14].

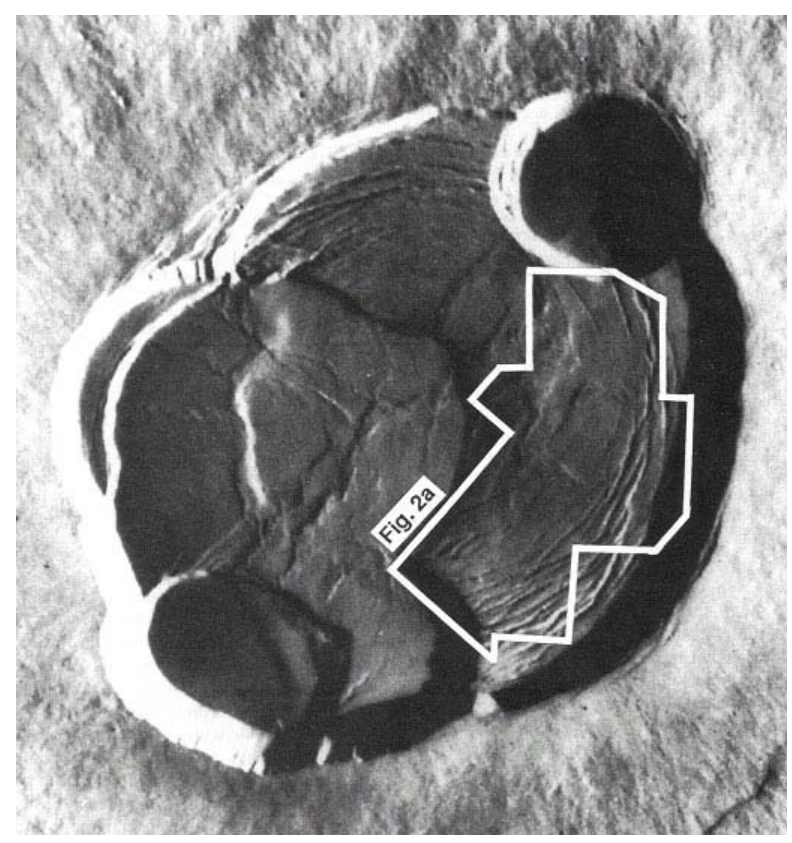

Figure 1: Viking Orbiter view of the caldera of Olympus Mons. The largest crater has a radius of $\sim 32 \mathrm{~km}$. The tectonic features used [9] to constrain the geometry of the magma chamber are in the box, which shows the location of Figure 2 and delineates all of the Viking Survey coverage for the largest crater. Illumination is from the right. Viking Orbiter frame number 890A68.

A new formal mapping effort has just been started to better understand the geologic history of the summit caldera of Olympus Mons (Fig. 1). This will be accomplished by creating a geologic map at a scale of 1:200,000 as part of the Mars Mapping Program. The area to be mapped extends from $17.50^{\circ} \mathrm{N}$ to $19.10^{\circ} \mathrm{N}$, and $225.75^{\circ} \mathrm{E}$ to $227.90^{\circ} \mathrm{E}$, which will make a final paper map product 20 inches by 19 inches in size (excluding additional text and diagrams). This map will serve as an update to the Vikingbased 1:1M geologic map [4].

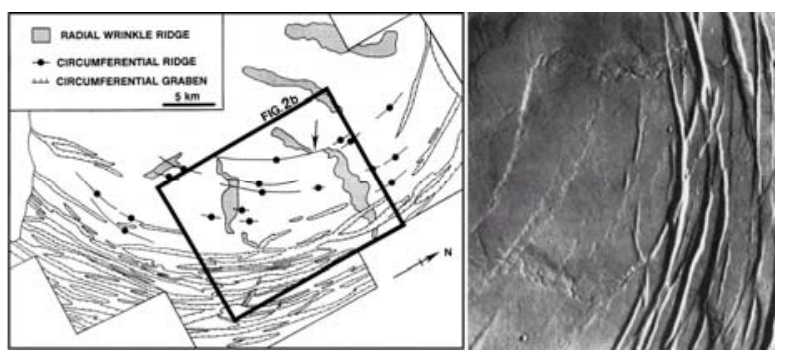

Figure 2: (Left): Sketch map of the tectonic features within the area of the main crater of Olympus Mons. See Figure 1 for location. (Right): Viking Survey image of the segment of the caldera that was used to constrain the transition from compression that formed the small wrinkle ridges (to the left of image) to extension in the form of the circumferential graben. Illumination direction is from the left. Viking Survey image number 473S30, which has a resolution of 16.5 $\mathrm{m} /$ pixel.

Due to the lack of suitable images, one of the key attributes of Olympus Mons that we were not able to study in our earlier work $[8,9]$ was to carry out a complete mapping of the caldera floor. This was unfortunate because the numerical models of magma chamber geometry, which relied heavily on the identification of the transition between areas of compression close to the center of the caldera and extension close to the caldera wall, could only be constrained in one section of the caldera (Fig. 2). The identification of the transition in the stress field of the caldera floor has a major impact on the calculated depth and geometry of the magma chamber, 
which in turn affects our interpretation of the internal plumbing system of the volcano. For example, some investigations [e.g., 15, 16] utilize the inferred depth beneath the surface of the Martian magma chamber to compute the longevity of magma within the chamber, the rate of volatile release to the surface, and the supply-rate of magma from the mantle. Such calculations are based on limited data and need updating.
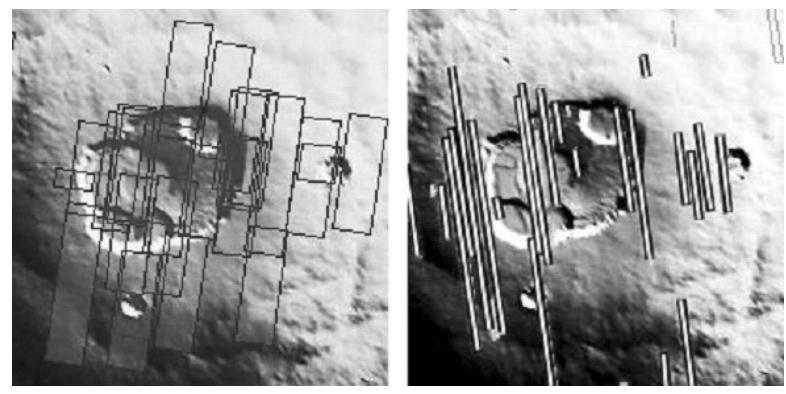

Figure 3: Coverage map of the Olympus Mons caldera, showing the availability of publicly-released THEMIS Visible (left) and MOC (right) images. Complete coverage of the caldera by THEMIS daytime IR data also exists. MOC data have different spatial resolutions, so that the MOC swath widths shown here are not exactly the same as the actual data.

Images to be used for the new mapping initiative will include visible and daytime IR THEMIS images, Mars Orbiter Camera (MOC) images at $\sim 1.5-6.0 \mathrm{~m} /$ pixel (Fig. 3), and a reanalysis of Viking Orbiter Survey images (15 - $20 \mathrm{~m} /$ pixel). New topographic and image data have also been collected for the Olympus Mons caldera by the stereo camera on the Mars Express spacecraft (http://www.esa.int/SPECIALS/Mars_Expres s/SEM9BA1PGQD_1.html\#subhead3), and when these Mars Express data become available we will include them in our mapping effort.

Mapping the rim of the caldera will also provide valuable input for future science investigations. In particular, MOC images show the caldera wall in sufficient detail to identify stratified lava flows in certain rim segments [17]. The horizontal extent of these stratified lavas indicates that lava flows ponded within the caldera in much the same way that the caldera of Fernandina volcano in the Galapagos Islands has been infilled prior to its current state of collapse [18]. To date, only a few MOC images of the caldera wall have been studied, so that it is not known whether the caldera was full at each phase of the evolution of the volcano. By mapping the rim materials we expect to improve our knowledge of the conditions of the caldera prior to each collapse episode, which in turn would further our understanding of the subsurface structure.

References: [1] Carr M. H. (1975) U.S. Geological Survey Misc. Map I-893. [2] Morris E. C. and Dwornik S. E. (1978) U.S. Geological Survey Misc. Map I-1049. [3] Scott D. H., Schaber G. G., Tanaka K. L., Horstman K. C. and Dial A. L. (1981) U.S. Geological Survey Misc. Maps I-1266 to I-1280. [4] Morris E. C. and Tanaka K. L. (1994) U.S. Geological Survey Misc. Map I-2327. [5] Hulme G. (1976) Icarus 27: 207 - 213. [6] Mouginis-Mark P. J. (1981) Proc. Lunar Planet. Sci. 12B: 1431 - 1447. [7] Wood C. A. (1984) J. Geophys. Res. 89: 8391 - 8406. [8] Mouginis-Mark P. J. and Robinson M. S. (1992) Bulletin Volcanology 54: 347 - 360. [9] Zuber M. T. and Mouginis-Mark P. J. (1992) J. Geophys. Res. 97: 18,295 - 18,307. [10] Crumpler L .S., Head J. W., and Aubele J. C. (1996) In "Volcano Instability on the Earth and Other Planets", eds. W. J. McGuire, A. P. Jones, and J. Neuberg, Geol. Soc. Spec. Publ., 110, 307 - 348. [11] Mouginis-Mark P. J. and Rowland S. K. (2001) Geomorphology 37: 201 - 223. [12] Blasius K. R. (1976) Icarus 29: 343 - 361. [13] Plescia J. B. and Saunders (1979) In: Proc. $10^{\text {th }}$ Lunar Plent. Sci. Conf., 9775 - 9791. [14] Hartmann W. K., Anguita J., de la Casa M. A., Berman D. C. and Ryan E. V. (2001) Icarus 149: 37 - 53. [15] Scott E. D. and Wilson L. (2000) J. Geol. Soc. London 157: 1101 - 1106. [16] Wilson L., Scott E. D. and Head J. W. (2001) J. Geophys. Res. 106: 1423 - 1433. [17] Mouginis-Mark P. J., Harris A. J. L., and Rowland S. K. In: "Environments on Earth: Clues to the Geology of Mars”, accepted for publication, April 2004. [18] Rowland S. K. and Munro M. C. (1992) Bull. Volcanol. 55: $97-109$. 
MAPPING OF THE MEDUSAE FOSSAE FORMATION USING THEMIS IMAGES. K.M. Shockey ${ }^{1}$ and J.R. Zimbelman ${ }^{1},{ }^{1}$ Center for Earth and Planetary Studies, National Air and Space Museum, Smithsonian Institution, MRC 315, Washington, DC 20013-7012, shockeyk@si.edu, zimbelmanj@si.edu.

Introduction: To better understand the origins of the Medusae Fossae Formation (MFF), we are mapping the Gordii Dorsum escarpment and surrounding areas in the eastern part of MFF between 202.5 and 225 E longitude, which is the southeast portion of quadrangle MC-8 on Mars. The MFF is a friable, areally extensive Amazonian deposit that overlies the crustal dichotomy boundary and adjacent lowlands between approximately 130 and $240 \mathrm{E}$ longitude [1], between the Tharsis and Elysium volcanic provinces. The area being mapped is slightly south west of Olympus Mons. Yardangs and pedestal craters attest to considerable aeolian deflation of the MFF in recent geologic time [1, 2]. Although diverse explanations for the MFF have been proposed (summarized by [1]), recent work has focused on deposition of loess or ignimbrite by aeolian processes [1, 36$]$. The origins of MFF are still controversial; the current and future mapping should provide new constraints for testing the many hypotheses of origin.

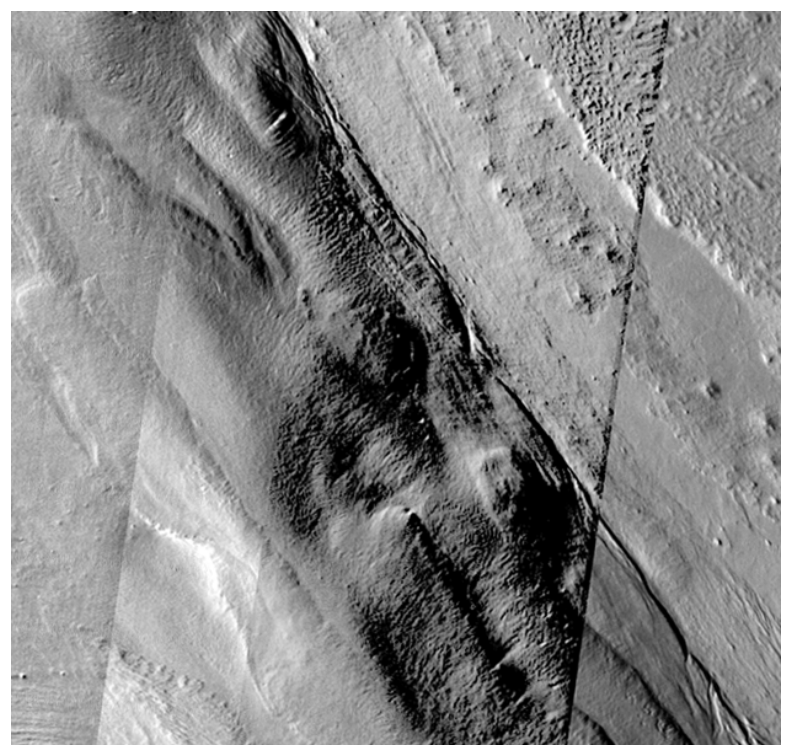

Figure 1: THEMIS daytime Infrared (IR) data show the eastern edge of the Gordii Dorsum escarpment to be much more complex then previous Viking data showed. Various layers and evidence of aeolian deflation can be seen in this image. North is at the top of this and all subsequent images. Scene shown is $\sim 60 \mathrm{~km}$ wide.

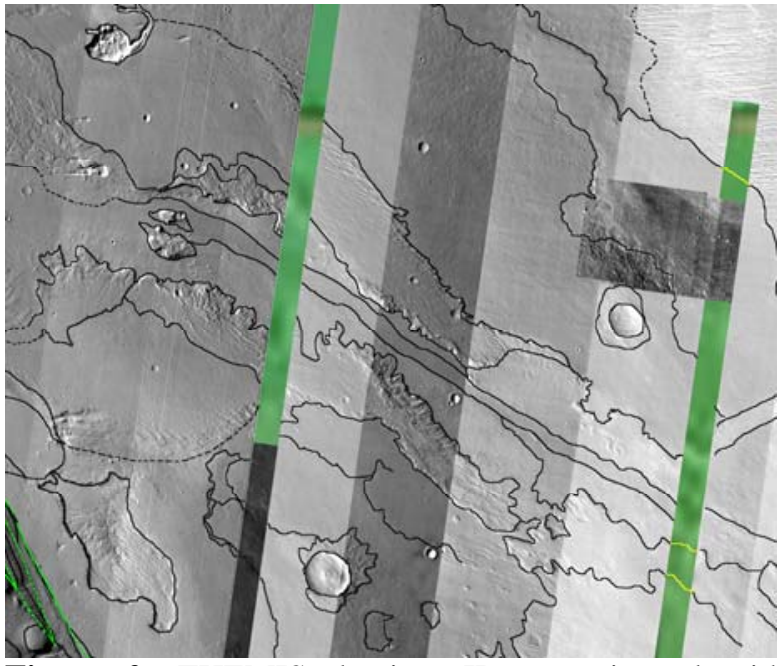

Figure 2: THEMIS daytime IR co-registered with MOLA show lava flows, Medusae Fossae Formation and a possible channel. This section of the map is directly east of the Gordii Dorsum escarpment. Scene shown is $\sim 250 \mathrm{~km}$ wide.

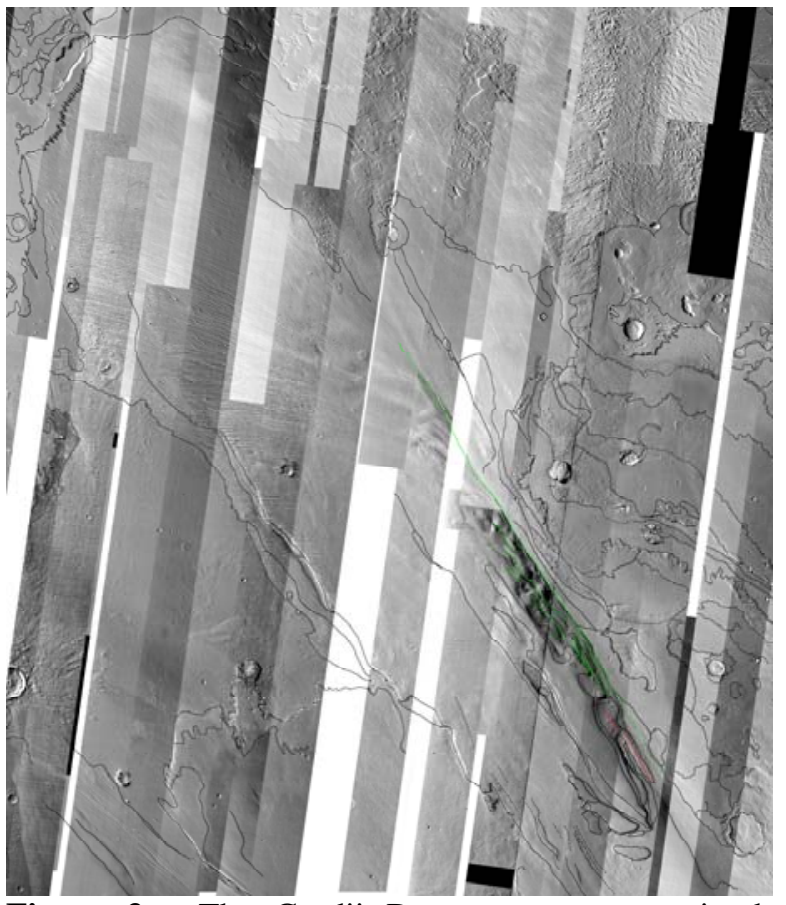

Figure 3: The Gordii Dorsum escarpment is the prominent focus of the mapping area. It lies near the center of the map and covers most of the map from north to south. Scene shown is $\sim 600 \mathrm{~km}$ wide. 


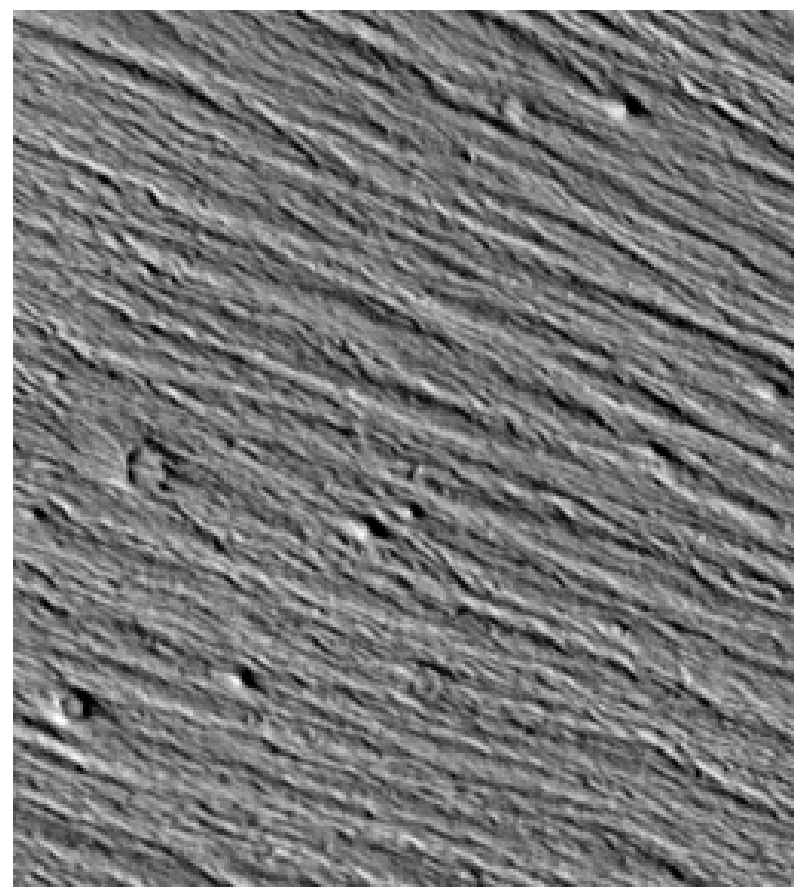

Figure 4: There are numerous yardangs found on the MFF. These yardangs, shown in THEMIS daytime IR data, are located on the northern section of the Gordii Dorsum escarpment.

Discussion: Though there is still much work to be done with the mapping project, a lot of work has been added since last year's meeting. We have extended the edge of the map 7.5 degrees west, from $210^{\circ}$ East to $202.5^{\circ}$ East. Several THEMIS releases have given more extensive coverage of the map area, filling in gaps and giving a more complete picture of the MFF.

The origins of the MFF are still controversial, but the three primary hypotheses are [1]: ash flow, ash fall, and aeolianite (i.e., loess). Detailed mapping should provide constraints for evaluating the various alternatives. Ash fall and aeolianite origins may be difficult to distinguish from one another, unless diagnostic volcanic characteristics can be identified within MFF [4]. However, topographic relief should provide strength constraints that may reduce the range of likely MFF materials.

During detailed mapping of the MFF at Gordii Dorsum, THEMIS data revealed many complex layers not previously seen using Viking data (Fig. 1). These layers indicate a repetitive or cyclical deposition of the MFF materials, as well as evidence of extensive aeolian deflation. Due to large amounts of wind erosion, indicated by linear markings throughout the map area, it is difficult to tell the original shape of this feature with any certainty.

In Figure 2 we see an elongated trough or trench that we have interpreted to be a channel. In none of the data sets can we see any fluvial bed forms. One possibility is a smaller channel formed from water was later widened by aeolian processes. The channel was originally thought to disappear under the Gordii Dorsum escarpment (Fig. 3). After studying the recent IR images, new possibilities were uncovered. Another possible channel runs alongside the linear portion of the escarpment (Fig. 1); these two channels may be connected. This channel may have led to sapping in the MFF at the northern portion of the Gordii Dorsum escarpment.

Figure 4 shows more evidence of aeolian activity. Yardangs are present all over the MFF shown here. Current global wind models are not necessarily consistent with the orientation of these yardangs, suggesting that the yardangs may provide valuable constraints on wind patterns under previous climatic regimes.

Conclusions: The area mapped by Zimbelman [7] from $15^{\circ} \mathrm{N}$ to $15^{\circ} \mathrm{S}$ latitude and from $202.5^{\circ}$ to $225^{\circ} \mathrm{E}$ longitude using Viking data is currently being remapped using the recent THEMIS data. When this is complete, a comparison will be made between the two maps in order to reformulate previous conclusions drawn on the origins of MFF. Further steps will include the analysis of yardang orientation for comparison with wind regimes and crater counting in order to determine relative ages of layers. In particular, we intend to ensure, as much as possible, that the terrains to be mapped correspond to discreet material units.

References: [1] Bradley, B. A. et al. (2002) JGR107(E8), 10.1029/2001JE001537. [2] Ward A. W. (1979) JGR, 84, 8147 8166. [3] Scott D. H. and Tanaka K. L. (1982) JGR, 87, 1179 1190. [4] Zimbelman J. R. (2003) GSA Abs. Prog. 35(6) 107-7, 128. [5] Hynek B. M. et al. (2003) JGR, 108(E9), doi: 10.1029/2003JE002062. [6] Head J. W. and Kreslavsky M. A. (2001) Conf. Geophys. Det. Water on Mars, LPI. abst. 7083. [7] Zimbelman, J. R. et al. (2003) Mappers meeting. 
GEOLOGIC MAPPING OF THE POLAR REGIONS OF MARS: PRELIMINARY RESULTS AND CLIMATE IMPLICATIONS. K. L. Tanaka ${ }^{1}$ and E. J. Kolb ${ }^{2},{ }^{1}$ USGS, 2255 N. Gemini Dr., Flagstaff, AZ 86001, ktanaka @usgs.gov, ${ }^{2}$ Arizona State U., Tempe, AZ, ekolb@cox.net.

Introduction: New detailed geologic mapping of the polar regions of Mars reveals their history of dust deposition and erosion and other geologic processes and events. We propose a climate history for the polar regions of Mars, based on our mapping results combined with previous crater density studies and climate modeling of orbitally driven variations.

Our geologic mapping includes the northern plains of Mars at 1:15M scale [1], the south polar region (60$90^{\circ} \mathrm{S}$ ) at $1: 5 \mathrm{M}$ [2], and the polar layered deposits at $1: 1.5 \mathrm{M}$ [3]. We primarily use MOLA topography at 460, 230, and $114 \mathrm{~m} /$ pixel resolutions at progressively higher latitudes as MOLA shot density increases, hundreds of THEMIS VIS images at 17 to $40 \mathrm{~m} / \mathrm{pixel}$, and hundreds of MOC images at meters/pixel.

\section{South polar region geologic mapping results:}

Noachian and Hesperian units. We have mapped Noachian cratered materials and seven primarily Hesperian Dorsa Argentea units, formerly mapped as two members of the Dorsa Argentea Formation [2]. Interpretations for the Dorsa Argentea units include glacial outwash deposits [4] and slurries erupted from groundwater-saturated, poorly consolidated substrate [2]. The units are marked by sinuous ridges previously interpreted as eskers [4] or inverted channel features [2].

Late Amazonian Australe units. The layered deposits of Planum Australe consist of two major units: (1) a thick, relatively smooth, flat-lying lower layer sequence that buries underlying Noachian and Hesperian materials, and (2) a thinner sequence of moderately to heavily pitted and knobby layers draped over the eroded topography of the lower sequence [3]. We named these units the Australe 1 and 2 units, respectively. Australe 1 unit displays local layer unconformities along the margins of Promethei and Ultimum Chasmata and Ultima Lingula (informally known as Ultimi lobe). It appears that soon after emplacement, most erosion of the Australe 1 unit took place, including formation of the chasmata and later, the spiral troughs [3]. Next, equatorwardfacing scarps and perhaps other surfaces of the unit hardened, possibly due to induration by salt precipitation or to other weathering processes. Upon continued scarp retreat, the hardened layer margins developed into ridges. During this hiatus, low-albedo dune fields within craters apparently formed on the margins of the Ultimi Scopuli area, perhaps made up of material reworked from the Dorsa Argentea Formation.

Later, Australe 2 unit was emplaced as a series of even-thickness mantles draped over the Planum Australe topography. The Australe 2 unit deposited most likely where residual ice had been present [5]. Crater counts completed for part of Planum Australe indicate a mean surface age of 30-100 Ma [6] but includes a diverse surface of flat-lying Australe 2 material west of Australe Scopuli, troughed Australe 1 unit of Australe Lingula and Scopuli, and windswept mainly Australe 2 unit on Promethei Lingula. The flat-lying area appears to have the highest crater density, whereas Promethei Lingula shows the fewest. The Australe 2 unit may also bury additional craters superposed on Australe 1 unit in the flat-lying area. In addition, we observe several mounds amongst Australe Sulci (the wirebrush terrain ridges) on Promethei Lingula that may be pedestal crater relicts. Thus the flat-lying area, which has about twice the crater density, has a 60-200 Ma age; other areas likely have been progressively stripped and thus have younger exposure ages. The thick sequence of layers of Australe Mensa are capped by residual, uncratered [6] $\mathrm{CO}_{2}$ ice that may represent recent and perhaps ongoing resurfacing.

North polar region geologic mapping results:

Early Amazonian units. The Vastitas Borealis Formation has been remapped as the Vastitas Borealis interior and marginal units based on current data sets [1]. In addition, the Vastitas Borealis units are proposed to define the beginning of the Amazonian [1]. They embay the floors of the outflow channels in Chryse Planitia, indicating that their formation followed the latest Chryse floods. The Vastitas Borealis units may be lacustrine deposits related to spring discharges that carved the Chyrse outflow channels and/or that sourced within the northern plains. In turn, the deposits underwent a period of intense cryoturbation, mud volcanism, and other volatile-related processes to account for their associated morphologies (including arcuate chains of pitted cones, troughs with medial ridges, and polygonal graben networks), their post-dating of the outflowchannel floors, and their abundance of ghost craters (yet lack of moderately degraded craters).

The Scandia unit is superposed on the Vastitas Borealis units. The unit is highly degraded into knobs and may even be completely removed across much of the plain south of Chasma Boreale, wherein a continuous outcrop of the unit occurs. We suggest that the unit is composed partly of material erupted by mud volcanism due to high heatflow, hydraulic gradients, and tectonic fabrics associated with magmatic activity at Alba Patera. The Scandia Cavi in particular have the form of mud volcanoes with peripheral moats that may reflect subsidence due to the removal of volatile-rich substrate. 
At the mouth of Chasma Boreale, the unit is layered and may consist of deposits distal to source areas that may have been reworked and emplaced by lacustrine or aeolian processes.

The Scandia unit also includes low-albedo, irregularly layered deposits superposed on the Vastitas Borealis units and forming part of lower Planum Boreum. It reaches upwards of a kilometer in thickness west of Chasma Boreale. The unit within Planum Boreum has been interpreted to be a sand-rich aeolian deposit [7-8] and may have resulted from erosion and redeposition of the Scandia unit in Vastitas Borealis.

Pedestal crater mantles and sinuous ridges. A large proportion of pedestal craters, perhaps even the majority larger than a few kilometers in diameter in some areas, dot the surface of Vastitas Borealis north of $\sim 70^{\circ} \mathrm{N}$. The pedestals are mostly $10-30 \mathrm{~m}$ high. A few scattered sinuous ridges similar in form to those of the south polar Dorsa Argentea occur in the plains and Scandia Cavi region surrounding Planum Boreum. The ages of these features are poorly constrained and may span most of the Amazonian following emplacement of the Vastitas Borealis units.

Late Amazonian Boreum units. Like the south polar Australe units, the Planum Boreum layered deposits can be divided into stacks of (a) fairly smooth layered deposits (Boreum 1 unit) exposed in equatorward-facing scarps and windswept surfaces in Chasma Boreale covered by (b) pitted layers (Boreum 2 unit) up to $150 \mathrm{~m}$ thick mantling the flat and poleward-facing surfaces of the Boreum 1 unit. Planum Boreum overall is marked by 2 craters $>330 \mathrm{~m}$ in diameter, resulting in an inferred surface age of 3.6 $2.5 \mathrm{Ma}$ [8].

Proposed polar climate history: The geologic record provides a starting point for interpreting the climate history of Mars, particularly where geologic materials are deposited, eroded, reworked, or otherwise modified due to changing climate conditions. Generally, the farther back in time, the less certain interpretations become. Overall, our observations indicate that climate histories at the poles have been remarkably diverse.

Noachian and Hesperian Periods ( 4.5 to 3.0 Ga). The Noachian and Hesperian geologic record for the north polar region was largely obscured by Amazonian activity. In the south polar region, Noachian surfaces exposed as far south as $83^{\circ} \mathrm{S}$ do not display any obvious extant polar geologic signatures such as layered deposits. During the Hesperian, the deposits and ridges of the Dorsa Argentea Formation point to volatile-driven activity, including fluvial action. Such activity appears to have been long-lived, at least periodically, over as much as the entire Hesperian [2], 700 million years.
The south polar region also includes local pedestal craters indicative of mantles of possible Hesperian age.

Early to Late Amazonian ( 3.0 to $\sim 0.1 \mathrm{Ga}$ ). The emplacement and modification of the Vastitas Borealis and Scandia units at the beginning of the Amazonian appear to require the activity of water and ice at and near the surface. Widespread preservation of pedestal craters atop Vastitas Borealis units and south polar surfaces indicates polar mantles were common. This may indicate moderate polar insolation to promote expansive deposits of polar ice and entrained dust.

Late Amazonian, Australe 1 and 2 stages ( 100 to $\sim 30 \mathrm{Ma}$ ). Layer deposition of Australe 1 and 2 units occurred, possibly at the expense of wider-spread mantles, due to decreased obliquity-driven polar insolation. Episodes of wind erosion during and after deposition of Australe 1 unit carved Planum Australe into its overall, current shape. Australe 2 unit suggests residual ice was present across much of Planum Australe to fix the dust. Layer deposition at Planum Boreum is uncertain and may include sequences lying below unconformities.

Late Amazonian, Australe 3 stage. ( 60 to $\sim 5 \mathrm{Ma}$ ). During this phase, polar insolation likely increased, leading to wind erosion of the Australe units, including formation of Australe Sulci.

Late Amazonian, Boreale 1 stage ( $\sim 5$ Ma to $~ 75$ $\mathrm{Ka}$ ). Significant decrease in polar insolation [9] drives emplacement of Boreum 1 unit $[8,10]$. Hiatuses, perhaps driven by the obliquity cycle, result in erosion and layer unconformities within the unit. At some point, the layers are eroded dramatically to form spiral troughs and Chasma Boreale. They subsequently harden and experience more gradual erosion.

Late Amazonian, Boreale 2 stage $(<20 \mathrm{Ka})$. Boreum unit 2 is deposited following the latest peak in the obliquity cycle at $\sim 20 \mathrm{Ka}$ [8]. Some deposition may have occurred during both Boreale stages on Australe Mensa, the high point of Planum Australe, where residual ice is currently observed.

Implications. Widespread, dust-rich polar mantles 10s of $m$ thick have been common during the Hesperian and Amazonian; their development may be related to the presence of residual ice during moderately low obliquity. The current polar plateaus may be the result of rapid dust deposition during relatively recent episodes of unusually low obliquity.

References: [1] Tanaka K. L. et al. (2005) USGS SIM-2888, in press. [2] Tanaka K. L. and Kolb E. J. (2001) Icarus 154, 3-21. [3] Kolb E. J. and Tanaka K. L. (2005) this volume. [4] Head J. W. III and Pratt S. (2001) JGR 106, 12,275-12,299. [5] Cutts J. A. (1973) JGR 78, 4231-4249. [6] Koutnik M. et al. (2002) JGR 107, 5100. [7] Byrne S. and Murray B. C. (2002) JGR 107, 5044. [8] Tanaka K. L. (submitted) Nature. [9] Laskar J. et al. (2004) Icarus 170, 343-364. [10] Laskar J. et al. (2002) Nature 419, 375-377. 
VALLEYS, VOLCANOES, CHANNELS, AND CHAOS NEAR MARGARITIFER BASIN. K. K. Williams, C. M. Fortezzo, and J. A. Grant, Center for Earth and Planetary Studies, National Air and Space Museum, Smithsonian Institution, Washington, D.C. 20013-7012; williamskk@si.edu.

Introduction: The geomorphology within much of Margaritifer Terra has been shaped by erosion and deposition associated with water transport, collection, and discharge. Because of the widespread effects of fluvial processes, this area has been a focus for studies of the history of water on Mars [1-5]. Margaritifer basin is a low-lying, oval region (Figure 1) into which the Uzboi-Holden-Ladon-Margaritifer (UHLM) system drains. Multiple episodes of discharge within the system have caused erosion and deposition in Margaritifer basin [1, 4, 5]. The Samara and Loire Valles systems approach Margaritifer basin from the south and southeast, respectively, and converge just before draining into the basin.

In addition to constraining the timing of fluvial activity and other resurfacing events [1, 4-6], mapping within MTMs -10022 and -15022 (Figure 1) has revealed volcanic features that are likely associated with phreatomagmatic activity [7]. The combination of new data sets, such as MOLA and THEMIS, with Viking data has revealed a more complex geologic history in this region than originally thought.

Recently funded mapping in southeastern Magaritifer Terra has begun in two groups of quadrangles. Four quads east of Paraná basin are discussed by [8], and three quadrangles adjacent to those covering the confluence of Samara and Loire Valles (Figure 1) are discussed below. The latter cover portions of eastern Margaritifer Terra, Loire Valles,
Jones crater and its ejecta, and the confluence of the Samara and Himera Valles systems.

Details in MTMs -10022 and -15022: 1:500,000 scale mapping in and around Margaritifer basin (Figure 2) has revealed details of this area's geologic history. As mentioned above, several topographic highs south of the basin have been interpreted as volcanic edifices with concentric, wave-like features resulting from the interaction of magma with water and/or ice [7, 9]. Previous interpretation of these features was hindered by the $\sim 250 \mathrm{~m} /$ pixel Viking image resolution covering MTM -15022, but THEMIS and MOC images allowed a more detailed analysis. Crater dating of these features constrains an N(5) age of early Amazonian [10].

Mapping within Margaritifer basin has also yielded interesting results related to the timing of events. The basin is characterized by a smooth plains unit embaying islands of HNsp3 material [10]. Crater dating of the smooth plains sets their age as early Amazonian. The youngest channel in the basin cuts the smooth plains and has also been dated as early Amazonian. This channel is disrupted by a later area of collapse, but it is indistinct between that small collapse and the larger Margaritifer Chaos to the northeast, suggesting that water may have ponded in the basin even during this late-stage flow event. In addition to the large areas of chaos, the basin contains numerous pits and linear collapse features that may be related to smaller episodes of the subsurface release of water.

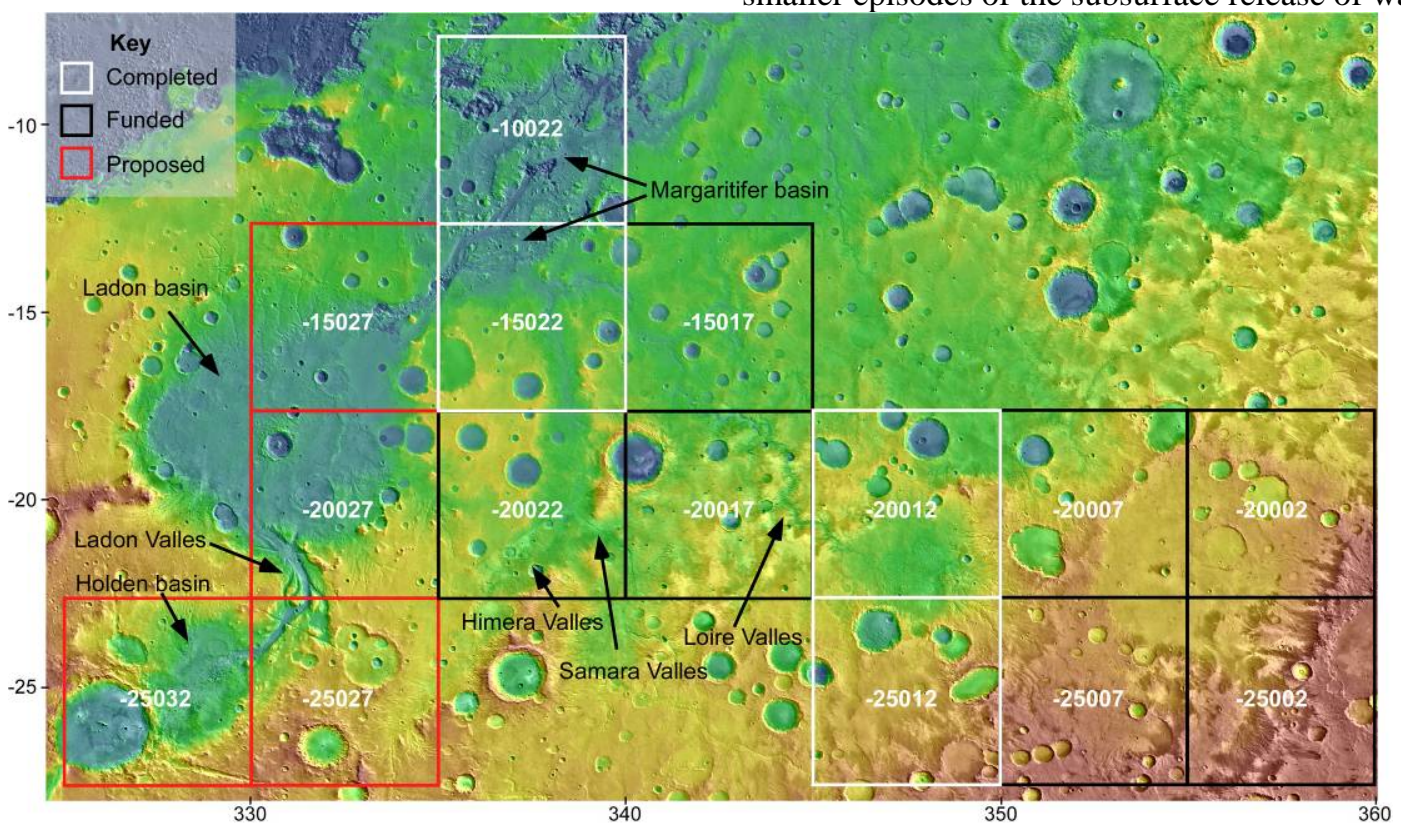

Figure 1. Locations of completed, funded, and proposed quadrangles within Margaritifer Terra. 


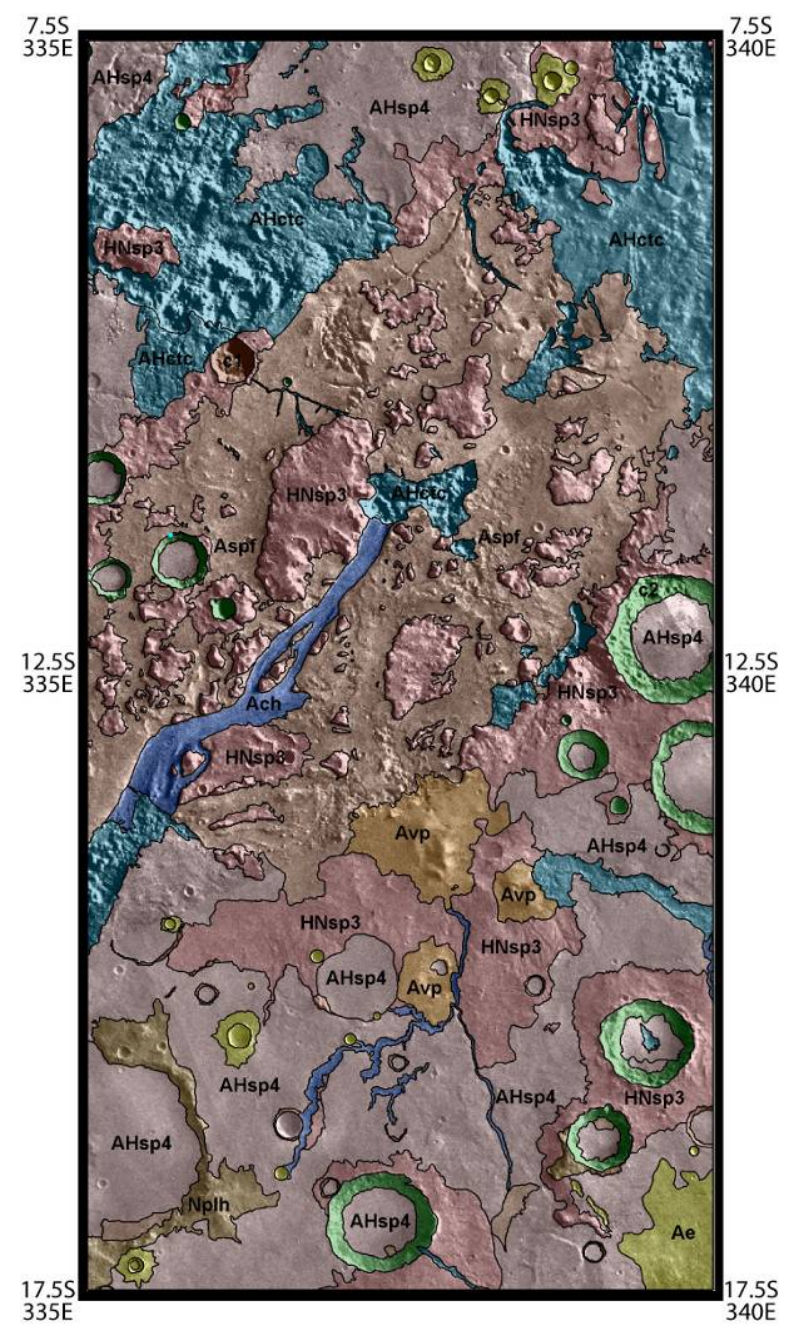

Figure 2. Map of MTMs -10022 and -15022. Corresponding map units are described in [10].

New mapping area: The Jones-Loire area (MTMs -15017, -20017, and -20022) covers a J-shaped area from Himera and Samara Valles in the southwest, around Jones crater, and northeast to Loire Valles to connect recent maps (Figure 1) [10].

One goal of mapping in the Jones-Loire region is to constrain the age of Jones crater relative to activity in Loire and Samara Valles. Consideration of the stratigraphic relationship between Loire Valles, Samara Valles, and Jones crater in drainage maps [6] and MOLA topography [11] (Figure 3) leads to the hypothesis that the drainage history of this area may have been affected by the emplacement of Jones crater. Specifically, a second order pathway may have once connected Samara Valles with Loire Valles east of the third ring of Ladon basin (Figure 3). Figure 4 shows one example where the course of Samara Valles may have been re-directed following the formation of Jones crater. New mapping will further constrain the history of fluvial activity in this area.

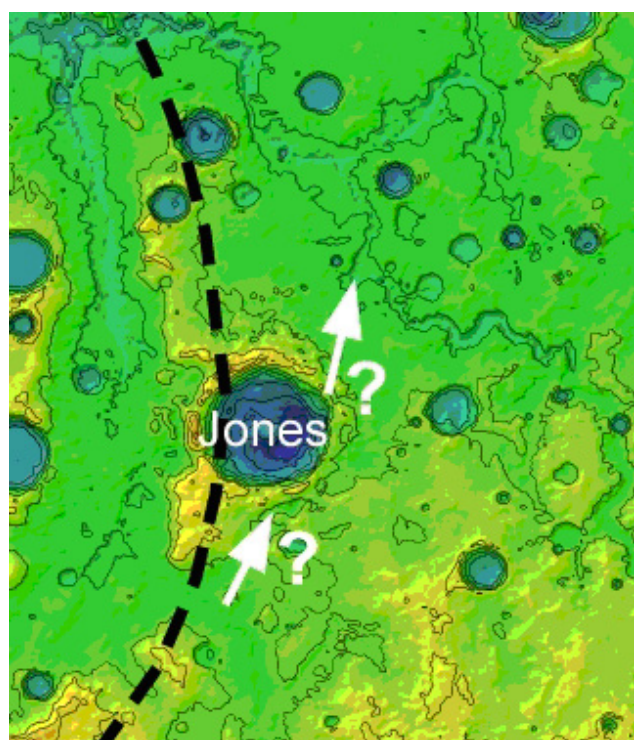

Figure 3. MOLA topography with arrows showing the course of a hypothesized valley interrupted by Jones crater.

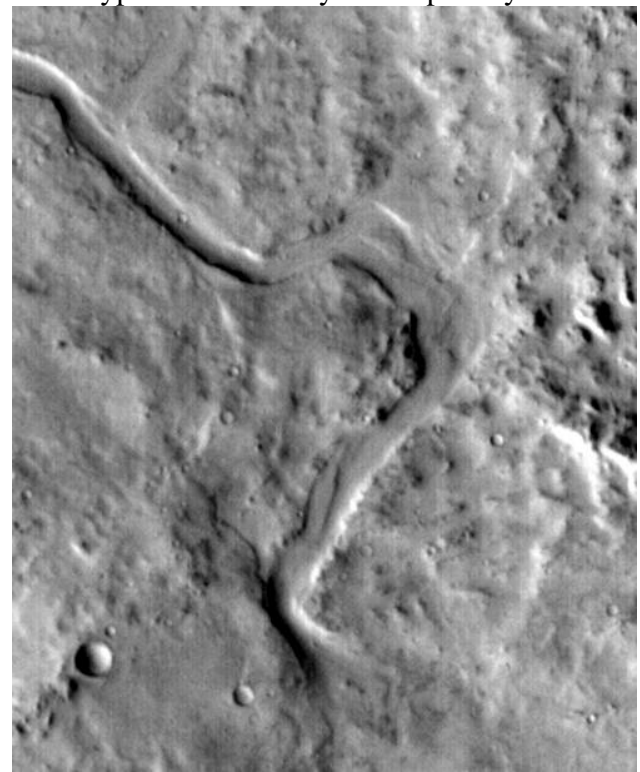

Figure 4. Portion of Samara Valles with Jones crater to the northeast. This is one area where further study will help constrain the relative timing of Jones crater with fluvial activity in nearby valley systems. North is toward the top, image is $\sim 31 \mathrm{~km}$ across. THEMIS image I08128003.

References: [1] Saunders, S. R. (1979) USGS I1144, USGS. [2] Baker V. R. (1982) The Channels of Mars, Univ. of TX Press, Austin. [3] Mars Channel Working Group (1983) GSA Bull., 94, 1035-1054. [4] Grant, J. A. (2000) Geology, 28, 223-226. [5] Grant, J. A. and T. J. Parker (2002) JGR, 107, 5066. [6] Grant, J. A. (1987) NASA Tech Memo 89871. [7] Williams, K. K. et al. (2005) LPSC 36, \#1439. [8] Fortezzo, C. F. et al. (2005) This volume. [9] Wilson, L. and J. W. Head (2004) GRL, 31. [10] Grant, J. A. et al. (2005) This volume. [11] Smith, D. E. et al. (1999) Science, 284. 